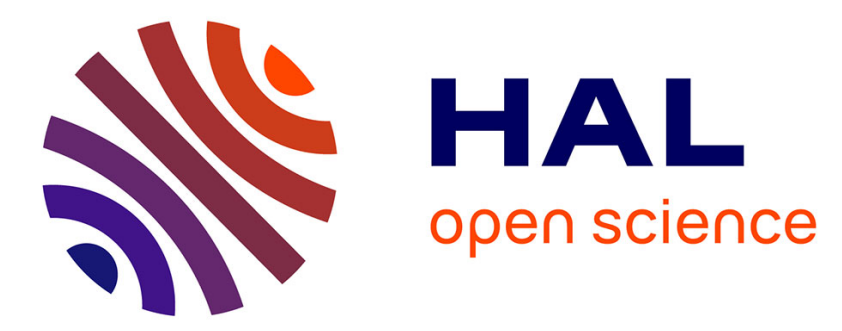

\title{
A comprehensive assessment of radioactivity monitoring in the Channel Islands
}

Bruno Fievet, Pascal Bailly Du Bois, Claire Voiseux, Claire Godinot, Olivier

Cazimajou, Luc Solier, Anne de Vismes, Catherine Cossonnet, Azza Habibi, Sandrine Fleury

\section{To cite this version:}

Bruno Fievet, Pascal Bailly Du Bois, Claire Voiseux, Claire Godinot, Olivier Cazimajou, et al.. A comprehensive assessment of radioactivity monitoring in the Channel Islands. Journal of Environmental Radioactivity, 2020, 223-224, pp.106381. 10.1016/j.jenvrad.2020.106381 . hal-03045146

\section{HAL Id: hal-03045146 \\ https://hal.science/hal-03045146}

Submitted on 7 Dec 2020

HAL is a multi-disciplinary open access archive for the deposit and dissemination of scientific research documents, whether they are published or not. The documents may come from teaching and research institutions in France or abroad, or from public or private research centers.
L'archive ouverte pluridisciplinaire HAL, est destinée au dépôt et à la diffusion de documents scientifiques de niveau recherche, publiés ou non, émanant des établissements d'enseignement et de recherche français ou étrangers, des laboratoires publics ou privés.

\section{(ㅇ)(1) $\$$}

Distributed under a Creative Commons Attribution - NonCommercial - NoDerivatives| 4.0 


\section{Manuscript Details}

\section{Manuscript number}

Title
JENVRAD_2020_256_R1

A comprehensive assessment of two-decade radioactivity monitoring around the Channel Islands

Research Paper

Article type

Abstract

The Channel Islands are located in the Normand-Breton Gulf (NBG), in the mid-part of the English Channel (France, Normandy). In the northern part, off Cap La Hague, controlled amounts of radioactive liquid waste are discharged by the ORANO La Hague nuclear fuel reprocessing plant (RP). Radionuclides were monitored in the NBG to assess the dispersion of radioactive discharges from the RP in the marine environment. The temporal and spatial distribution of the data are consistent with the history of the discharges, with most gamma emitter radionuclide environmental levels being close to or below the current limits of detection. A clear fingerprint of $\mathrm{H}-3, \mathrm{C}-14$ and $\mathrm{I}-129$ radionuclides discharged from the RP is measured. The hydrodynamics in the NBG do not yield a simple gradient with linear distance from the outfall of the RP. Modelling tools were used to understand how radioactive discharges spread from the source of input. Dispersion patterns clearly illustrate the different behaviours of soluble and non-soluble radionuclides. The study indicated that the footprint of radioactive liquid discharges by French nuclear facilities was still measurable in species collected from the NBG for the mostly dissolved radionuclides. The less conservative ones, with a high affinity for suspended matter, are potentially influenced by old releases. These pathways could be investigated by dedicated hydrodynamic dispersion models. Overall, in the Channel Islands the levels are low and consistent with the general decrease in liquid radionuclide discharges by the RP since the 1990s.

\section{Keywords}

\section{Taxonomy}

Corresponding Author

Corresponding Author's
Institution

Order of Authors

Suggested reviewers
Radioactivity monitoring; Marine environment; English Channel; Channel Islands; Hydrodynamic modelling; Transfer modelling

Nuclear Waste, Environmental Science, Radioactivity in Marine Environment

Bruno FIEVET

Institut de Radioprotection et de Sûreté Nucléaire

Bruno FIEVET, Pascal Bailly du Bois, Claire Voiseux, Claire GODINOT, Olivier CAZIMAJOU, Luc Solier, Anne de Vismes Ott, Catherine CossonNET, Azza Habibi, Sandrine Fleury

Sofia Luque, Kinson Leonard 


\section{Submission Files Included in this PDF}

\section{File Name [File Type]}

Reply_2Rev1.doc [Response to Reviewers (without Author Details)]

Reply_2Rev2.doc [Response to Reviewers (without Author Details)]

Radioactivity_Channel_Islands_Highlights.docx [Highlights]

Radioactivity_Channel_Islands_Abstract.docx [Abstract]

Radioactivity_Channel_Islands_TitlePage.docx [Title Page (with Author Details)]

Radioactivity_Channel_Islands_Manuscript.docx [Manuscript (without Author Details)]

Fig_1.tif [Figure]

Fig_2.tif [Figure]

Fig_3.tif [Figure]

Fig_4.tif [Figure]

Fig_5.tif [Figure]

Fig_6.tif [Figure]

Fig_7.tif [Figure]

Fig_8.tif [Figure]

Fig_9.tif [Figure]

Fig_10.tif [Figure]

Fig_11.tif [Figure]

Fig_12.tif [Figure]

Radioactivity_Channel_Islands_Tables.docx [Table]

declaration-of-competing-interests.docx [Conflict of Interest]

Radioactivity_Channel_Island_English_Supplementary_Material.pdf [Supplementary Material]

Radioactivity_Channel_Islands_Fig_Table Caption.docx [Supporting File]

\section{Submission Files Not Included in this PDF}

\section{File Name [File Type]}

Radioactivity_Channel_Island_English_Supplementary_Material.xlsx [Supplementary Material]

To view all the submission files, including those not included in the PDF, click on the manuscript title on your EVISE Homepage, then click 'Download zip file'. 


\section{Reply to Reviewer \#1}

Reviewer \#1 comments:

After reviewing the article, it would be appreciated to consider by the following minor comments:

1. The title, although precise, may not express the scope of the study, which is broader than what is reflected in it. The comprehensive assessment has been developed not only in the Channel Islands, but also in the whole Normand-Breton Gulf (NBG).

2. In comparing figures 9 and 10 for the year 2015 it is observed that figure 10 , which makes reference to mean annual $\mathrm{H}-3$ concentration in seawater (Bq. $\mathrm{m}-3$ ) calculated by the MARS2D model with real discharges, wind and tide conditions, shows values four orders of magnitude higher than figure 9, which makes reference to mean annual seawater concentrations resulting from a theoretical constant discharge of 1 TBq.y-1 (31 709 Bq.5-1) calculated by MARS2D with real wind and tide conditions. Does the latter make reference to the sum of soluble radionuclides? If affirmative, wouldn't it include $\mathrm{H}-3$ and therefore the values be higher than in figure 10 ? In figure 9 the units are $\mathrm{Bq} / \mathrm{m} 3$ but in the text that accompanies figure 9 it doesn't make reference to the units of the figure. Could there be a mistake in the units of this figure?

\section{Revision:}

1. To express the broader scope of the study, the title was changed to "A comprehensive assessment of two-decade radioactivity monitoring around the Channel Islands". The reason why "the Channel Islands" was preferred to "the Normand-Breton Gulf" is that the Channel Islands are better known internationally whilst the Normand-Breton Gulf sometimes refers to the Saint-Malo Bay which may be confusing.

2. The first dispersion modelling of a constant discharge of $1 \mathrm{TBq} \cdot \mathrm{y}^{-1}$ is purely theoretical and shows the influence of the wind and tide annual changes on the average dispersion of any soluble radionuclide. It is not related to the real content of the discharges from the Reprocessing Plant. The second one however reproduces the dispersion of the real tritium discharges from the RP. Tritium discharges from the RP are in the $1 \mathrm{E}+16 \mathrm{~Bq} \cdot \mathrm{y}^{-1}$, so the resulting concentrations are logically four orders of magnitude higher than those resulting from $1 \mathrm{E}+12 \mathrm{~Bq} \cdot \mathrm{Y}^{-1}$ discharge.

This has been clarified accordingly in the text of the revised version. 


\section{Reply to Reviewer \#2}

Reviewer \#2 comments:

The article entitled as "A comprehensive assessment of radioactivity monitoring in the Channel Islands", presents a large dataset, and use model to understand transfer and dispersion of conservative and non-conservative radionuclides. And I am really glad to have such opportunity to see this work again, since the authors put great efforts to make the big change comparing to the later version submitted to JER two years ago. This work is very important, not only for radioactivity monitoring in vicinity of ORANO $R P$, but also benefiting for understand the environmental behaviors and using these radionuclides as indicators of water current movement and biological metabolism. For instance, the seasonal cycle of Co-60, Ru-206, Pu and Am isotopes well reflect the resuspension process of sedimentary materials. In addition, the preparation of this manuscript is also very thoughtful and reasonable.

Therefore, I strongly to recommend this work to be published on Journal of Environmental radioactivity after minor revision.

A few comments are listed below.

1. Maybe it is better to change the title as "A comprehensive assessment of two-decade radioactivity monitoring in the Channel Islands".

2. Seaweed grows in the shallow coastal seawater, and the radionuclides concentraction in it, of cource, reflect the surface level and change of radioactivity. I was wondering how the author consider the vertical distribution and transder of these radionuclides (both conservative and non-conservative ones) from the outfall

3. Line 59," The limpet parts were finally burned at $450^{\circ} \mathrm{C}$ to ash." For 1291 analysis, the measured sample is the ash of limpet part or the raw sample?

4. Fig. 7 seems no practical meaning, since data and other figure have shown the trend. It is better to delete it for simplification.

5. Line 437-440, please add some references to support this discussion part.

\section{Revision:}

1. The title was changed to "A comprehensive assessment of two-decade radioactivity monitoring around the Channel Islands".

2. In the Normand-Breton Gulf, the vertical distribution in the water column is not a critical issue because it is a very shallow sea. High resolution 3D water sampling around the outlet of the Reprocessing Plant showed that the water column is homogeneous after 1500 meters distance (Bailly du Bois PB, Dumas F, Voiseux C, Morillon M, Oms PE, Solier L (2020) Dissolved radiotracers and numerical modeling in North European continental shelf dispersion studies (1982-2016): Databases, methods and applications. Water (Switzerland) 12). This was added to the text in the revised version.

3. 1291 was quantified on dry seaweed only but it was not measured in limpet.

4. Fig. 7 and related section were deleted for concision purpose.

5. Reference Carvalho FP (2018) Radionuclide concentration processes in marine organisms: A comprehensive review. Journal of Environmental Radioactivity 186: 124-130 was added in the revised version. 


\section{Radioactivity monitoring around the Channel Islands}

\section{Highlights}

Controlled amounts of radioactive liquid wastes are discharged by French nuclear facilities in the Channel Sea. After two decades of seaweed radioactivity monitoring in the Channel Islands, the data are put in perspective with levels in the Normand-Breton Gulf. Hydrodynamic modelling tools were used to yield a comprehensive assessment of radioactive transfer to biota in the area. 


\title{
A comprehensive assessment of two-decade radioactivity monitoring around the Channel Islands
}

\begin{abstract}
The Channel Islands are located in the Normand-Breton Gulf (NBG), in the mid-part of the English Channel (France, Normandy). In the northern part, off Cap La Hague, controlled amounts of radioactive liquid waste are discharged by the ORANO La Hague nuclear fuel reprocessing plant (RP). Radionuclides were monitored in the NBG to assess the dispersion of radioactive discharges from the RP in the marine environment. The temporal and spatial distribution of the data are consistent with the history of the discharges, with most gamma emitter radionuclide environmental levels being close to or below the current limits of detection. A clear fingerprint of H-3, C-14 and I-129 radionuclides discharged from the RP is measured. The hydrodynamics in the NBG do not yield a simple gradient with linear distance from the outfall of the RP. Modelling tools were used to understand how radioactive discharges spread from the source of input. Dispersion patterns clearly illustrate the different behaviours of soluble and non-soluble radionuclides. The study indicated that the footprint of radioactive liquid discharges by French nuclear facilities was still measurable in species collected from the NBG for the mostly dissolved radionuclides. The less conservative ones, with a high affinity for suspended matter, are potentially influenced by old releases. These pathways could be investigated by dedicated hydrodynamic dispersion models. Overall, in the Channel Islands the levels are low and consistent with the general decrease in liquid radionuclide discharges by the RP since the 1990s.
\end{abstract}




\section{A comprehensive assessment of two-decade radioactivity monitoring around the Channel Islands}

Bruno Fiévet ${ }^{1}$, Pascal Bailly du Bois ${ }^{1}$, Claire Voiseux ${ }^{1}$, Claire Godinot ${ }^{1}$, Olivier Cazimajou ${ }^{1}$ Luc Solier $^{1}$, Anne De Vismes $\mathrm{Ott}^{2}$, Catherine Cossonnet ${ }^{2}$, Azza Habibi ${ }^{3}$, Sandrine Fleury ${ }^{4}$

${ }^{1}$ Laboratoire de Radioécologie de Cherbourg-Octeville, IRSN/PSE-ENV/SRTE, Rue Max Pol Fouchet, BP10, 50130 Cherbourg-en-Cotentin, France.

${ }^{2}$ Laboratoire de Mesure de la Radioactivité dans I'Environnement, IRSN/PSE-ENV/SAME, Bât. 501, Bois des Rames, Rue du Belvédère, 91400 Orsay, France.

${ }^{3}$ Laboratoire d'Expertise, de Radiochimie et de Chimie Analytique, IRSN/PSE-ENV/SAME, Bât. C4, 31 rue de l'Écluse, BP 40035, 78116 Le Vésinet Cedex, France.

${ }^{4}$ Laboratoire de Mesure Nucléaire, IRSN/PSE-ENV/SAME, Bât. C4, 31 rue de l'Écluse, BP 40035, 78116 Le Vésinet Cedex, France.

Institut de Radioprotection et de Sûreté Nucléaire

FIEVET Bruno <bruno.fievet@irsn.fr>;

BAILLY DU BOIS Pascal <pascal.bailly-du-bois@irsn.fr>;

VOISEUX Claire<claire.voiseux@irsn.fr>;

GODINOT Claire<claire.godinot@irsn.fr>;

CAZIMAJOU Olivier <olivier.cazimajou@irsn.fr>;

SOLIER Luc<luc.solier@irsn.fr>;

DE VISMES Anne <anne.de-vismes@irsn.fr>;

COSSONNET Catherine <catherine.cossonnet@irsn.fr>;

HABIBI Azza<azza.habibi@irsn.fr>;

FLEURY Sandrine <sandrine.fleury@irsn.fr> 
1 A comprehensive assessment of two-decade radioactivity monitoring around 2 the Channel Islands

3 Keywords : Radioactivity monitoring / Marine environment / English Channel / Channel Islands /

4 Hydrodynamic modelling / Transfer modelling

Introduction

The Channel Islands are located in the Normand-Breton Gulf (hereafter NBG), in the mid-part of the English Channel (France, Normandy). In the northern part of the NBG, controlled amounts of radioactive liquid are discharged by the ORANO nuclear fuel reprocessing plant off Cap La Hague. The Flamanville nuclear power plant operated by EDF is also located on the west coast of the Cotentin peninsula but its liquid radioactive discharges are smaller ( 2 orders of magnitude lower) than those of the reprocessing plant. Two decades ago, a complete survey of the consequences of these radioactive discharges was carried out by the Nord-Cotentin Radioecology Group (NCRG, 1999). However, the amounts of liquid discharges have substantially declined since the 1990 s and an update of the radionuclide levels in the marine environment is necessary, using modelling tools that have become available to appraise the dispersion of local radioactive discharges in the marine environment. This paper presents annual radioactivity measurements in the brown seaweed Fucus serratus performed by the Institut de Radioprotection et de Sûreté Nucléaire (IRSN) in the Channel Islands from 1998 to 2017 . The results are compared with radioactivity monthly time-series measurements in the same seaweed collected at Goury, about $6 \mathrm{~km}$ north of the reprocessing plant outfall for radioactive liquid discharges, between September 2013 and June 2016. They are also compared with the results from two sampling surveys undertaken by IRSN in 2014 and 2015, spanning the whole NBG between Paimpol and Goury. The 2014 and 2015 data from the NBG, including the islands, are compared with radioactivity measurements in reference samples collected away from the French nuclear facilities in the Cotentin, at Concarneau (North Atlantic) and Roscoff (the western end of the English Channel) in Brittany. Data for the seaweed $F$. serratus from the French shoreline were also compared with data collected at the same locations for the soft parts of limpets Patella sp. (a Mollusk Gastropod), as a representative of another biological compartment. Finally, hydrodynamic modelling tools were used in the NBG to support the data from the biota with a comprehensive assessment of the general pattern of seawater radionuclide dispersion.

\section{Material and methods}

Annual discharges from the ORANO reprocessing plant at La Hague: The amounts of controlled radioactive liquid waste discharges from the ORANO RP at La Hague are published annually (https://www.orano.group). Figure 1 shows the history of liquid discharges from 1982 to 2015 (a color version is available in the supplementary material: Fievet_etal_2020_Supplementary Material.pdf).

Figure 1

Bioindicators. Brown seaweeds and limpets are common bioindicators used to monitor radioactivity in the marine environment in Western Europe (OSPAR Commission, 2009; CEFAS, 2016). They are easily collected manually on the shore all year round. They are known to accumulate radionuclides 
with respect to seawater (IAEA, 2004), thereby making them magnifying tools for monitoring levels in the environment.

Sampling and processing. Toothed wracks (Fucus serratus) and limpets (Patella sp) were collected on shore in different locations of the maritime area between Paimpol and Goury. The sampling locations are shown in Figure 2 (geographical coordinates are provided in the supplementary material: Fievet_etal_2020_Supplementary_Material.xIsx). This included the French shoreline as well as the Channel Islands and a few other minor islands (Les Écrehou, Chausey, Roches-Douvres). The samples were collected annually in summer from 1998 to 2017 in the Channel Islands and in spring in 2014 and 2015 at other locations in the NBG. Annual samplings in the Channel Islands were carried out in Jersey, Guernsey and Alderney. Although Les Écrehou does belong to the Channel Islands, this sampling location is included in the spring 2014 and spring 2015 NBG group throughout the paper. At Goury, close to the source of the radioactive liquid discharges, samplings were collected monthly between September 2013 and June 2016 to address temporal variability with a higher time resolution. Fucus serratus samples were also collected in 2014 and 2015 at reference locations away from the French nuclear facilities of the Cotentin, at Concarneau and Roscoff in Brittany. About $8 \mathrm{Kg}$ of Fucus serratus and $15 \mathrm{Kg}$ of limpet were collected for each sample. The limpets were frozen at $20^{\circ} \mathrm{C}$ for a week and thawed to separate the soft parts from the shell. The whole seaweed thallus and limpet parts were then dried at $90^{\circ} \mathrm{C}$ for about a week prior to grinding into a fine powder. The limpet parts were finally burned at $450^{\circ} \mathrm{C}$ to ash. Another fresh fraction was freeze-dried to measure $\mathrm{C}-14$ and $\mathrm{H}-3$ in some of the seaweed and limpet samples.

Figure 2

Radionuclide measurements. Radioactivity measurements were performed at the Laboratoire de Radioécologie de Cherbourg-Octeville, the Laboratoire de Mesure de la Radioactivité dans I'Environnement (IRSN, Orsay) and the Laboratoire de Mesure Nucléaire (IRSN, Le Vésinet). Ground material (dry seaweed or ashes of limpets' soft parts) was transferred to calibrated cylindrical containers for gamma spectrometry on HPGe germanium detectors. The detectors were equipped with anti-cosmic devices as described in de Vismes Ott et al., (2008; 2012) and the gamma-gamma coincidence technique, as described in Paradis et al. (2016), was used. This high-performance gamma spectrometry guaranteed very low limits of detection (LoD). I-129 was quantified in dried Fucus serratus by gamma-X spectrometry according to Lefèvre et al., (2003) and Bouisset et al., (1999). $\mathrm{C}-14$ was analyzed at LMRE by dry material combustion, $\mathrm{CO}_{2}$ trapping and conversion into benzene and C-14 beta scintillation counting on a Tricarb counter (Perkin-Elmer), as described in Fiévet et al., (2006). As of 2010, H-3, in the form of tritiated water molecules (HTO), was measured in the water extracted from the fresh material by freeze-drying and scintillation counting on a Tricarb counter (Perkin-Elmer) as described in Fiévet et al., (2013). In the 2014, 2015 and 2017 samples, H-3 as organically bound tritium (OBT) was measured at LMRE after combustion of dry material and combustion water scintillation counting on a Tricarb counter (Perkin-Elmer) as described in Fiévet et al., (2013). The dry material was finally burned to ash, and tracers (Pu-242 and Am-243) were added for extraction yield correction. Actinides were then extracted by 3 successive coprecipitations: 1 calcium oxalate at $\mathrm{pH} 1.5$; 2-iron hydroxide at $\mathrm{pH} 8.5$; 3-calcium oxalate at $\mathrm{pH} 1.5$; and destruction of the second calcium oxalate precipitate and dissolution of the residue in $8 \mathrm{M} \mathrm{HNO}_{3}$. $\mathrm{Pu}(\mathrm{IV})$ was separated from Am-Cm using anion exchange chromatography on resin AG1X8 (Biorad), conditioned in $8 \mathrm{M} \mathrm{HNO}_{3}$. After loading and washing with $8 \mathrm{M} \mathrm{HNO}_{3}$, the solution was preserved for the 
purification of the Am-Cm fraction. Pu was eluted with $12 \mathrm{M} \mathrm{HCl} / 0.1 \mathrm{M} \mathrm{NH}_{4} \mathrm{l}$. Am-Cm fraction purification involved 3 successive chromatography columns: 1- separation of $\mathrm{Am}-\mathrm{Cm} / \mathrm{Fe}, \mathrm{U}$, Th on a double column with AG1X8/AG50W resin (Biorad); 2- separation of $\mathrm{Am}-\mathrm{Cm} / \mathrm{Cu}$, Ni metals on a column with TRU resin (Biorad); and 3- separation of $\mathrm{Am}-\mathrm{Cm} / \mathrm{rare}$ earth elements on a column with AG1X4 resin (Biorad). Pu and Am residues were dissolved in concentrated $\mathrm{HNO}_{3}$ and diluted in water. The 2 sources were prepared by electrodeposition onto stainless steel discs as the cathode (Pt anode), current $1 \mathrm{~A}$, time 2 hours, $5 \mathrm{~mm}$ between the 2 electrodes. Pu and $\mathrm{Am}-\mathrm{Cm}$ isotopes were determined with a low level background alpha spectrometer (alpha-analyst, MIRION Technologies). The detectors were $450 \mathrm{~mm}^{2} \mathrm{PIPS}$ detectors, with an efficiency around $34 \%$ for ${ }^{239} \mathrm{Pu}$. Counting time was 14 days. The data processing software to quantify the radionuclide activities included Interwinner ${ }^{\mathrm{TM}}$ (Hi-Tech Detection Systems), Genie $2000^{\mathrm{TM}}$ (MIRION Technologies), QuantaSmart ${ }^{\mathrm{TM}}$ (PerkinElmer). C-14 concentrations were expressed in Bq. $\mathrm{Kg}^{-1}$ Carbon and $\mathrm{H}-3$ concentrations were expressed in $\mathrm{Bq} . \mathrm{L}^{-1}$. Other radionuclide concentrations were reported in $\mathrm{Bq} . \mathrm{Kg}^{-1}$ dry weight. Activity results were reported with $2 \times$ Sigma uncertainties. The wet/dry $(w w / d w)$ weight ratios are provided for conversion purposes. For clarity, radionuclides are categorized in the paper as gamma, beta and alpha emitters according to the spectrometry detection method used for their activity quantification. However, for a more comprehensive assessment of the data, radionuclides were categorized in the discussion section as soluble and non-soluble.

Seawater circulation and radionuclide dispersion in the NBG: Previously validated modelling tools are available to document the hydrodynamic dispersion of radionuclides in the NBG (Salomon et al., 1988; Bailly du Bois et al., 2012 and references therein). They include a Lagrangian residual model, which calculates the tidal residual currents, and an instantaneous current model (MARS2D) which calculates currents and dispersion every 60-300s (see details below). These tools were used here to provide the following information:

- The general water circulation pattern in the NBG was illustrated by the trajectory and velocity of Lagrangian residual currents (Salomon et al., 1988, 1996, Bailly du Bois and Dumas, 2005). The residual current is the water's residual movement after one complete back-and-forth tide movement has occurred. Residual currents mainly result from tidal forcing, wind surface friction, bottom shape and roughness, which are the main driving forces for the long-term dispersion of dissolved material in seawater. The dispersion pattern in the NBG is complex due to the presence of the Channel Islands and other emerged areas. It is highly dynamic and variable depending on the wind and tide conditions and the exact time of the discharge. This pattern of average residual currents was calculated by the MARS2D Model using a previously published method (Salomon et al., 1996; Bailly du Bois et al., 2005 and references therein). A theoretical constant wind direction $\left(\mathrm{SW}=231^{\circ}\right)$ and speed $(8 \mathrm{~m} / \mathrm{s})$ and a constant medium tide coefficient $(70)$ were applied. This average wind condition corresponded to the quadratic mean of the wind direction and speed calculated between 1984 and 2017 at a central location in the English Channel $\left(2^{\circ} \mathrm{W} ; 50^{\circ} \mathrm{N}\right)$.

- A further insight was gained with the MARS2D model by calculating the annual mean concentrations resulting from a theoretical constant discharge from the RP plant with real wind and tide conditions between 1984 and 2015 (radioactive decay was not implemented for this constant discharge). The MARS2D model uses two-dimensional horizontal approximation (i.e. shallow-water equations) capable of producing a satisfactory representation of dissolved-substance transport in the English Channel. These equations were solved using the finite-difference MARS model, with implicit 
alternate direction time-stepping for gravity-driven inertia waves. Non-linear terms were discretized semi-implicitly. Full details concerning the MARS algorithm are given by Lazure and Dumas (2008). The model used here involved a nesting strategy, starting from a broad region covering the entire North-West European continental shelf (with a 5-km grid resolution) down to a detailed domain covering the whole English Channel with a mesh size of $500 \mathrm{~m}$. It accounted for real releases (but could be set as theoretical constant), tide and meteorological forcing to simulate instantaneous currents with a mean time step of $60 \mathrm{~s}$. Real wind data were provided by Météo France and corresponded to the outputs from the European Centre for Medium-Range Weather model (The ERA - Interim reanalysis, 2011). Tide conditions were provided according to Lyard et al., 2006. This yielded a normalized dispersion pattern in the NBG corresponding to realistic forcing during the period. Annual mean data extend from 1984 to 2015. The aim was to shows the influence of the wind and tide annual changes on the average dispersion of any soluble radionuclide released by the outlet of the Reprocessing Plant (It is not related to the real content of the discharges from the RP).

- To link this information on the average dispersion pattern in the NBG with realistic data, the $\mathrm{H}-3$ concentrations resulting from real discharges from the RP plant with real wind and tide were calculated and annually averaged. The $\mathrm{H}-3$ radionuclide was selected because it is released as HTO and thus, as a conservative tracer in seawater, it traces the dispersion of discharges by water movements exactly (the half-life of $\mathrm{H}-3$, which is 12.3 years, was implemented in this modelling).

Normalization of biota radionuclide concentrations to the discharges. For a comprehensive assessment of radionuclide transfers into the NBG, the biota data were normalized to discharges. The approach was similar to the concept of normalized activity concentrations previously used on data from the Irish Sea (Hunt et al. 1985, 2013; Hunt and Kershaw 1990). In the present study, normalization transform was performed according to the following relationship:

$$
[R n]_{N o r m, S}=\frac{[R n]_{s, B q . k g}{ }^{-1} d r y}{w d r_{s} * C F_{s} * 12 M D_{d a t}} \text {, in Bq. }(1000 \mathrm{~kg})^{-1} \text { per TBq.Y } \mathrm{Y}^{-1} \text { or Bq.kg-1 per GBq. } \mathrm{Y}^{-1} \text {. }
$$

where

$$
[R n]_{\text {Norm }, s}=\text { Concentration of radionuclide } \mathrm{Rn} \text { in species s normalized as a "dilution\&transfer }
$$
factor"

$[R n]_{s, B b . k g^{-1} d r y}=$ Concentration of radionuclide $\mathrm{Rn}$ in species $s$ in Bq. $\mathrm{kg}^{-1} \mathrm{dry}$ $w d r_{s}=$ Wet/dry ratio value for species $s$ $\mathrm{CF}_{\mathrm{s}}=$ Concentration Factor for radionuclide $\mathrm{Rn}$ in species $\mathrm{s}$ $12 \mathrm{MD}_{\text {dat }}=12$ months of discharges of radionuclide $\mathrm{Rn}$ in TBq preceding the date of sample $1000=$ converts Bq. $\mathrm{Kg}^{-1}$ to $\mathrm{Bq} .1000 \mathrm{~kg}^{-1}$ in biota because the concentrations in seawater calculated by the hydrodynamic model were expressed in Bq. $\mathrm{m}^{-3}$.

This normalization transform resulted in the expression of species concentrations as a "dispersion factor-like" value resulting from both dilution and transfer to the biota from the source of input, assuming a constant discharge of $1 \mathrm{TBq} \cdot \mathrm{y}^{-1}$. It can thus be directly compared to the normalized average dispersion pattern in seawater calculated by the MARS-2D hydrodynamic model, assuming a constant discharge of $1 \mathrm{TBq} . \mathrm{Y}^{-1}$. It should be pointed out that radioactive decay is implemented by MARS-2D in the dilution\&transfer process. However, except for Co-60 and Ru-106 (half-lives $5.27 \mathrm{y}$ and $373 \mathrm{~d}$, respectively), the influence of radioactive decay is small with regard to the estimated half- 
167 time turnover of radionuclides in the NBG (see Results section). The CFs values are given in the

168 following table:

169

170

171

172

173

174

175

176

177

178

179

180

181

182

183

184

185

186

187

188

189

190

191

192

193

194

195

196

197

198

199

200

201

202

203

204

205
Table 1

For Cs-137 and C-14, the average observation level at Concarneau in 2014 and 2015 was deduced from biota concentrations to account for the background level at the entrance to the Channel. This background level results from sources other than the ORANO La Hague RP (Cs-137: fallout from past nuclear weapons tests, the contribution of discharges from Sellafield, the Chernobyl accident, etc.; C14: natural, fallout, etc.). This data transform made it possible to visualize whether or not the radionuclides dispersed in the NBG as soluble radionuclides in seawater before transfer to the biota. If not, the discrepancy illustrates the non-conservative behavior of radionuclides in the marine environment of the NBG.

\section{Results}

Annual time-series measurements in the Channel Islands. Radionuclide concentrations measured annually in Fucus serratus from 1998 to 2017 in the Channel Islands are provided in the supplementary material: Fievet_etal_2020_Supplementary_Material.xIsx. To illustrate the trends in radionuclide concentrations, the data from the location nearest to the source of input in the Channel Islands, Alderney, Corblet Bay (NE), and from the westernmost site, Guernsey, Portelet Harbour (SW), are displayed graphically for Co-60, Cs-137 and I-129 (Figure 3).

Figure 3

A wider view over the NBG area. Data from the Channel Islands were put into perspective through comparison with the levels in the wider area of the NBG, as well as reference levels from two locations away from the radioactive discharges. For this purpose, radionuclide measurements were performed in 12 locations across the NBG (in addition to the locations in Jersey, Guernsey and Alderney) on Fucus serratus samples collected in the spring of 2014 and 2015. To estimate the reference levels, samples from 2 additional remote locations in Brittany (Concarneau) and at the western end of the Channel (Roscoff) were collected. The data, including those from the Channel Islands for comparison, are illustrated as bar charts sorted by (linear) distance from the outfall of the nuclear fuel reprocessing plant (RP) (Figure 4). Spreadsheets with all the data are provided as supplementary material: Fievet etal 2020 Supplementary Material.xlsx.

\section{Figure 4}

Monthly time-series measurements in the near vicinity of the input source. To provide further insight into the temporal variability of radionuclide levels, the same gamma emitter radionuclides were analyzed on a monthly basis in the same seaweed and in the soft parts of limpets collected at Goury, $6 \mathrm{~km}$ north of the radioactive liquid discharge outfall at the reprocessing plant. In this location, close to the source of input, changes over time are expected to show the widest variations due to the proximity of the labelled plume of each release which could influence the coastal measurements. The data are presented in Figure 5 and tabulated in the supplementary material: Fievet_etal_2020

Supplementary_Material.xIsx.

Figure 5: 
Alpha and Beta emitters. C-14, H-3, Pu-238, Pu-239,240 (the sum of Pu-239 and Pu-240 isotopes) and Am-241 were also measured in some of the samples from the Channel Island annual time-series (there was no such measurement in 1998). The data are presented in Table 2.

Table 2

The same alpha and beta emitter radionuclides were also measured in seaweed samples collected in the NBG area for comparison. The data are reported as bar charts in Figure 6, with locations sorted with respect to the distance from the outfall of the RP, using the same presentation as in Figure 4 and tabulated in the supplementary material: Fievet_etal_2020_Supplementary_Material.xisx. The isotopic ratio between Pu-238 and Pu-239,240 was calculated in biota samples collected in the NBG. The results are reported in the supplementary material: Fievet etal 2020 Supplementary Material.xIsx.

Figure 6

Seawater circulation and radionuclide dispersion in the NBG: The general water circulation pattern in the NBG was illustrated by calculating the trajectory and velocity of average residual currents (Figure 7).

\section{Figure 7}

The map of average residual currents in Figure 7 shows a major northbound pathway in the Alderney race, towards the eastward trend of the main water mass in the English Channel (not shown). However, persistent counterclockwise recirculation gyres around Guernsey, Jersey and other minor islands contribute to another progressive southbound route towards the bottom of the NBG. The description of the divergence zone near the RP outfall is accurately documented in Bailly du Bois et al., (2012).

The normalized dispersion pattern of radioactive discharges from the RP in the NBG was illustrated using the MARS2D model (Bailly du Bois et al., 2012) to calculate annual mean concentrations resulting from a theoretical constant discharge from the RP plant with real wind and tide conditions between 1984 and 2015. Only 1985 and 2015 are shown (Figure 8) to demonstrate that the pattern was similar throughout the whole period of the study (in 1984, the mixing spins up to reach a stable situation). It shows that variations in hydrodynamic forcing have a weak influence at the annual time scale. The complete annual color maps time-series is provided in the supplementary material: Fievet_etal_2020_Supplementary_Material.pdf.

Figure 8

Since the model's calculation based on a constant discharge yielded a steady state in 1985, the time taken to reach this steady state during 1984 provided an estimate of the average turnover of soluble radionuclides between the source of input and the different locations in the NBG. Starting from concentration "zero", the time taken to reach half of the 1985 mean annual concentration at each biota sampling location in the NBG was derived from the model results. The values were added to the 1985 map in Figure 8 at the sampling locations, as an estimate of the average half-time turnover of soluble radionuclides discharged by the RP (in days). 
Finally, the $\mathrm{H}-3$ concentrations in seawater resulting from real discharges from the RP plant with real wind and tide conditions were calculated, along with the annual mean values. The annual means extend from 1984 to 2015 but only the 2014 and 2015 annual mean data are shown, for conciseness (Figure 9). 2014 and 2015 maps with a higher color-levels resolution are available in the supplementary material: Fievet_etal_2020_Supplementary_Material.pdf.

Figure 9

Transfer to the biota between the outfall of the RP and the NBG: For a comprehensive assessment of the dispersion pattern of radionuclides in the NBG, the data in the biota were transformed to give "dilution\&transfer factor-like" values from the source of radioactive input (after background substraction for Cs-137 and C-14, divided by the Concentration Factors, normalized to the discharges, see Methods).

The first step was to illustrate the annual average dilution factor calculated by the hydrodynamic model for the different biota sampling locations. This consisted in extracting the 2014 and 2015 data values from the time-series illustrated in Figure 8 (for 2015 and shown in the supplementary material for 2014: Fievet_etal_2020_Supplementary_Material.pdf) for the biota sampling locations. This is the reference showing the dispersion of soluble radionuclides constantly discharged by the RP in the seawater currents. However, radioactive liquid waste is not discharged constantly by the RP but is discharged mainly during a special time window with regard to the tide schedule in order to optimize hydrodynamic dispersion to the north and the eastern English Channel (see Bailly du Bois et al., 2012). This discharge timing reduces dispersion towards the NBG where the water mass residence time is longer than in the median area of the Channel. To take this discharge time frame into account, the dispersion pattern of real $\mathrm{H}-3$ discharges was used to represent the dispersion of soluble radionuclides from the RP. However, to use it as a reference, it had to be normalized to an annual amount. We selected $1 \mathrm{TBq} . \mathrm{Y}^{-1}$ because it was the order of magnitude of ${ }^{137} \mathrm{Cs}$ releases as of 2000. For this purpose, annual average seawater $\mathrm{H}-3$ concentrations $\left(\mathrm{Bq} . \mathrm{m}^{-3}\right)$ resulting from real $\mathrm{H}-3$ discharges by the RP calculated by the MARS2D model (Figure 9) were divided by the annual H-3 discharge amount (TBq). This calculation was performed at each biota sampling location in 2014 and 2015. It yielded dilution factor values that could be used specifically in 2014 and 2015 as a reference for the soluble radionuclide dispersion pattern in the NBG for other radionuclides. The dispersion patterns of other radionuclides provided by concentrations normalized to discharges were thus compared to this reference. Background values estimated on the basis of the average concentrations measured at Concarneau were substracted from NBG data for Cs-137, C-14 and the transuranic elements (background was considered negligible for $\mathrm{H} 3$ ). The radionuclides were presented as two groups on the basis of their expected behaviour depending on their solubility (Figure 10 and Figure 11).

Figure 10

Figure 11

Transfer to the biota near the RP outfall: A second way to discriminate between soluble and particulate radionuclides was to look at the temporal variability of the relationship between the observed radionuclide concentrations and the discharges, regardless of the dispersion pattern. At a short distance from the source of input, dispersion is just beginning, so the influence of interactions 
with suspended matter and sedimentation should be less. For this purpose, the monthly time-series measurement data for seaweeds from Goury were processed the same way, divided by the CFs (Table 1) and normalized to the 12-month discharges preceding the sampling dates. The results are presented in Figure 12.

Figure 12

\section{Discussion}

In addition to naturally occurring radionuclides and fallout from past atmospheric nuclear weapons tests, the sources of radioactivity in the English Channel mainly include radioactive discharges from the nuclear industry. On the French coast, the ORANO reprocessing plant (RP) at La Hague is by far the major contributor, even though liquid discharges have fallen considerably since the 1980s. The reduction in discharges is due to the constant implementation of the BAT (Best Available Techniques) strategy (OSPAR Commission, 2014). Four EDF nuclear power plants (NPP), at Flamanville, Paluel, Penly and Gravelines, are located on the French coast, in addition to the nuclear power plant at Nogent-sur-Seine on the Seine River, which flows into the English Channel. The NPPs' contribution to radionuclide levels in the NBG is small compared to that of the RP. Since radioactive liquid discharges from the French RP into the English Channel occur in the NBG, it was particularly relevant to assess the dispersion of those discharges in this area. It was also useful to put the observed data in the NBG into perspective by comparing them with reference locations, remote from radioactive discharges. This was the purpose of the two reference locations at Concarneau (Brittany, Atlantic) and Roscoff (the western part of the English Channel). A comprehensive assessment of the radiological impact of radioactive discharges by French facilities in the English Channel was previously carried out by the North Cotentin Radioecology Group (NCRG, 1999). It included a review of environment radioactivity concentration measurements up to 1996 . Because liquid discharges into the sea have substantially decreased since this assessment (Figure 1), it was essential to provide an update of environmental radionuclide levels two decades later.

The English Channel is a shallow megatidal sea and the outfall of the RP is located in an area well known for strong tidal currents. The hydrodynamics of the English Channel are well characterized and reliable hydrodynamic models have been developed and extensively validated (Bailly du Bois and Dumas, 2005; Bailly du Bois et al., 2012). It must be outlined than the vertical distribution of radionuclides released by the $\mathrm{RP}$ is already homogeneous in the water column at $1500 \mathrm{~m}$ distance from the outlet (Bailly du Bois et al., 2020b). Once the source terms of discharges are known with accuracy (time and location), seawater concentrations in the English Channel and up to the North Sea can be predicted by models. In addition to residual currents (resulting from back-and-forth tidal movements), the general water circulation in the English Channel is also driven by wind friction. Because of the tidal residual currents and common prevailing wind directions, the English Channel usually flows slowly from west to east, i.e. from the Atlantic to the North Sea. However, when the wind blows from the north-east for several weeks, this circulation temporarily reverses. It should be added that because of radioactive discharges from the Sellafield facility (United Kingdom), radionuclide concentrations in the marine environment in the Irish Sea are substantially higher than in the English Channel (CEFAS, 2016). The potential contribution of dissolved radionuclide inputs at the western end of the English Channel coming from the Irish Sea has been estimated to be about $1 \%$ of discharges from Sellafield (Bailly du Bois et al., 1995, 2002). This estimate was recently confirmed (Castrillejo et al., 2020). At present, this contribution is considered to be low. The slight difference 
between the levels of Cs-137 in seaweeds observed in 2014 and 2015 in Roscoff (potentially influenced by Sellafield discharges) compared to Concarneau (situated on the Atlantic coast of Brittany and not influenced by Sellafield discharges) was not likely to be significant for two reasons. First, the uncertainties ( $2 \times$ sigma) accounted for at least a third of the reported activities and second, the minimum levels observed in the NBG (Roches Douvres) were lower than at Roscoff and were similar to those at Concarneau. If we account for error magnitudes, these three locations could not be distinguished from one another. Annual data were obviously not enough to address this point accurately.

Hydrodynamics of radionuclide dispersion from the RP in the NBG: Prior to looking at the data in the biota, a rapid survey of the general water mass circulation in the NBG was crucial to understand the dispersion of radionuclides and their transfer to marine species. The hydrodynamics in the NBG are complex and so an intuitive interpretation of the data was challenging. The only way to achieve a comprehensive assessment of radionuclide monitoring in the biota of the NBG was to use models to simulate the local hydrodynamics and water mass pathways (Figure 7). The models used in this study provided powerful tools for deciphering the major processes governing the fate of radioactive discharges from the RP in the area and made it possible to attempt to relate the radionuclide concentrations observed in the biota with their sources of origin. The general pattern of the residual currents is shown in Figure 7. It was calculated using average conditions, with a constant wind corresponding to the average for meteorological conditions in the NBG and a medium tide. It should be emphasized that this average residual current pattern explains the long-term dispersion of dissolved substances (Salomon et al. 1988). But the short-term excursion of radionuclide movements resulting from real back-and-forth tide currents extends over a much larger spatial magnitude (see Bailly du Bois et al., 2012, for details). After documenting the general pattern of the dispersion, a good way to assess the exposure levels of the biota was to look at the average concentrations resulting from the discharges. Many parameters influenced radionuclide concentrations in the seawater where the biota was monitored. They include the wind, the tide and, last but not least, the exact time of the discharges. To understand the relative influence of these components, a first step was to calculate with MARS2D the average concentrations resulting from a theoretical constant discharge with the real wind and tide conditions. The calculation results in Figure 8 showed that after one year of discharge starting in 1984, average concentrations in 1985 showed a spatial distribution which was more complex than just a gradient with respect to linear distance from the outfall of the discharges. However, this spatial distribution calculated in 1985 turned out to correspond to a "steady state" at an annual time scale, so the 2015 map in Figure 8 looked very similar. The 19852015 annual color map time-series provided in the supplementary material (Fievet_etal_2020_Supplementary_Material.pdf) support this conclusion. This information demonstrated that, on a yearly basis, real rapid changes in wind and tide were smoothed and resulted in similar calculated annual average concentrations. This provided an opportunity to look at the time-course of changes in concentrations from zero to the steady state observed as of the end of 1984 and to estimate the average half-time turnover of soluble radionuclides discharged in the NBG by the RP. These estimated average half-time turnover values (in days) completed the average trajectories information displayed on the 1985 map in Figure 8. Close to the outfall (Goury), the 23day average turnover value characterized the time to reach half the average steady state level. Barneville and Alderney had values of around 2 months whilst central and southern locations of the NBG had values of between 3 and 4 months. In the innermost area of the NBG, in Granville and 
Cancale, where a slower average half-time turnover is logically expected, the values were estimated to be 8 to 9 months, respectively. The spatial modelled average concentration distribution shown in Figure 8 provided a first insight to understand the distribution of radionuclides in the biota monitored in the NBG. To make it more realistic, the data should be calculated with real discharge data. This was the purpose of the third step where all model inputs were "real-world" data for $\mathrm{H}-3$, i.e. the exact time course of the discharges, and the real wind and tide conditions. It should be pointed out that the real discharges were not routinely evenly distributed over time but were released in a particular time frame with regard to the tide schedule. This optimized their dispersion to the main English Channel water mass flux to the north and east, and prevented them from being held in the NBG where the water mass renews less rapidly. $\mathrm{H}-3$ dispersion thus provided the best possible representation of dispersion by water currents in the area. This information was reliable because this modelling had been extensively validated with many measurements (Bailly du Bois et al., 2005, 2012 and references therein). The resulting annual mean concentrations were calculated from 1984 to 2016 and the maps for the years 2014 and 2015 are given in Figure 9 for illustration purposes. In Figure 9, the average distribution pattern was similar to that of Figure 8 but the annual average seawater $\mathrm{H}-3$ concentration values were realistic. Since annual tritium discharges are around $1 \mathrm{E}+04 \mathrm{TBq} . \mathrm{Y}^{-1}$ (Figure 1), concentrations are logically four orders of magnitude higher than those resulting from 1 TBq. $\mathrm{Y}^{1}$ theoretical constant discharge. This general pattern of soluble substance dispersion in the NBG assessed by hydrodynamic modelling tools provided a basis to look at radionuclide transfers between the outfall of the ORANO La Hague RP and the marine biota. Nevertheless, it should be emphasized that annual means provided the general scheme but obviously smoothed out temporal variability and should be used cautiously when comparing with individual measurement data, particularly in the vicinity of the release outfall.

The biota data reported in this study helped to address three main questions about the radiological consequences of radioactive discharges by French nuclear facilities in the marine environment of the NBG. Firstly, how did radioactivity increase in the NBG compared to a reference background level? Secondly, the geographical variability in the whole of the NBG and how did the levels observed in the Channel Islands compare with this variability? Thirdly, what was the significance of annual observations with regard to the temporal variability (had we overlooked something?). Analyzing the same bioindicator, toothed wrack (Fucus serratus), all along the shoreline in the marine environment enabled comparisons to be made to address these three issues. The data for the soft parts of limpets (Patella sp) collected in the vicinity of the radioactive input sources provided an insight into transfer to mollusks, as a representative of an upper level in the trophic web. Radionuclide concentrations observed in the soft parts of Patella were below those observed in Fucus, so emphasis has been placed on the seaweed in the discussion. The data are presented in the Results section by metrology categories (gamma spectrometry, liquid scintillation, alpha spectrometry) because this is how radioactivity monitoring data are usually collected and sorted. However, for a more comprehensive discussion of radionuclide dispersion in the marine environment, they can be better categorized as conservative or non-conservative. Conservative radionuclides stay soluble in seawater with no loss during dispersion by water currents. Some transfer to particulate material and the biota is possible but the process has little influence compared to the amount of dissolved material (i.e. losses below $5 \%$ at the English Channel scale). In the present context, $\mathrm{H}-3, \mathrm{C}-14, \mathrm{I}-129$ and $\mathrm{Cs}-137$ were included in this category (Bailly du Bois and Guéguéniat, 1999). However, due to potential concentration in the sediment compartment and possible future desorption, as in the Irish Sea (Jones et al., 2007, Hunt et 
al., 2013), caution is required in the case of Cs-137. Loss of radiocaesium was estimated at $17 \%$ at the English Channel scale (Bailly du Bois and Guéguéniat, 1999). Conversely, because of their higher affinity for suspended matter, non-conservative radionuclides do not behave as soluble substances only. They are readily discharged as particulate material or they adsorb to suspended matter and thus follow the fate of particulate material. For these radionuclides, the partitioning of the radionuclide between the aqueous and the particulate phases must be taken into account. Depending on their particulate fraction or the contribution of their adsorption, they may disappear from the aqueous phase with time and distance from the source of input. The adsorption capacity of particles depends on their specific surface area, so the smaller the particles, the greater their capacity to capture radionuclides. This process also potentially influences their capacity to transfer to the biota (bioavailability). However, the biota incorporates not only soluble radionuclides but also particulate material either by adsorption (sticking to protective mucus) or by ingestion (filter feeders, food chain, etc.). When collected in the marine environment, the biota is likely to carry suspended matter either adsorbed or inside its digestive tract (if present) (Carvalho, 2018). Non-conservative radionuclides are known to partition mainly in the particulate phase rather than in the aqueous phase. Since these radionuclides share the same fate as particulate material, they eventually sediment and get temporarily trapped in the sediment. When they do so, they carry the signature of the discharges at the time when they adsorbed to the suspended matter. If the sediment resuspends for some reason later on, its potential interaction with the biota carries this old discharge signature, which may be different from that of the present discharge. It is currently impossible to find out what the relative contributions are of desorption following sediment particle resuspension and of the "contamination" of biota samples by sediment particles. However, a thorough examination of suspended matter is necessary to properly interpret the data for non-conservative radionuclides. In the present context, the non-conservative radionuclides included Co-60, Ru-106, Pu-238, Pu-239,240 and Am-241. At the scale of the English Channel, losses were estimated for Co- 60 and Ru-106 to be $92 \%$ and $81 \%$, respectively (Bailly du Bois and Guéguéniat, 1999).

Looking at the biota concentration data sorted by linear distance from the outfall of the RP was a convenient way to illustrate graphically the dispersion of the radionuclide discharges (Figure 4 and Figure 6). However, because of the very complex water circulation in the NBG, some discrepancies between the concentrations observed in the biota sampling locations and their linear distance from the source of input were expected. To attempt to link the data for radionuclides in the biota with the dispersion pattern in the NBG, the concentrations observed in the biota were normalized to the discharges and transformed using Concentration Factor values to yield "Dilution\&transfer factor-like" data that could be directly compared to the hydrodynamic information (see Methods for details). But since hydrodynamic models were used to provide information on the dispersion of soluble material, the success of this comparison obviously depended on the conservative vs non-conservative behaviour of the different radionuclides. The method shed light on three major components of the system: the dispersion throughout the NBG area; the background levels in the seawater entering the English Channel; and the putative influence of past discharges trapped in the sediment compartment on present biota concentrations revealed by non-conservative radionuclide data in the near vicinity of the outfall from the RP.

Conservative radionuclides: Four mainly soluble radionuclides were routinely detected in seaweed collected on the southern shores of the English Channel, namely H-3, C-14, I-129 and Cs-137. Regarding $\mathrm{H}-3$, we focused on the HTO form measured in water extracted from seaweed by freeze- 
drying. The data ranged between our LoD of $2 \mathrm{~Bq} \cdot \mathrm{L}^{-1}$ and 7.4 Bq. $\mathrm{L}^{-1}$ in the Channel Islands and in other locations of the NBG (supplementary material: Fievet_etal_2020_Supplementary_Material.xIsx) except in the vicinity to the outfall from the RP, where higher levels up to $30 \mathrm{~Bq} \cdot \mathrm{L}^{-1}$ were found (Fiévet et al., 2013). Recent data for the Bay of Biscay indicated that the $\mathrm{H}-3$ background level in seawater at the western entrance to the English Channel ranged between 0.07 and $0.33 \mathrm{~Bq} \cdot \mathrm{L}^{-1}$ (Oms, 2018). $\mathrm{H}-3$ is released by the RP as HTO and is a perfect tracer of soluble radioactive discharge dispersion. There was a slight difference in the modelled dispersion patterns across the NBG, between a theoretical discharge distributed evenly over time, and real discharges, which are performed in the right time-frame to optimize dilution to the north towards the general water flow of the Channel (Figure 8 and Figure 9, respectively). H-3 dispersion was used as a reference to show how soluble radionuclides spread out from the RP into the NBG in 2014 and 2015. Near the outfall of the RP, the monthly time-series data normalized to the discharges (Figure $12 \mathrm{~A}$ ) displayed a noisy pattern reflecting the highly dynamic mixing in the Alderney race off Cap La Hague (Bennis et al., 2020; Bailly du Bois et al., 2012, 2020a). This also gave the reference temporal pattern of soluble radionuclide dispersion in that location during that period [Sept. 2013-June 2016], since Fiévet et al., (2013) have demonstrated that HTO in seaweed very accurately reflects HTO in seawater when considering the horizontal resolution of the model. H-3 levels in the NBG clearly resulted from discharges by the RP but the levels were low. These observations were consistent with data from our previous review of the radiological impact of $\mathrm{H}-3$ discharges from French nuclear facilities in the English Channel (Fiévet et al., 2013). The relationship between $\mathrm{H}-3$ in seawater, $\mathrm{H}-3$ in the biota in the form of $\mathrm{HTO}$, and $\mathrm{H}-3$ in the form of OBT (Organically Bound Tritium) was addressed in the same publication. OBT was determined in seaweed samples collected in the Channel Islands only in 2017 but the observed levels were consistent with HTO, in agreement with Fiévet et al., (2013).

C-14 was measured in the Channel Islands in 1999, 2002, 2014, 2015 and 2017 and ranged from 268 to $360 \mathrm{~Bq} . \mathrm{Kg}^{-1} \mathrm{C}$. This reporting unit was chosen for comparison with the actual background $\mathrm{C}-14$ level in the marine environment, which is presently around $249 \mathrm{~Bq} \cdot \mathrm{Kg}^{-1} \mathrm{C}$ according to Muir et al., (2017), and ranged from 237 to $242 \mathrm{~Bq} \cdot \mathrm{Kg}^{-1} \mathrm{C}$ on the basis of our observations at Concarneau and Roscoff (supplementary material: Fievet_etal_2020_Supplementary_Material.xIsx). The dispersion pattern of C-14 across the NBG (Figure $10 \mathrm{C}$ ) was consistent with that of measured HTO (Figure $10 \mathrm{~B}$ ) and simulated $\mathrm{H}-3$ in seawater (Figure $10 \mathrm{~A}$ ). It was therefore considered as conservative. However, $\mathrm{C}-14$ is mainly released by the RP as dissolved inorganic carbon and this element is incorporated into organic matter via photosynthesis (and then the food chain). The kinetics of this incorporation into organic matter are slow and C-14 changes in the biota were smoothed compared to $\mathrm{C}-14$ in seawater (Fiévet et al., 2006). This was clearly observed in the monthly time-series measurements near the outfall of the RP (Figure $12 \mathrm{C}$ ). Changes over time looked obviously smoothed with regard to the HTO pattern (Figure $12 \mathrm{~A}$ ). Our results were consistent with measurement results in the whole NBG (supplementary material: Fievet_etal_2020_Supplementary_Material.xIsx) as well as previously published data (Fiévet et al., 2006). The fingerprint of C-14 discharges from the RP in the NBG was clear. This radionuclide was pointed out as a major relative contributor to the very low dose to humans from seafood consumption in the critical group (Goury fishermen) chosen by the NordCotentin Radioecology Group (NCRG, 1999). In short, H-3 and C-14 are definitely good markers of the footprint of discharges by the ORANO RP in the NBG. They are both distributed with respect to hydrodynamics between Cap La Hague and the NBG (Figure $10 \mathrm{~A}, \mathrm{~B}, \mathrm{C}$ ) and the present data did not challenge the conclusions from previous studies (Fiévet et al., 2006; 2013). 
504 One choice of indicator to assess the fate of discharges from nuclear fuel reprocessing in the marine environment was the long-life radionuclide $\mathbf{I}-129$, in particular for seaweed because of their wellknown capacity to concentrate iodine up to 10,000 times with respect to seawater (Küpper et al., 1998; IAEA, 2004; Leblanc et al., 2006). Although I-129 was potentially present in background levels (naturally occurring and as a remnant from past nuclear weapons tests), it was below our LoD in seaweed from the reference locations at Concarneau and Roscoff. However, I-129 was routinely detected in seaweed collected on shore in the NBG, as shown by our measurement results in Fucus serratus. Most levels in the NBG were below $25 \mathrm{~Bq} . \mathrm{Kg}^{-1}$ dry while the highest levels, of up to 120 Bq. Kg ${ }^{-1}$ dry, were observed in the vicinity of the RP outfall. The dispersion pattern across the NBG (Figure $10 \mathrm{D}$ ) corresponded to the family of conservative radionuclides (Figure $10 \mathrm{~B}$ ). When looking at the monthly time-series close to Cape La Hague, the pattern in the seaweed was somewhat smoothed out compared to that of HTO. As for C-14, the kinetics of the transfer between seawater and seaweed were very likely to be responsible for this smoothing. lodine transfer between seawater and seaweed certainly deserves to be further investigated.

In 2014 and 2015 in the NBG, Cs-137 concentrations in seaweed ranged from 0.15 to $0.35 \mathrm{~Bq}^{-\mathrm{Kg}^{-1} \mathrm{dry}}$ but, during the same period, the levels at Concarneau and Roscoff were in the same range. Considering the measurement uncertainties, it can be concluded that the increase in Cs-137 levels due to discharges in the NBG was low. In the annual time-series measurements from the Channel Islands, the maximum levels of around $0.7 \mathrm{~Bq} \cdot \mathrm{Kg}^{-1} \mathrm{dry}$ observed in the late $1990 \mathrm{~s}$ have dropped to below $0.2 \mathrm{~Bq} \cdot \mathrm{Kg}^{-1} \mathrm{dry}$ at the present time, following the decrease in discharges (Figure 3 and supplementary material: Fievet_etal_2020_Supplementary_Material.pdf). At Goury, about $6 \mathrm{Km}$ north of the RP outfall, recent Cs-137 concentrations in seaweed were very close to the background level observed at the western end of the English Channel. Nowadays, Cs-137 is obviously not a good marker of recent radioactive discharges by French nuclear facilities in the NBG because of the existing background level. Figure $11 \mathrm{~A}$ confirmed this conclusion because, although Cs-137 can be considered soluble, its dispersion pattern in the NBG did not match well that of other conservative radionuclides. The substraction of the background level estimated from average values at Concarneau yielded some negative results in the NBG because of uncertainties on measurements. Remobilisation from the sediment compartment of past Cs-137 discharges was also a probable reason to explain the dispersion pattern illustrated in Figure $11 \mathrm{~A}$. It is only very close to the outfall of the RP that the monthly time-series measurements in seaweed displayed a noisy dispersion pattern like that of HTO (Figure $12 \mathrm{D}$ and A, respectively) and typical of soluble radionuclides.

Non-conservative radionuclides: Co-60 is a local marker of radioactive liquid discharges from the ORANO RP in the NBG (discharges from Flamanville NPP are two orders of magnitude lower) and it is an example of a non-conservative radionuclide. Though it has a half-life of 5.27 years, it was continuously present in the discharges from the plant. Co-60 was not detected in seaweed from Concarneau and Roscoff but was routinely observed at Goury and occasionally in the northern area of the NBG. The levels were mostly below $1 \mathrm{~Bq} \cdot \mathrm{Kg}^{-1}$ dry and the highest levels observed were up to 3.4 Bq. $\mathrm{Kg}^{-1}$ dry in the late 1990s in Alderney. The annual time-series in the Channel Islands reflected the decrease in the amounts of discharge from the RP and two decades later, Co-60 in seaweed had dropped to around $0.5 \mathrm{~Bq} \cdot \mathrm{Kg}^{-1}$ dry. A wider view with the 2014-2015 data shows that Co- 60 was only detected in the northern area of the NBG. The dispersion pattern of Co-60 depicted in Figure 11B differed drastically from that of typical soluble radionuclides (Figure 10), with much lower 
548 (Gaudaire, 1996) and a closer look at the fate of suspended matter would be crucial to interpret properly that of Co-60 concentrations in the marine environment. Its interaction with particulate material results in a potential reduction in its bioavailability to seaweed (the same applies to the soft parts of limpets, supplementary material: Fievet_etal_2020_Supplementary_Material.xIsx) and, together with its radioactive decay, a likely major contributing process was its disappearance because of sedimentation to the seabed. The further from the source of input, the longer it took to reach the location, the less it remained in seawater and was available for transfer to the biota. The monthly time-series at Goury (Figure 5), close to the source of input, very clearly displayed annual cycling, although the monthly discharges did not (ORANO, personal comm.). Once Co-60 has reached the sediment compartment, the potential return of sedimentary material to the water column would bring up the signature of possibly ancient discharges. Since most radionuclide discharges from the RP fell considerably in previous decades, the imprint of previous discharges is likely to influence the signal in present suspended matter where resuspension occurs. The resuspension of sedimentary material is thus a component to consider because contamination of marine biota samples by suspended matter is likely. This seasonal cycle was confirmed when normalizing the concentrations to the discharges. The profile displayed for Co-60 (Figure $12 \mathrm{E}$ ) clearly differed from that of a typically soluble radionuclide (Figure $12 \mathrm{~A}$, for example). Seaweed Co-60 concentrations were obviously partly disconnected from actual discharges and were influenced by a seasonal cycle with highs in winter and lows in summer. Recent specific studies provided evidence that resuspension of sedimentary material displays annual cycling in the Channel (Gohin, 2010; Rivier, 2013). Interestingly, the cycling of Co-60 levels in seaweed and that of the concentration of resuspended sedimentary material in seawater coincided with highs in winter and lows in summer. Correlation does not mean demonstration but it suggests that further investigating would be worthwhile into the relationship between Co-60 in suspended matter and subsequently in marine biota samples, with potential Co-60 contamination of the latter by the former.

Ru-106 is another radionuclide which may be non-conservative because of its complex chemical speciation and affinity to particulate forms (Gandon et al., 1993). However, even back in the late 1990s, it was not detected in seaweed from the Channel Islands and in 2014-2015, it was only detected in seaweed and soft parts of limpets from Goury near the RP (Figure 5). Ru-106 discharges from the RP dropped by two orders of magnitude in the early 1990 s and this reflected accordingly on the levels in the marine environment. Due to its short half-life ( $373 \mathrm{~d}$ ), only recent discharges could be detected. Ru-106 concentrations in the biota from Goury were normalized to discharges but the data for seaweed included a majority of values below the LoDs and only data for the soft parts of limpets were informative. As for Co-60, the Ru-106 data for the soft parts of limpets displayed a profile with different "Dilution\&transfer factor-like" values than HTO and a seasonal cycle with highs in winter and lows in summer, typical of non-conservative radionuclides (supplementary material: Fievet_etal_2020_Supplementary_Material.xIsx).

Pu-238, Pu-239,240 and Am-241 levels were measured in seaweed samples in the NBG. These longlived radionuclides are well known to strongly adsorb to suspended matter and small mineral particles, and to persist in the sediment compartment of the marine environment. Sediment acts as an historical record of radionuclide levels (Boust et al., 1996) and the remobilisation of transuranic elements from sediment can result in seawater concentrations that are not connected to present discharges. This is especially crucial in the current context, given that discharges fell substantially during the 1980 s and 1990 s, because the contribution of this remobilisation process can become the 
main source of labelling for the seawater column. Since biological samples from the marine environment may include adsorbed (or ingested) mineral material with high concentrations of these radionuclides. Their total concentrations may thus be influenced by past discharges. The dispersion profiles of Pu-239,240 and Am-241 shown in Figure 11 were typical of non-conservative radionuclides. This was further supported by the normalized data from the monthly time-series for Goury which showed seasonal cycling profiles (Figure $12 \mathrm{~F}, \mathrm{G}, \mathrm{H}$ ), also typical of non-conservative radionuclides like Co-60 (Figure $12 \mathrm{E}$ ) and Ru-106 (supplementary material: Fievet_etal_2020_Supplementary_Material.xIsX). Nevertheless, the levels observed in seaweed collected in the NBG were in the $\left[10^{-1}-10^{-2}\right] \mathrm{Bq} \cdot \mathrm{Kg}^{-1}$ dry order of magnitude, in agreement with previous reports (Germain et al., 2000). It is noteworthy that the isotopic ratio Pu-238/Pu-239,240 was clearly inversely correlated with the distance from the source of radioactive input in the NBG (supplementary material: Fievet etal 2020 Supplementary Material.xlsx). Values close to 0.7 in the biota from Goury agreed with the isotopic signature of radioactive discharges from the RP. The lowest values, close to 0.2 , were observed in Roches Douvres and the SW of Guernsey whilst values around 0.3 were observed along the south coast of the NBG. This gradient with distance to the RP outfall reflected mixing with other sources. They include the background level resulting from fallout of past atmospheric nuclear tests with an isotopic signature of around 0.04 (Boust et al., 1996, 1997; Boust 1999; Germain et al., 2000). They also include the potential influence of resuspended sedimentary material, which carries the signature of past discharges from the RP. This issue deserves to be studied more thoroughly by characterizing the potential contribution of biota contamination by suspended matter.

Conclusion: Although most radionuclide discharges from the ORANO RP at La Hague decreased in the 1980 s, three radionuclides are discharged in proportion to nuclear fuel recycling activity, namely $\mathrm{H}-3$, C-14 and I-129. The temporal and spatial distribution of the data are consistent with the history of the discharges, with most gamma emitter radionuclide levels being close to or below the current LoDs and a clear fingerprint of the ORANO RP at La Hague for the three aforementioned radionuclides. A comparison of the data for Fucus serratus I-129 distributions in the Channel Islands, in the whole NBG and close to the source of the radioactive discharge input (Goury) showed a sharp gradient, with the highest levels in close proximity to the RP and dropping rapidly through dilution in the NBG. The strong hydrodynamics in this area result in rapid mixing and dilution. The lowest levels of radionuclides were observed in the westernmost part (Guernsey and Roches Douvres) of the NBG. Nevertheless, the hydrodynamics in the NBG are non-intuitive and do not yield a simple gradient with linear distance from the outfall of the RP. Modelling tools were essential to understand how radioactive discharges spread from the source of input. Using comparison with modelling, dispersion patterns clearly illustrated the different behaviours of soluble and non-soluble radionuclides. Despite the high magnitude of the back-and-forth water currents related to the tide, soluble radionuclides spread in the NBG according to mean residual water currents, and the quantitative relationship with the discharges is consistent. Conversely, this quantitative relationship is not consistent for nonsoluble radionuclides because their concentrations resulted from two sources: the present discharges and the sediment compartment, which is labelled by past discharges and by fallout from past nuclear tests. Non-soluble radionuclides associate with particulate material sediment of the seabed where they accumulate and potentially remobilise. Moreover, biota samples can be contaminated by small mineral particles (adsorbed or ingested). Since discharges of these nonsoluble radionuclides have substantially declined since the 1980 s, the contribution of this labelling of 
sedimentary origin has potentially overwhelmed that of present discharges. The synchronicity of the signal in the biota for non-soluble radionuclides and the seasonal cycle of mineral suspended matter in the Channel supports this hypothesis. In depth investigation of the relative contributions of the two sources of labelling remains to be specifically carried out.

In summary, this comprehensive assessment of biota monitoring data indicated that the imprint of radioactive liquid discharges by French nuclear facilities was measurable in the Normand-Breton Gulf and the Channel Islands but the levels are low and generally declining. The temporal and spatial distribution of the data are consistent with the history of the discharges, with most gamma emitter radionuclide environmental levels being close to or below the actual limits of detection. This is in line with the conclusions from the Nord-Cotentin Radioecology Group assessment carried out two decades ago (NCRG, 1999) and is consistent with the subsequent decrease of most liquid radionuclide discharges by the ORANO La Hague reprocessing plant.

\section{Acknowledgments}

The authors would like to thank the Director of Environmental Health and Pollution Regulation from the Office of Environmental Health and Pollution Regulation in Guernsey and the Director of Environmental Health from the Department of the Environment in Jersey for their welcome and authorization to collect seaweed samples in the Channel Islands. The radioactivity monitoring in the NBG in spring in 2014 and 2015 was co-funded by the operator ORANO La Hague. The monthly timeseries for Goury was co-funded by the AMORAD project (French state financial support was managed by the National Agency for Research, allocated under the "Investments for the Future" framework program with reference ANR-11-RSNR-0002). Finally, the authors wish to thank all IRSN/PSE-ENV colleagues from the Laboratoire de Radioécologie de Cherbourg-Octeville, the Laboratoire de Mesure de la Radioactivité dans l'Environnement (IRSN, Orsay), the Laboratoire d'Expertise, de Radiochimie et de Chimie Analytique and the Laboratoire de Mesure Nucléaire (IRSN, Le Vésinet) who contributed by generating the environmental measurement data for this review.

\section{References}

Bailly du Bois P, Salomon J-C, Gandon R, Guéguéniat P (1995) A quantitative estimate of English Channel water fluxes into the North Sea from 1987 to 1992 based on radiotracer distribution. Journal of Marine Systems 6: 457-481

Bailly du Bois $P$, Guéguéniat $P$ (1999). Quantitative assessment of dissolved radiotracers in the English Channel: Sources, average impact of La Hague reprocessing plant and conservative behaviour (1983, 1986, 1988, 1994). Continental Shelf Research 19: 1977-2002

Bailly du Bois P, Germain P, Rozet M, solier L (2002) Water masses circulation and residence time in the Celtic Sea and English Channel approaches, characterisation based on radionuclides labelling from industrial releases. In International Conference on Radioactivity in Environment, pp 395 - 399. Monaco 
673 Bailly du Bois P, Dumas F. (2005). Fast hydrodynamic model for medium- and long-term dispersion in 674 seawater in the English Channel and southern North Sea, qualitative and quantitative validation by 675 radionuclide tracers. Ocean Modelling. 9:169-210.

676 Bailly du Bois P, Dumas F, Solier L, Voiseux C (2012). In-situ database toolbox for short-term 677 dispersion model validation in macro-tidal seas, application for 2D-model. Continental Shelf Research $678 \quad 36: 63-82$

679 Bailly du Bois P, Dumas, F, Morillon M, Furgerot L, Voiseux C, Poizot E, Méar Y, Bennis AC (2020a). 680 Alderney Race, general hydrodynamic and particular features. Philosophical Transactions of the Royal 681 Society A (in press).

682 Bailly du Bois PB, Dumas F, Voiseux C, Morillon M, Oms PE, Solier L (2020b) Dissolved radiotracers 683 and numerical modeling in North European continental shelf dispersion studies (1982-2016):

684 Databases, methods and applications. Water (Switzerland) 12.

Bennis A-C, Furgerot L, Bailly Du Bois P, Dumas F, Odakae T, Lathuilière C, Filipot j-F (2020). Numerical modelling of three-dimensional wave-current interactions in complex environment: Application to Alderney Race. Applied Ocean Research 95:102021

Bouisset P, Lefevre O, Cagnat X, Kerlau G, Ugron A, Calmet D (1999) Direct gamma-X spectrometry measurement of $129 \mathrm{l}$ in environmental samples using experimental self-absorption corrections. Nuclear Instruments and Methods in Physics Research Section A: Accelerators, Spectrometers, Detectors and Associated Equipment 437: 114-127

Boust D, Mitchell PI, Garcia K, Condren O, Leon Vintro L, Leclerc G (1996) A Comparative Study of the Speciation and Behaviour of Plutonium in the Marine Environment of Two Reprocessing Plants. Radiochimica Acta 74: 203-210.

Boust D, Colin C, Leclerc G, baron Y (1997) Distríbution and transit times of Plutonium-bearing particles throughout the Channel. Radioprotection - Colloques 32: 123-128.

Boust $D$ (1999) Distribution and inventories of some artificial and naturally occurring radionuclides in medium to coarse-grained sediments of the channel. Continental Shelf Research 19: 1959-1975

Carvalho FP (2018) Radionuclide concentration processes in marine organisms: A comprehensive review. Journal of Environmental Radioactivity 186: 124-130

Castrillejo M, Witbaard R, Casacuberta N, Richardson CA, Dekker R, Synal H-A, Christl M (2020) Unravelling 5 decades of anthropogenic ${ }^{236} \mathrm{U}$ discharge from nuclear reprocessing plants. Science of The Total Environment 717: 137094

Centre for Environment, Fisheries and Aquaculture Science (2016). Radioactivity in Food and the Environment, RIFE-22 report, available on line at https://www.sepa.org.uk/media/328601/rife22.pdf.

The ERA - Interim reanalysis: configuration and performance of the data assimilation system. D. P. Dee S. M. Uppala A. J. Simmons P. Berrisford P. Poli S. Kobayashi U. Andrae M. A. Balmaseda G. Balsamo P. Bauer P. Bechtold A. C. M. Beljaars L. van de Berg J. Bidlot N. Bormann C. Delsol R. 
Dragani M. Fuentes A. J. Geer L. Haimberger S. B. Healy H. Hersbach E. V. Hólm L. Isaksen P. Kållberg M. Köhler M. Matricardi A. P. McNally B. M. Monge - Sanz J. - J. Morcrette B. - K. Park C. Peubey P. de Rosnay C. Tavolato J. - N. Thépaut F. Vitart. First published: 28 April 2011 https://doi.org/10.1002/qj.828

Fiévet B, Voiseux C, Rozet M, Masson M, Bailly du Bois $\mathrm{P}$ (2006) Transfer of radiocarbon liquid releases from the AREVA La Hague spent fuel reprocessing plant in the English Channel. Journal of Environmental Radioactivity 90: 173-196

Fiévet B, Pommier J, Voiseux C, Bailly du Bois P, Laguionie P, Cossonnet C, Solier L (2013) Transfer of Tritium Released into the Marine Environment by French Nuclear Facilities Bordering the English Channel. Environmental Science \& Technology 47: 6696-6703

Gandon R, Boust D, Bédué O (1993) Ruthenium complexes originating from the Purex process : coprecipitation with copper ferrocyanides via ruthenocyanide formation. Radiochimica Acta 61: 4145

Gaudaire J-M (1999) Etude de la spéciation du 60Co dans les effluents de l'usine de retraitement de combustibles irradiés de La Hague; devenir après rejet dans les eaux de la Manche. Paris XI Orsay, (in French)

Germain P, Leclerc G, Le Cavelier S, Solier L, Baron Y (2000) Evolution spatio-temporelle des concentrations, des rapports isotopiques et des facteurs de concentration du plutonium dans une espèce d'algue et deux espèces de mollusques en Manche. Radioprotection 35: 175-200.

Gohin F. (2010) Atlas de la Température, de la concentration en Chlorophylle et de la Turbidité de surface du plateau continental français et de ses abords de l'Ouest européen. Ifremer. (in French: https://archimer.ifremer.fr/doc/00057/16840/14306.pdf)

Hunt GJ (1985) Timescales for dilution and dispersion of transuranics in the Irish Sea near Sellafield. The Science of the Total Environment 46: 261-278

Hunt G J and Kershaw P J (1990). Remobilisation of artificial radionuclides from the sediment of the Irish Sea. J. Radiol. Prot. 10 147-51

Hunt J, Leonard K, Hughes L (2013) Artificial radionuclides in the Irish Sea from Sellafield: Remobilisation revisited. Journal of Radiological Protection 33: 261-279

IAEA. (2004) Sediment distribution coefficients and concentration factors for biota in the marine environment. IAEA, Vienna, p. 103.

Jones DG, Kershaw PJ, McMahon CA, Milodowski AE, Murray M, Hunt GJ (2007) Changing patterns of radionuclide distribution in Irish Sea subtidal sediments. Journal of Environmental Radioactivity 96 : 63-74

Küpper F, Schweigert N, Ar Gall E, Legendre J, Vilter H, Kloareg B (1998) lodine uptake in Laminariales involves extracellular haloperoxidase-mediated oxidation of iodide. Planta 207: 163-171 
Lazure P., Dumas F., 2008. An external-internal mode coupling for a 3D hydrodynamical model for applications at regional scale (MARS). Advances in Water ResourcesVolume 31, Issues 32, Pages 233250.

Leblanc C, Colin C, Cosse A, Delage L, La Barre S, Morin P, Fiévet B, Voiseux C, Ambroise Y, Verhaeghe E, Amouroux D, Donard O, Tessier E, Potin P (2006) lodine transfers in the coastal marine environment: the key role of brown algae and of their vanadium-dependent haloperoxidases. Biochimie 88: 1773-1785

Lefevre O, Bouisset P, Germain P, Barker E, Kerlau G, Cagnat X (2003) Self-absorption correction factor applied to ${ }^{129} \mathrm{I}$ measurement by direct gamma-X spectrometry for Fucus serratus samples. Nuclear Instruments and Methods in Physics Research Section A: Accelerators, Spectrometers, Detectors and Associated Equipment 506: 173-185

Lyard F, Lefevre F, Letellier T, Francis O (2006)) Modelling the global ocean tides: modern insights from FES2004. Ocean Dynamics 56: 394-415

McGill, Robert; Tukey, John W.; Larsen, Wayne A. (1978). "Variations of Box Plots". The American Statistician. 32 (1): 12-16. doi:10.2307/2683468

Muir GKP, Tierney KM, Cook GT, MacKinnon G, Howe JA, Heymans JJ, Hughes DJ, Xu S (2017) Ecosystem uptake and transfer of Sellafield-derived radiocarbon (14C). Part 1. The Irish Sea. Marine Pollution Bulletin 114: 792-804

NCRG, Nord-Cotentin Radioecology Group, 1999. Estimation of exposure levels to ionizing radiation and associated risks of leukemia for populations in the Nord-Cotentin. Summary Report, $357 \mathrm{pp}$. (French and English versions on line at http://www.gep-nucleaire.org/norcot/gepnc/sections/ travauxgep).

Oms, P-E (2018): Tritium in oceans: a compilation. PANGAEA, https://doi.pangaea.de/10.1594/ PANGAEA.892125

OSPAR Commission, 2009. Third Periodic Evaluation of progress towards the objective of the Radioactive Substances Strategy. Publication Number 455/2009. https://www.ospar.org/ documents?d=7135.

OSPAR Commission, 2014. Sixth Implementation Report: Report in accordance with PARCOM Recommendation 91/4 on radioactive discharges. France. https://www.ospar.org/ documents? $\mathrm{d}=7353$ )

Paradis H, de Vismes Ott A, Luo M, Cagnat X, Gurriaran R (2016) Low level measurement of 60Co by gamma ray spectrometry using $\gamma-\gamma$ coincidence. Applied Radiation and Isotopes, Volume 109, March 2016, Pages 487-492

Rivier A (2013) Dynamique des matières en suspension minérales des eaux de surface de la Manche observée par satellite et modélisée numériquement. Docteur de l'université Thesis, IFREMER DYNECO/PELAGOS et et CETMEF LGCE Université de Bretagne Occidentale, Brest. (in French: https://archimer.ifremer.fr/doc/00157/26783/24884.pdf) 
782 Salomon JC, Guéguéniat $\mathrm{P}$, Orbi A, Baron Y (1988) A lagrangian model for long term tidally induced 783 transport and mixing. Verification by artificial radionuclide concentrations. In : Radionucléides : A

784 tool for oceanography. Cherbourg 1-5 juin 1987, Ed. Guary, J.C., Guéguéniat, P., Pentreath, R.J., 785 Elsevier Applied Science Publishers, pp. 384-394.

786 Salomon J.C., Garreau P., Breton M., 1996. The Lagrangian barycentric method to compute 2D and 787 3D long term dispersion in tidal environments, In: mixing in estuaries and coastal seas, Coastal and 788 estuarine studies, ed. C. Pattiaratchi American Geophysical Union, Washington, D.C., 50, pp 59-76.

789 de Vismes A, Gurriaran R and Cagnat X (2009) Anti-Compton gamma spectrometry for

790 environmental Samples Radioprotection, vol. 44, n॰ 5, pages 613-618

791 de Vismes Ott A, Aubry S, Mekhlouche D, Cagnat X, Gurriaran R (2012) Simple cost-effective anti792 cosmic device. Proceedings of the 6th International Conference on Radionuclide Metrology - Low793 Level Radioactivity Measurement Techniques, Jeju (Korea) 17th-21st September 2012 


\section{Supplementary material}

795

796 Microsoft Excel 2010 file: Fievet_etal_2020_Supplemental_Material.xlsx

797 Additional figures in pdf format: Fievet_etal_2020_Supplemental_Material.pdf 


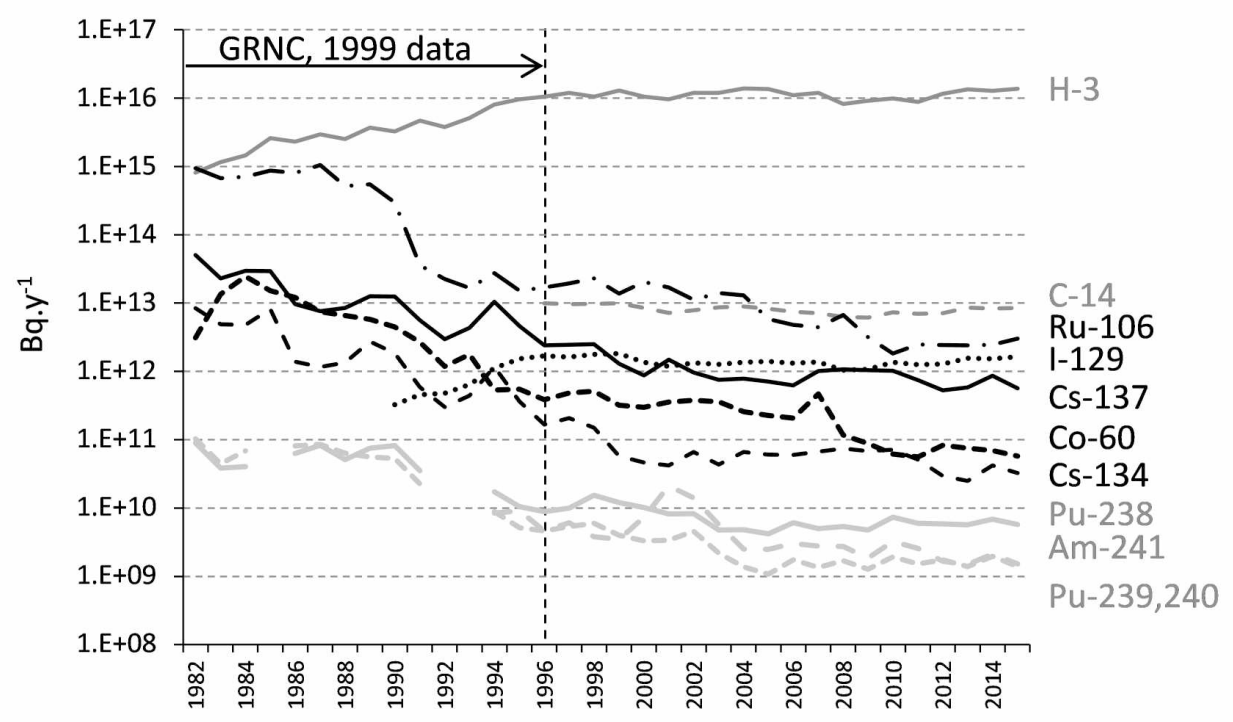




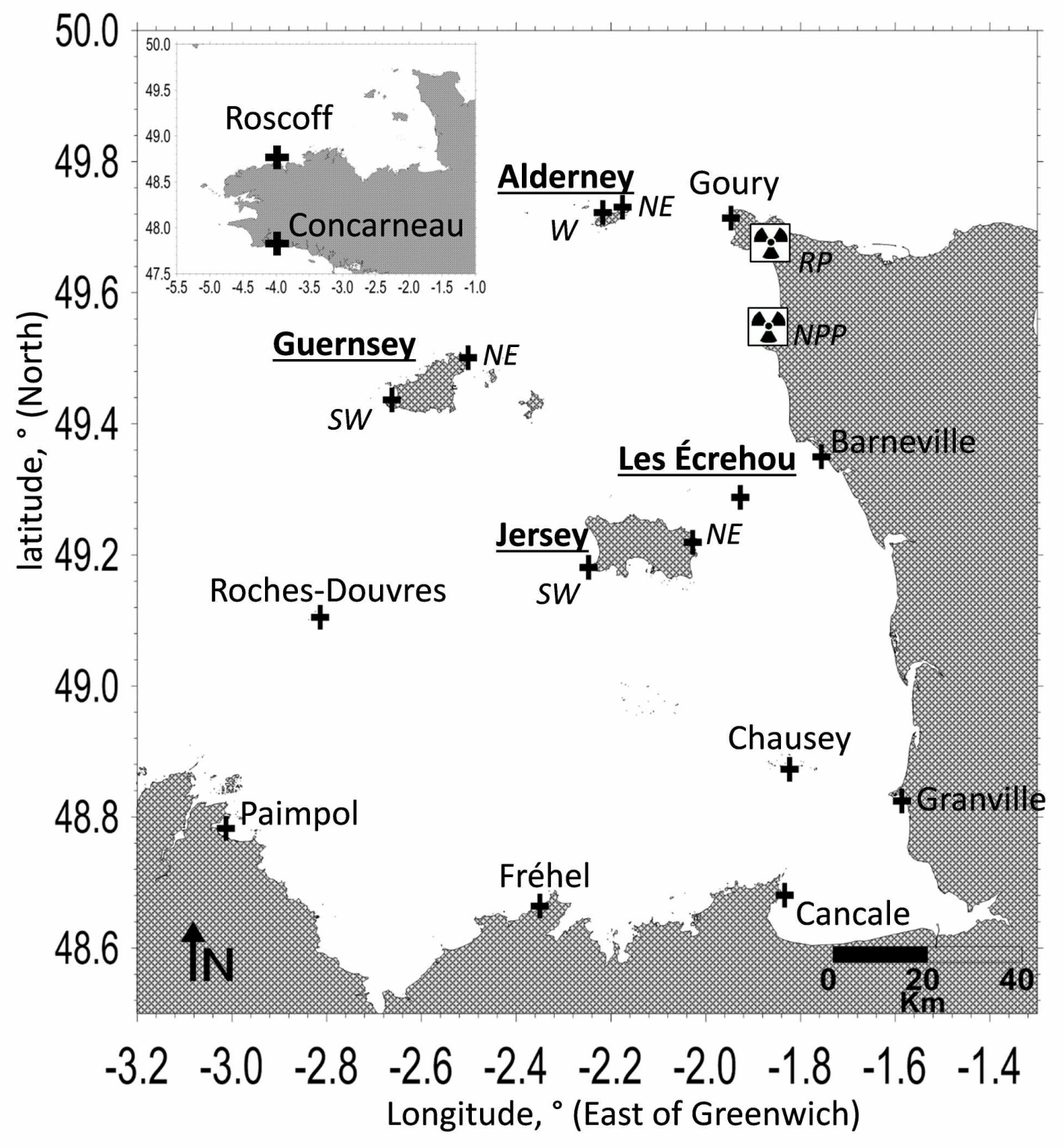



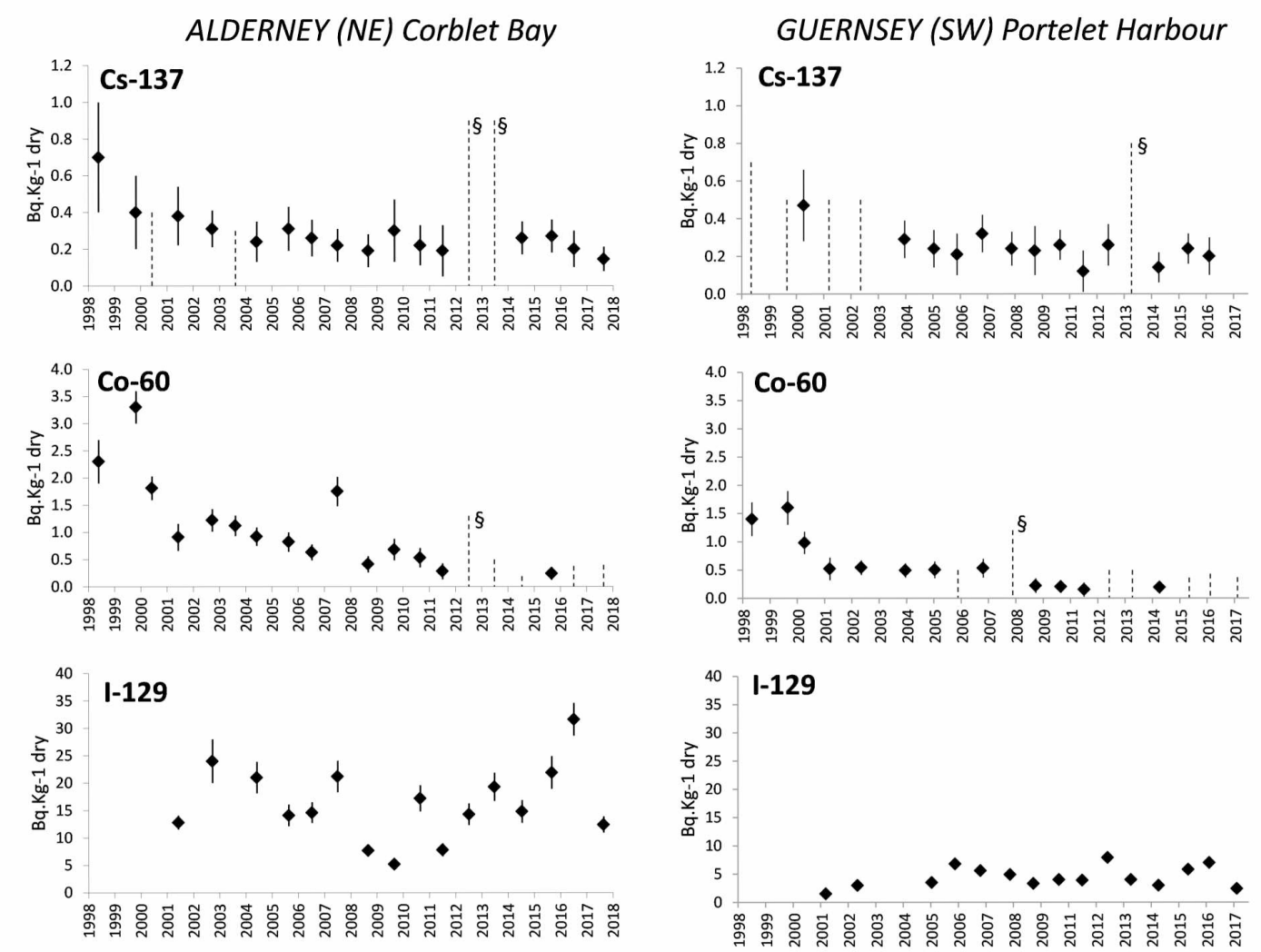
Bq.Kg-1 dry

○

Carney

Bq.Kg-1 dry

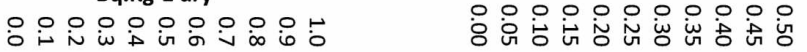

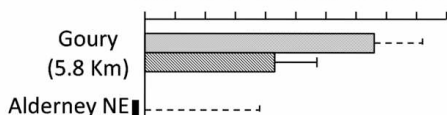

Alderney NE

(17 Km)

Alderney SW

$(20 \mathrm{Km})$

Barneville

(38 Km)

Les Ecréhou
(42 Km)

Guernsey NE

$(43 \mathrm{~km})$

Jersey N

$(50 \mathrm{Km})$

Guernsey SW

(57 Km)

Jersey SW

(57 Km)

Roches

Douvres...

Chausey

(88 Km)

(97 Km)

Cancale

$(110 \mathrm{Km})$

Cap Fréhel

(115 Km)

Paimpol

(124 Km)
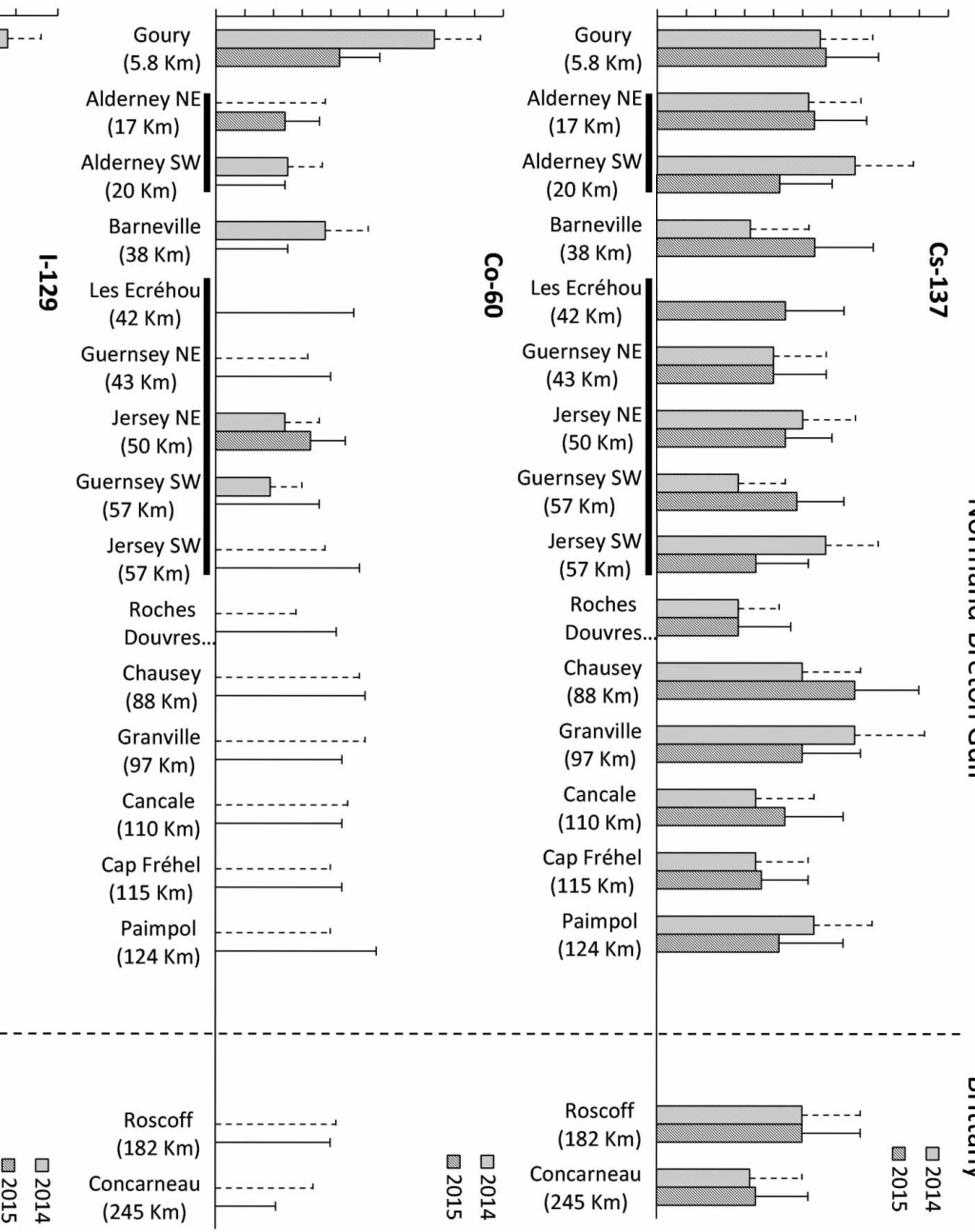

$(182 \mathrm{Km})$

Concarneau

(245 Km)

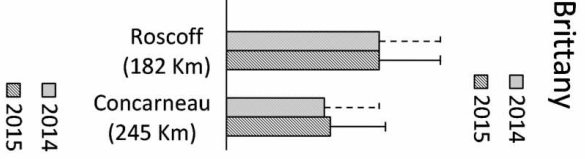

2
을
3
0
$\frac{0}{2}$
$\frac{0}{1}$
0
0
0
0
0
$\frac{0}{2}$
0
$\frac{1}{7}$

(97 Km)

Cancale

$(110 \mathrm{Km})$

Cap Fréhel

$(115 \mathrm{Km})$
Paimpol

Paimpo
(124 Km) 
Radioactivity in the Channel Island

Figure 5
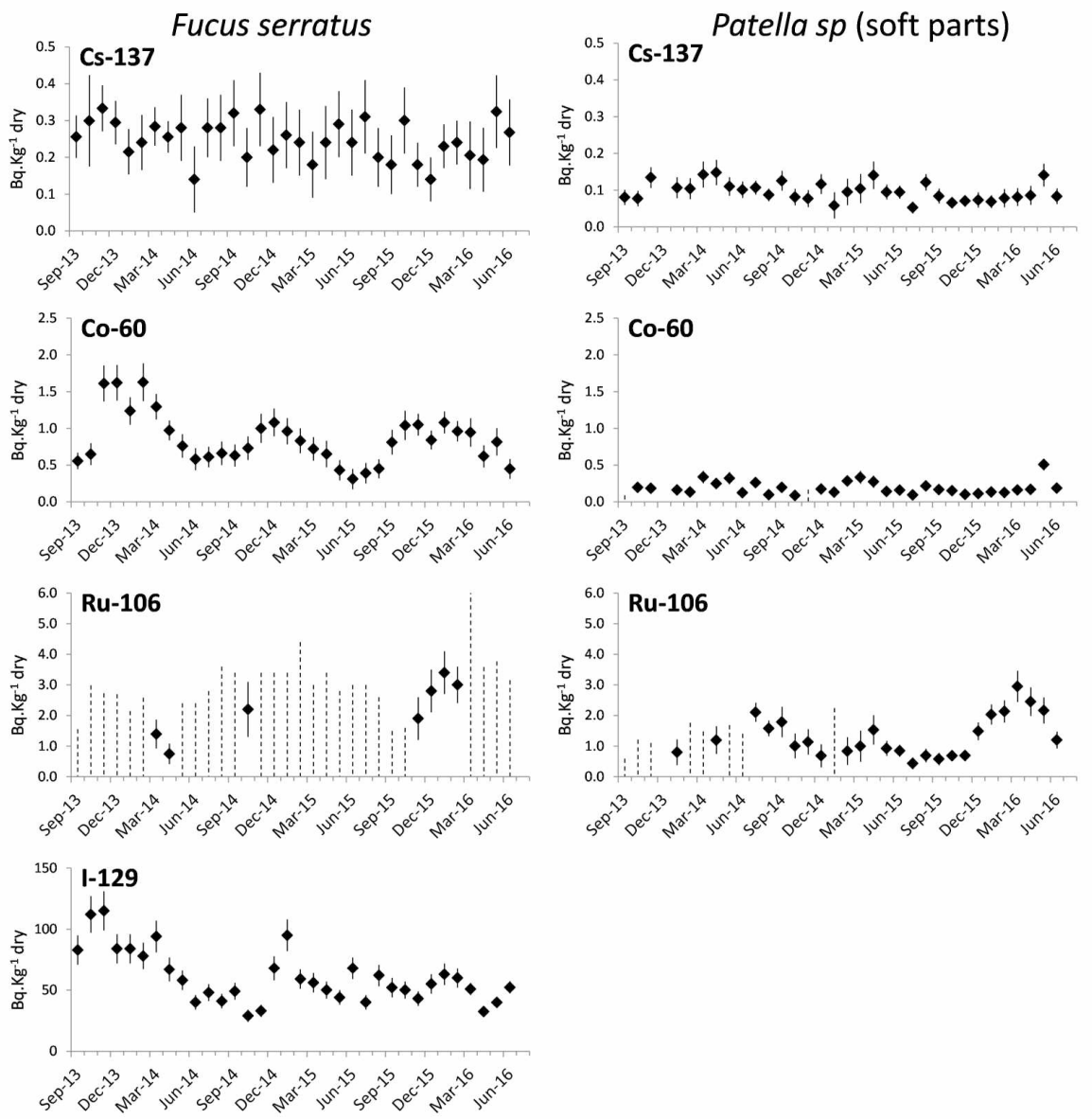


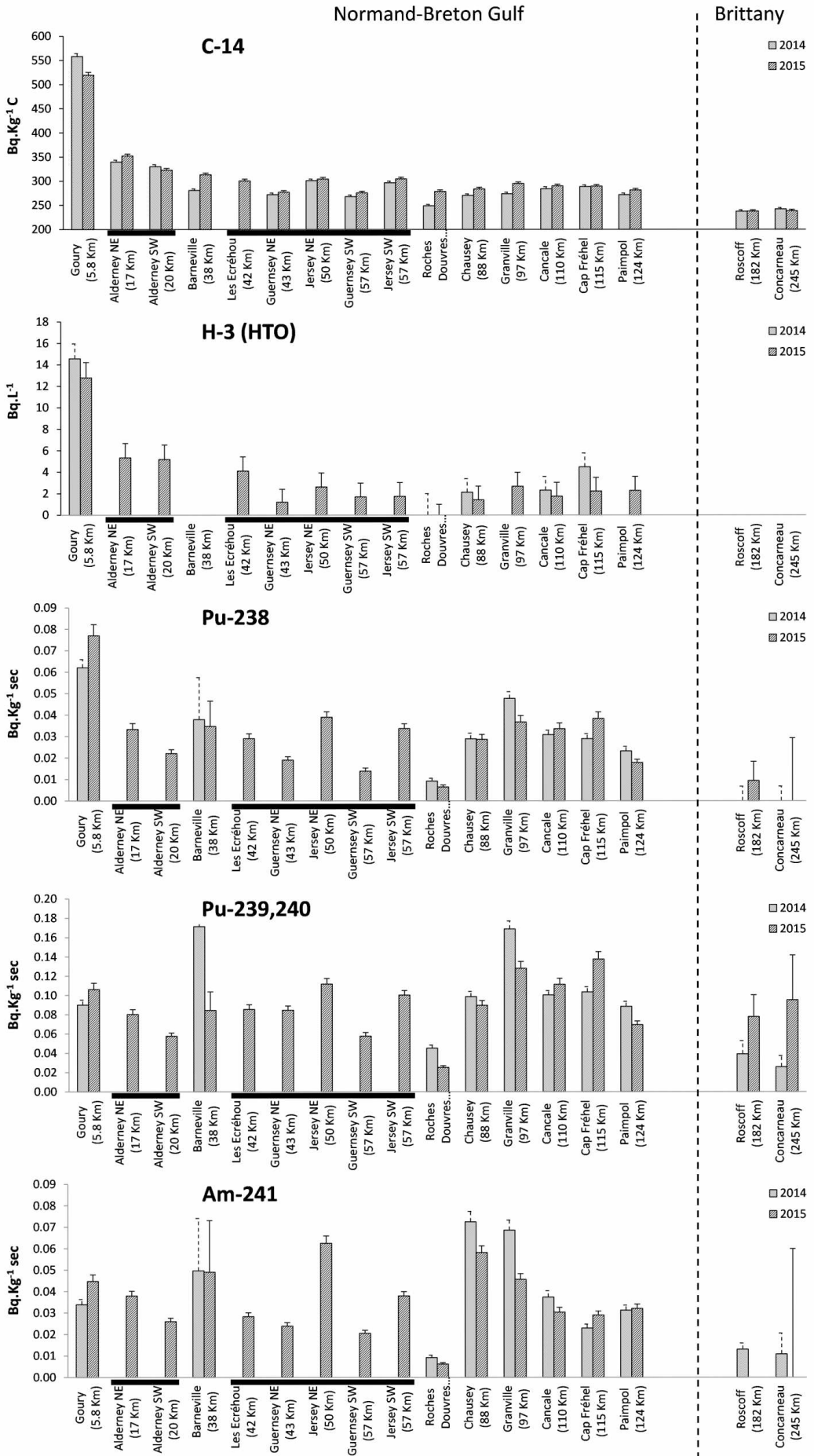


Average residual trajectory and velocity constant wind: $\mathrm{SW}\left(231^{\circ}\right), 8 \mathrm{~m} / \mathrm{s}$; medium tide: coeff. 70$)$

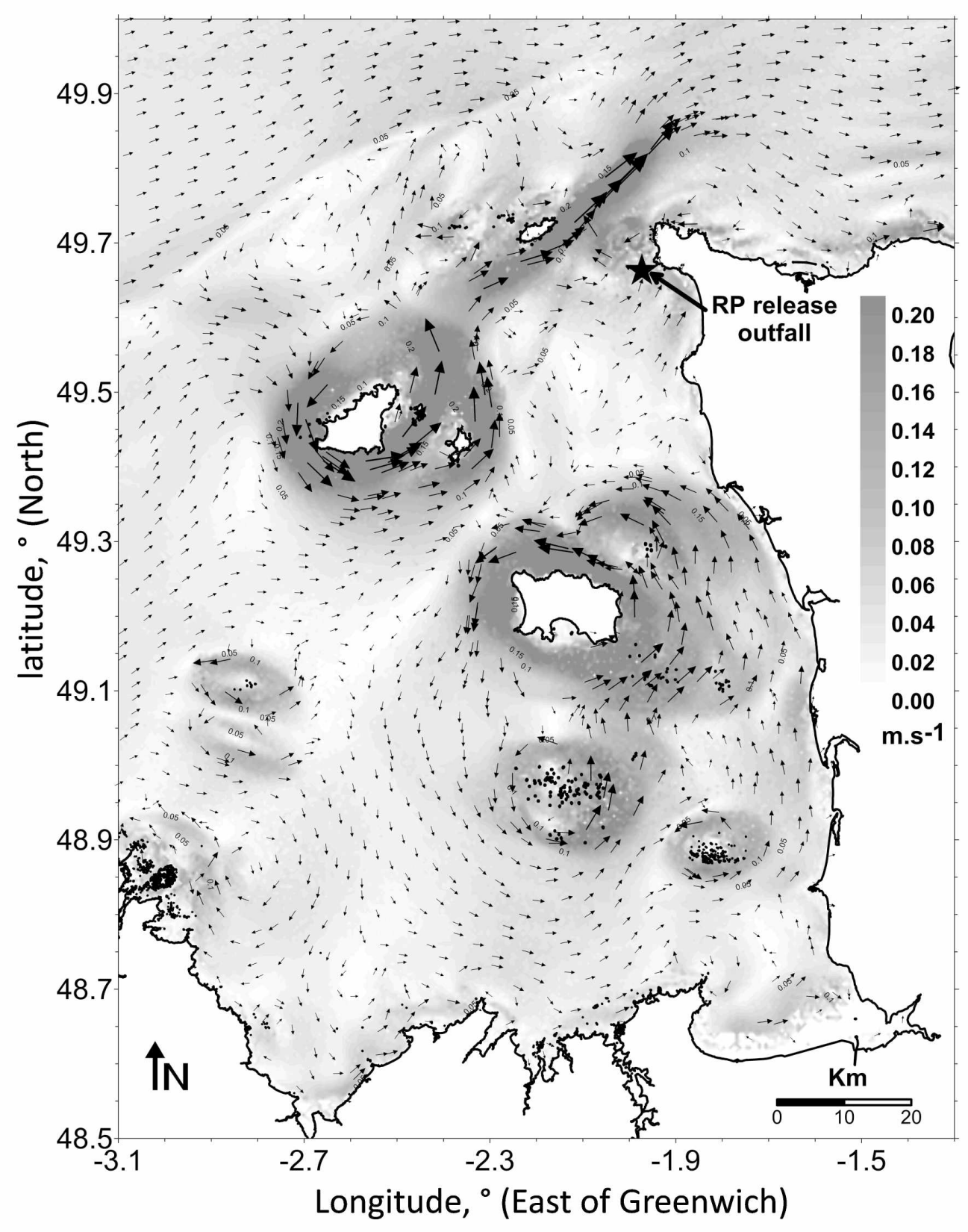



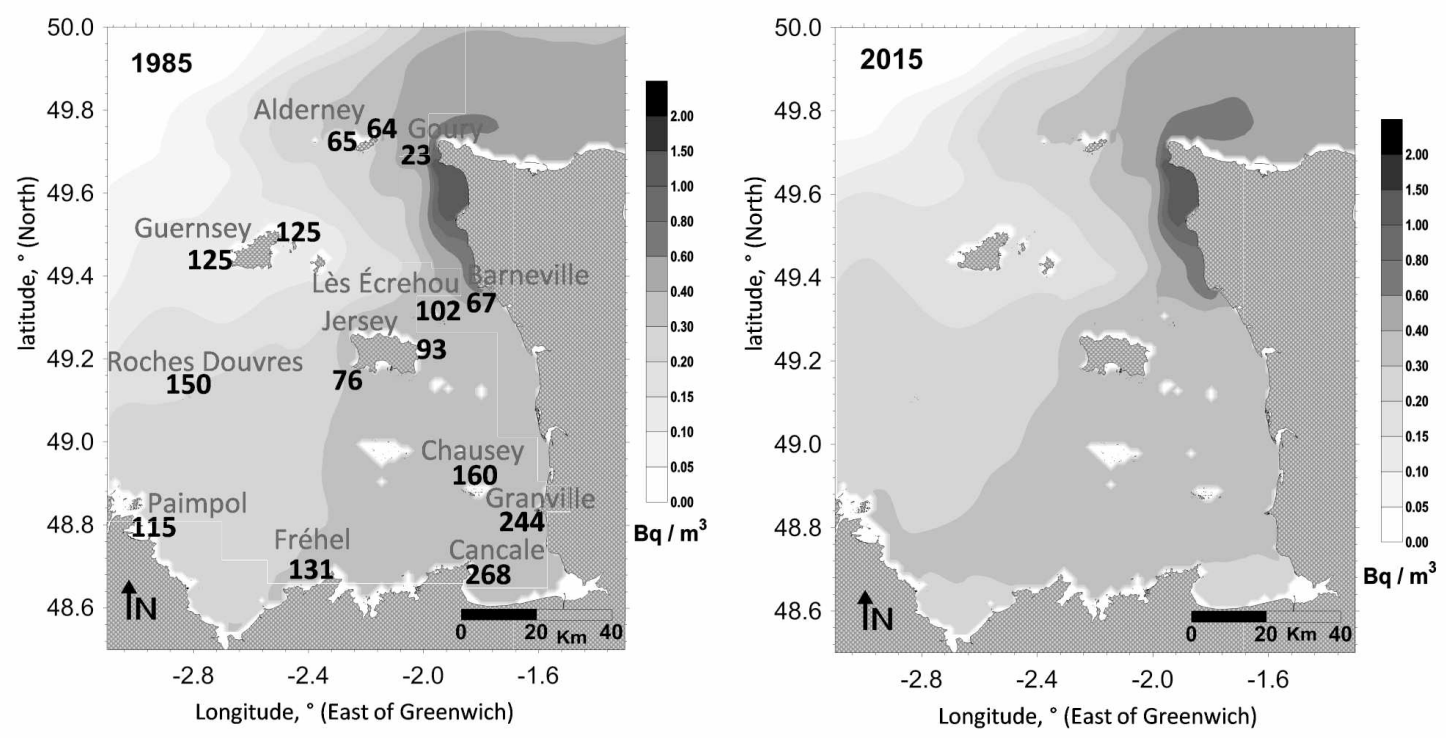

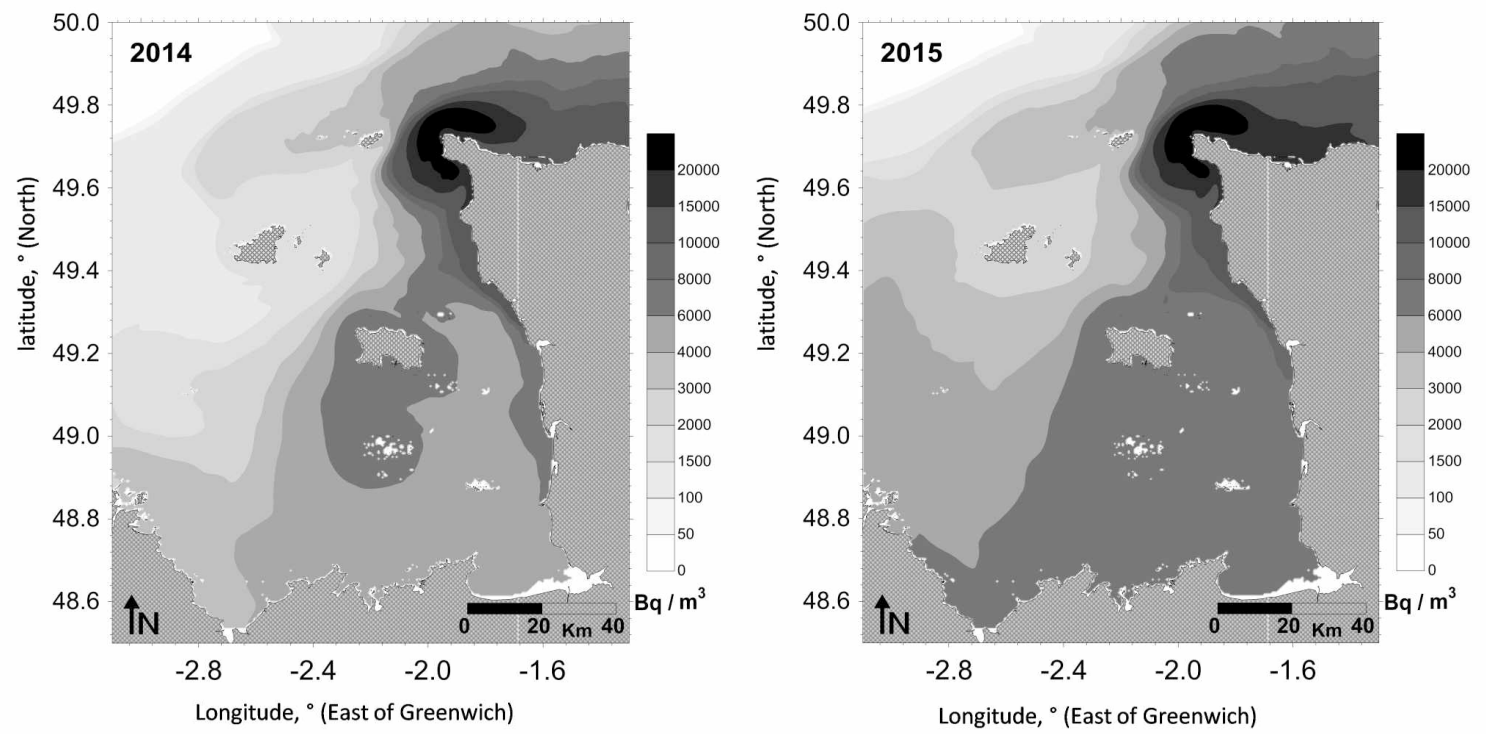


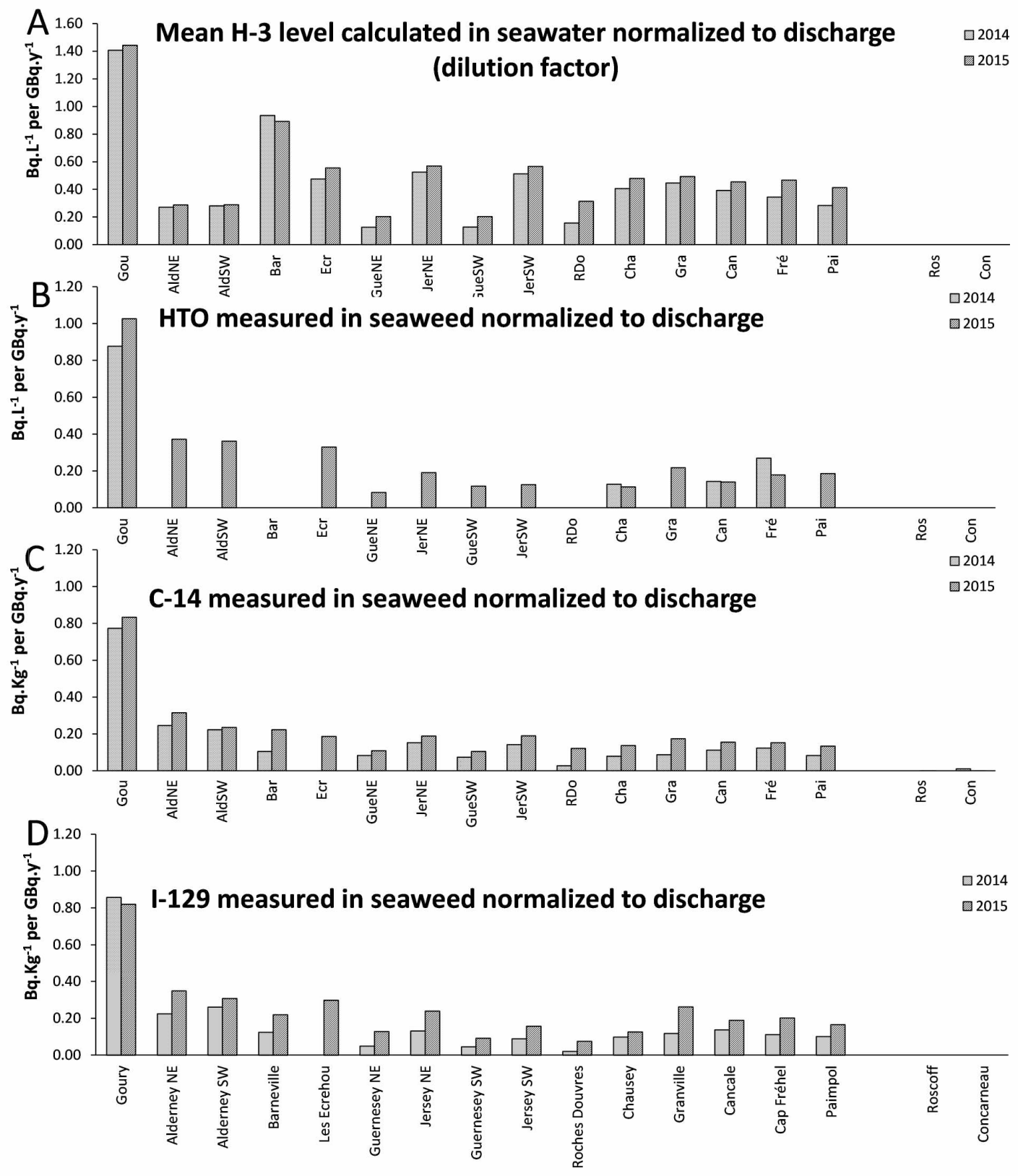



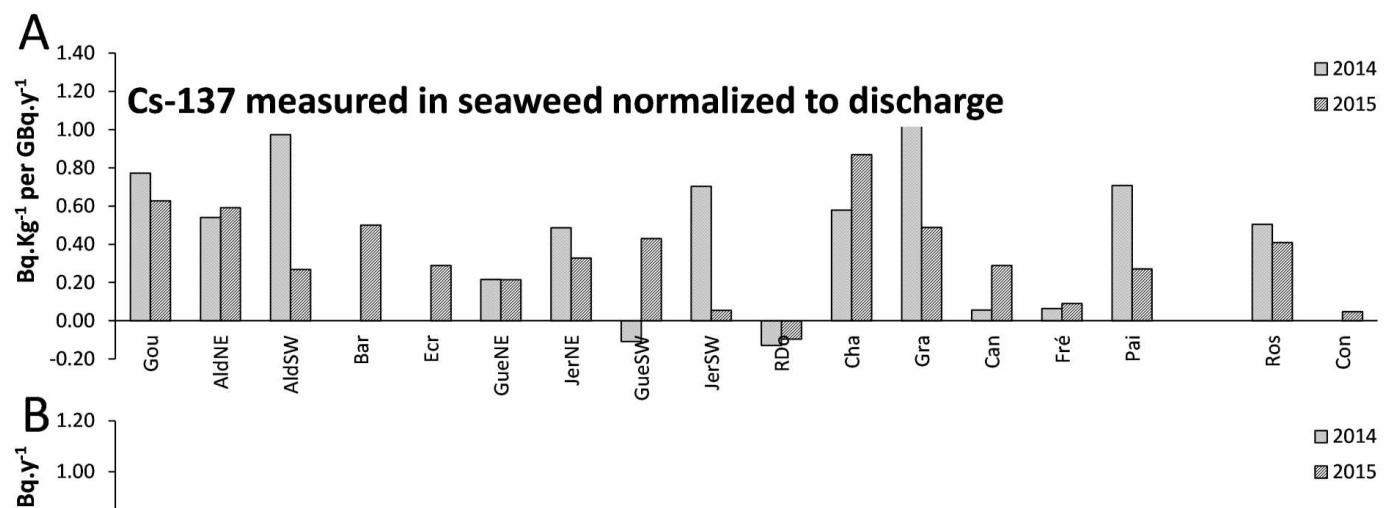

2014 to

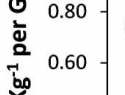

Co-60 measured in seaweed normalized to discharge म्षं 0.40 0.20

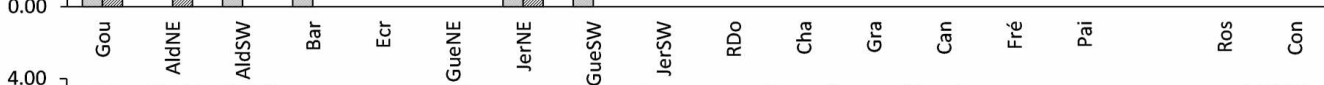

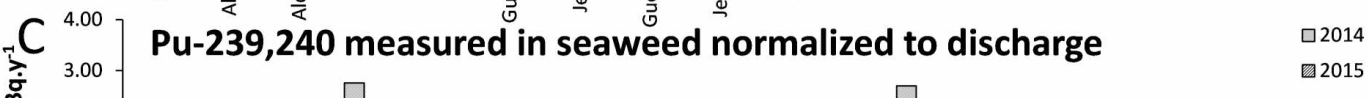
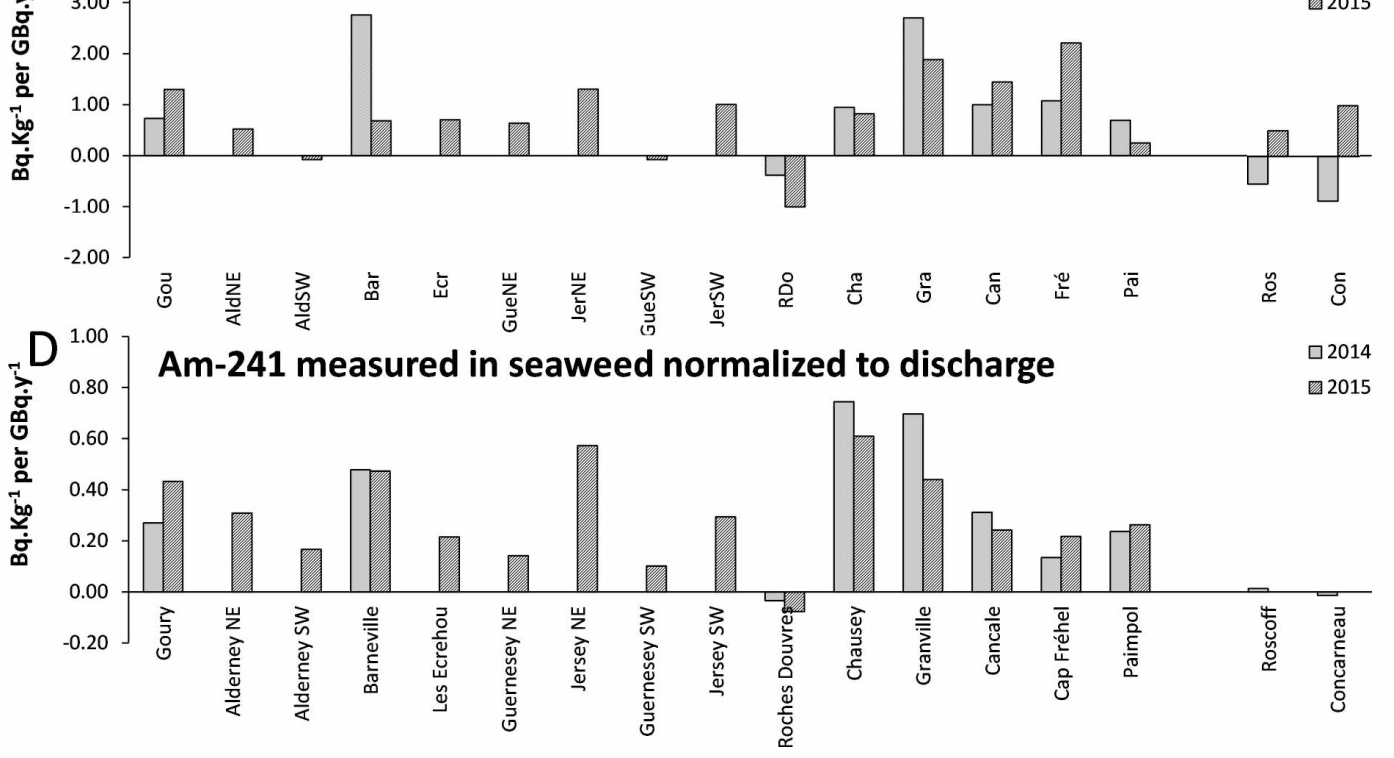

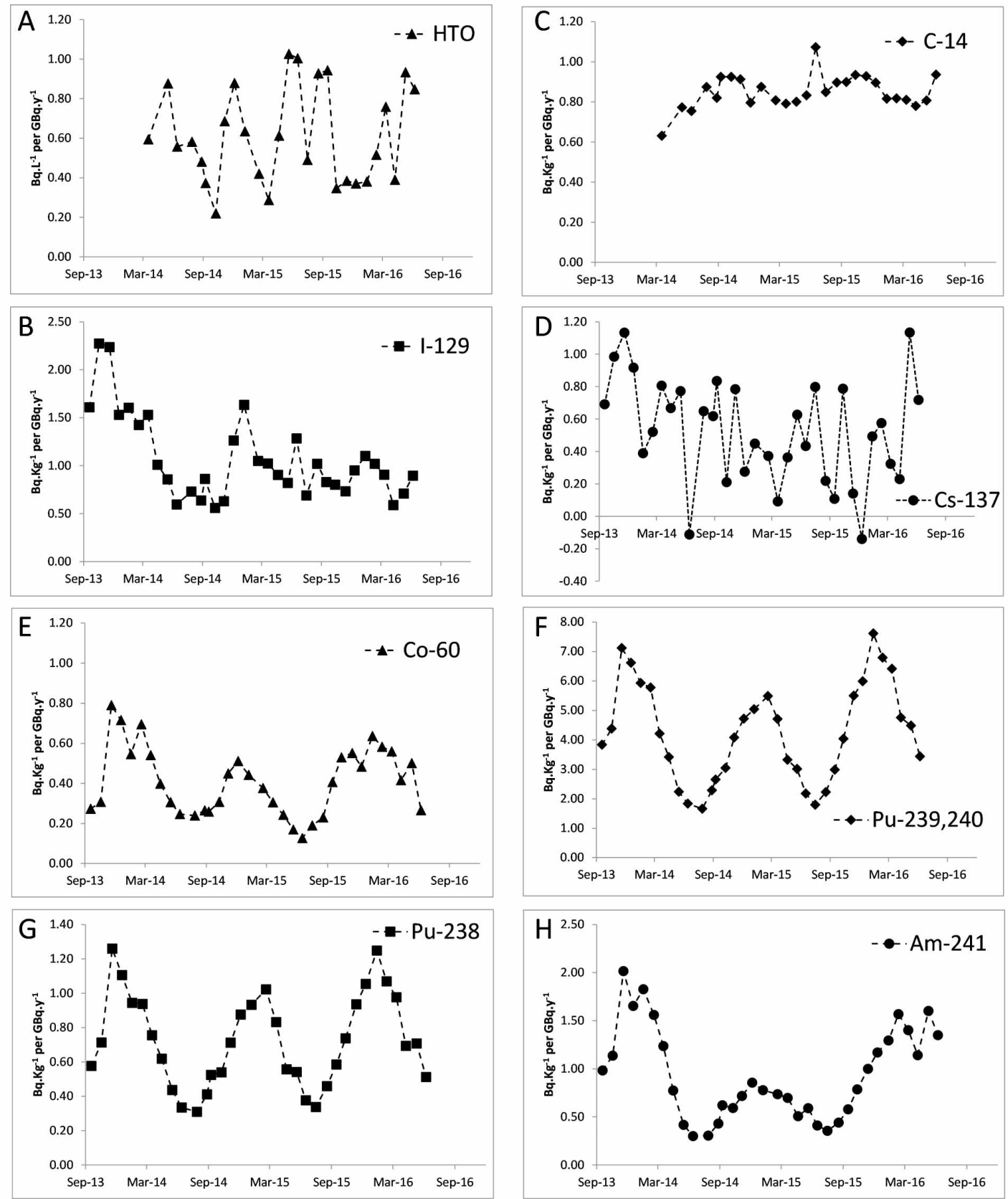


\section{Radioactivity monitoring in the Channel Islands}

\section{Table 1}

\begin{tabular}{|l|l|l|l|l|l|l|l|l|l|l|l|}
\hline Species & $\begin{array}{l}\text { wet/dry } \\
\text { ratio }\end{array}$ & Cs-137 & Cs-134 & Co-60 & I-129 & H-3 & C-14 & Pu-238 & $\begin{array}{l}\text { Pu- } \\
239,240\end{array}$ & $\begin{array}{l}\text { Am- } \\
241\end{array}$ & $\begin{array}{l}\text { Cm- } \\
244\end{array}$ \\
\hline Fucus sp. & 5.04 & 50 & 50 & 6000 & 7000 & 1 & 2800 & 4000 & 4000 & 8000 & 5000 \\
\hline $\begin{array}{l}\text { Patella/Mussel } \\
\text { soft parts }\end{array}$ & 5.00 & 60 & 60 & 1000 & 10 & 1 & 2300 & 3000 & 3000 & 8000 & 1000 \\
\hline
\end{tabular}

Table 2

\begin{tabular}{|c|c|c|c|c|c|c|}
\hline $\begin{array}{l}\text { Sampling } \\
\text { date }\end{array}$ & $w w / d w$ & $\begin{array}{c}\mathrm{C}-14 \\
\mathrm{~Bq} \cdot \mathrm{Kg}^{-1} \mathrm{C}\end{array}$ & $\begin{array}{c}\mathrm{H}-3 \mathrm{HTO}(\mathrm{OBT}) \\
\text { Bq. } \mathrm{L}^{-1}\end{array}$ & Pu-238 & $\begin{array}{c}\text { Pu-239,240 } \\
\text { Bq. } \mathrm{Kg}^{-1} \text { dry }\end{array}$ & Am-241 \\
\hline \multicolumn{7}{|c|}{ ALDERNEY (NE) Corblet Bay } \\
\hline $27 / 10 / 1999$ & 4.7 & $360 \pm 9$ & & & & \\
\hline 06/06/2000 & 6.0 & & & $0.0399 \pm 0.0038$ & $0.0915 \pm 0.0071$ & $0.0415 \pm 0.0067$ \\
\hline $24 / 09 / 2002$ & 4.6 & $330 \pm 5$ & & & & \\
\hline $26 / 08 / 2010$ & 5.3 & & $<2.0$ & & & \\
\hline $05 / 07 / 2011$ & 5.6 & & $4.6 \pm 1.2$ & & & \\
\hline 05/07/2012 & 5.7 & & $5.9 \pm 1.3$ & & & \\
\hline $25 / 06 / 2013$ & 5.8 & & & $0.0151 \pm 0.0016$ & $0.0435 \pm 0.0030$ & $0.0174 \pm 0.0016$ \\
\hline $02 / 09 / 2015$ & 5.2 & & $5.3 \pm 1.3$ & $0.0333 \pm 0.0028$ & $0.0802 \pm 0.0051$ & $0.0379 \pm 0.0023$ \\
\hline 06/07/2016 & 5.6 & & $6.7 \pm 1.4$ & & & \\
\hline $24 / 08 / 2017$ & 3.9 & $356 \pm 3$ & $7.4 \pm 1.4(5.8 \pm 0.4$ & & & \\
\hline \multicolumn{7}{|c|}{ ALDERNEY (SW) Fort Tourgis } \\
\hline 28/10/1999 & 4.8 & $344 \pm 9$ & & & & \\
\hline $06 / 06 / 2000$ & 5.8 & & & $0.0333 \pm 0.0031$ & $0.0839 \pm 0.0058$ & $0.0328 \pm 0.0027$ \\
\hline $24 / 09 / 2002$ & 4.6 & $319 \pm 4$ & & & & \\
\hline $26 / 08 / 2010$ & 5.2 & & $<2.0$ & & & \\
\hline $05 / 07 / 2011$ & 5.6 & & $5.4 \pm 1.2$ & & & \\
\hline 05/07/2012 & 6.0 & & $5.5 \pm 1.3$ & & & \\
\hline $25 / 06 / 2013$ & 5.2 & & & $0.0131 \pm 0.0018$ & $0.0527 \pm 0.0043$ & $0.0127 \pm 0.0014$ \\
\hline $02 / 09 / 2015$ & 5.4 & & $5.2 \pm 1.3$ & $0.0221 \pm 0.0018$ & $0.0576 \pm 0.0032$ & $0.0260 \pm 0.0016$ \\
\hline 06/07/2016 & 5.1 & & $6.6 \pm 1.4$ & & & \\
\hline $24 / 08 / 2017$ & 3.9 & $331 \pm 3$ & $5.3 \pm 1.4(5.0 \pm 0.4$ & & & \\
\hline \multicolumn{7}{|c|}{$\begin{array}{l}\text { GUERNSEY (NE) Mielette } \\
\end{array}$} \\
\hline 29/10/1999 & 4.7 & $297 \pm 8$ & & & & \\
\hline $23 / 09 / 2002$ & 4.6 & $284 \pm 4$ & & & & \\
\hline $06 / 06 / 2000$ & 6.2 & & & $0.0299 \pm 0.0042$ & $0.0894 \pm 0.0081$ & $0.0803 \pm 0.0071$ \\
\hline $25 / 08 / 2010$ & 5.2 & & $1.9 \pm 1.1$ & & & \\
\hline 04/07/2011 & 4.9 & & $4.2 \pm 1.2$ & & & \\
\hline 04/07/2012 & 5.8 & & $1.9 \pm 1.3$ & & & \\
\hline $24 / 06 / 2013$ & 6.0 & & & $0.0164 \pm 0.0018$ & $0.0660 \pm 0.0047$ & $0.0135 \pm 0.0013$ \\
\hline $01 / 09 / 2015$ & 5.3 & & & $0.0189 \pm 0.0016$ & $0.0845 \pm 0.0043$ & $0.0239 \pm 0.0016$ \\
\hline $01 / 09 / 2015$ & 5.3 & & $1.2 \pm 1.2$ & & & \\
\hline $05 / 07 / 2016$ & 5.0 & & $1.5 \pm 1.3$ & & & \\
\hline 23/08/2017 & 4.1 & $278 \pm 3$ & $<2.0(2.5 \pm 0.2)$ & & & \\
\hline
\end{tabular}


Table 2 (Cont.)

\begin{tabular}{|c|c|c|c|c|c|c|}
\hline \multicolumn{7}{|c|}{ GUERNSEY (SW) Portelet Harbour } \\
\hline 29/10/1999 & 4.7 & $298 \pm 8$ & & & & \\
\hline 23/09/2002 & 4.1 & $274 \pm 3$ & & & & \\
\hline $06 / 06 / 2000$ & 5.2 & & & $0.0204 \pm 0.0031$ & $0.0627 \pm 0.0062$ & $0.0298 \pm 0.0023$ \\
\hline $25 / 08 / 2010$ & 5.1 & & $1.7 \pm 1.1$ & & & \\
\hline 04/07/2011 & 4.7 & & $3.6 \pm 1.2$ & & & \\
\hline $24 / 06 / 2013$ & 6.5 & & & $0.0111 \pm 0.0012$ & $0.0529 \pm 0.0029$ & $0.0121 \pm 0.0012$ \\
\hline 01/09/2015 & 4.8 & & & $0.0138 \pm 0.0014$ & $0.0576 \pm 0.0037$ & $0.0205 \pm 0.0014$ \\
\hline 04/07/2012 & 5.8 & & $1.5 \pm 1.2$ & & & \\
\hline $01 / 09 / 2015$ & 4.8 & & $1.7 \pm 1.3$ & & & \\
\hline $05 / 07 / 2016$ & 4.1 & & $1.3 \pm 1.3$ & & & \\
\hline $23 / 08 / 2017$ & 3.3 & $268 \pm 3$ & $<2.0(2.4 \pm 0.2)$ & & & \\
\hline \multicolumn{7}{|c|}{ JERSEY (NE) Anse de Ste Catherine } \\
\hline 06/07/2012 & 5.5 & & $2.7 \pm 1.3$ & & & \\
\hline $31 / 08 / 2015$ & 5.3 & & & $0.0390 \pm 0.0025$ & $0.1119 \pm 0.0057$ & $0.0624 \pm 0.0034$ \\
\hline $31 / 08 / 2015$ & 5.3 & & $2.6 \pm 1.3$ & & & \\
\hline $04 / 07 / 2016$ & 4.5 & & $2.7 \pm 1.3$ & & & \\
\hline $22 / 08 / 2017$ & 3.6 & $298 \pm 3$ & $2.6 \pm 1.3(3.5 \pm 0.3)$ & & & \\
\hline \multicolumn{7}{|c|}{ JERSEY (SW) Corbière Lighthouse } \\
\hline $06 / 07 / 2012$ & 5.4 & & $2.4 \pm 1.3$ & & & \\
\hline $26 / 06 / 2013$ & 5.7 & & & $0.0327 \pm 0.0023$ & $0.1016 \pm 0.0049$ & $0.0308 \pm 0.0023$ \\
\hline $31 / 08 / 2015$ & 5.8 & & $1.7 \pm 1.3$ & $0.0336 \pm 0.0022$ & $0.1001 \pm 0.0051$ & $0.0379 \pm 0.0020$ \\
\hline $04 / 07 / 2016$ & 4.5 & & $4.0 \pm 1.3$ & & & \\
\hline $22 / 08 / 2017$ & 3.8 & $297 \pm 3$ & $2.9 \pm 1.3(3.4 \pm 0.2)$ & & & \\
\hline
\end{tabular}




\section{Declaration of interests}

$\square$ The authors declare that they have no known competing financial interests or personal relationships that could have appeared to influence the work reported in this paper.

$\square$ The authors declare the following financial interests/personal relationships which may be considered as potential competing interests: 


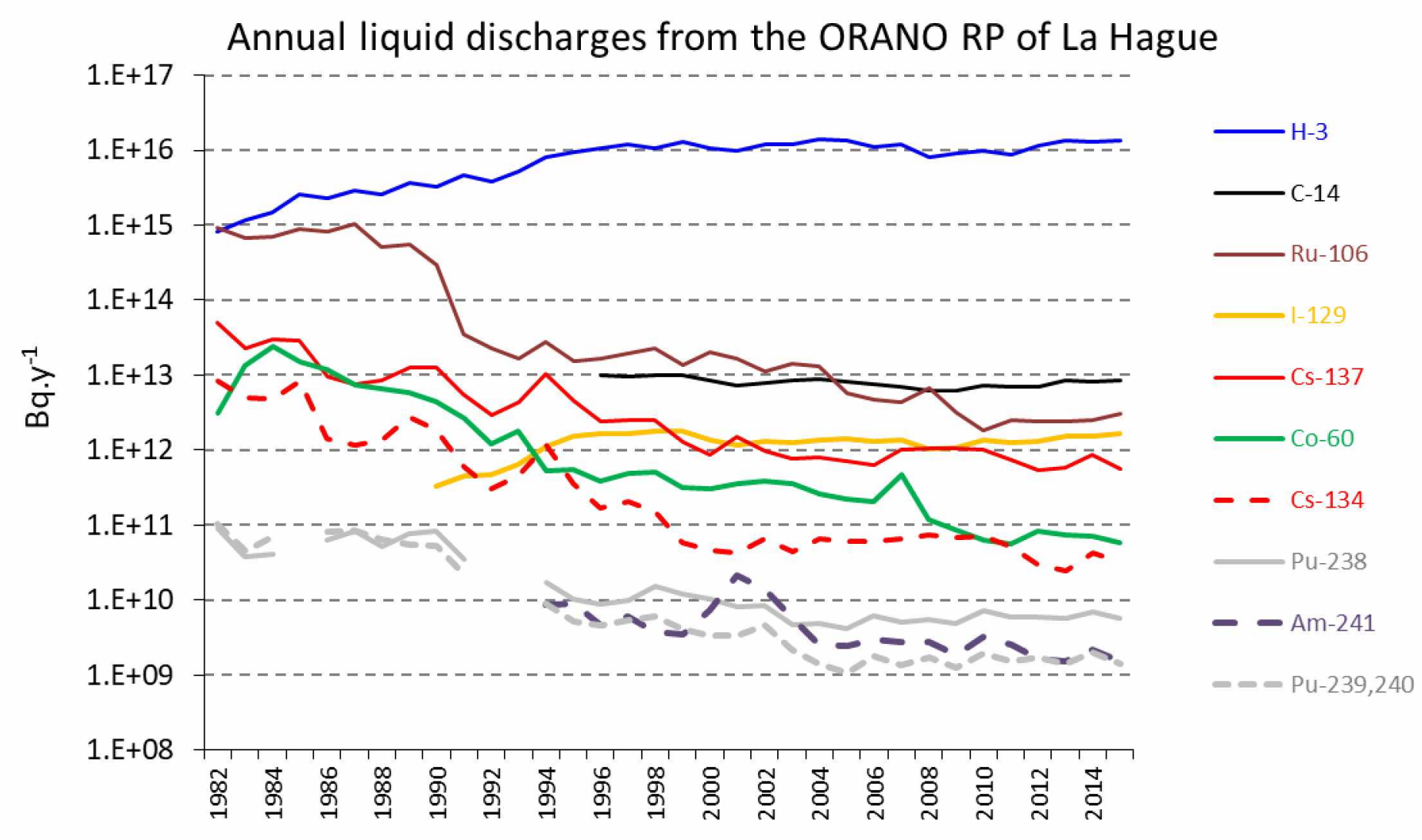


Concentrations resulting from constant discharge of 1 TBq. $\mathrm{y}^{-1}$ (31 709 Bq. $\left.\mathrm{s}^{-1}\right)$

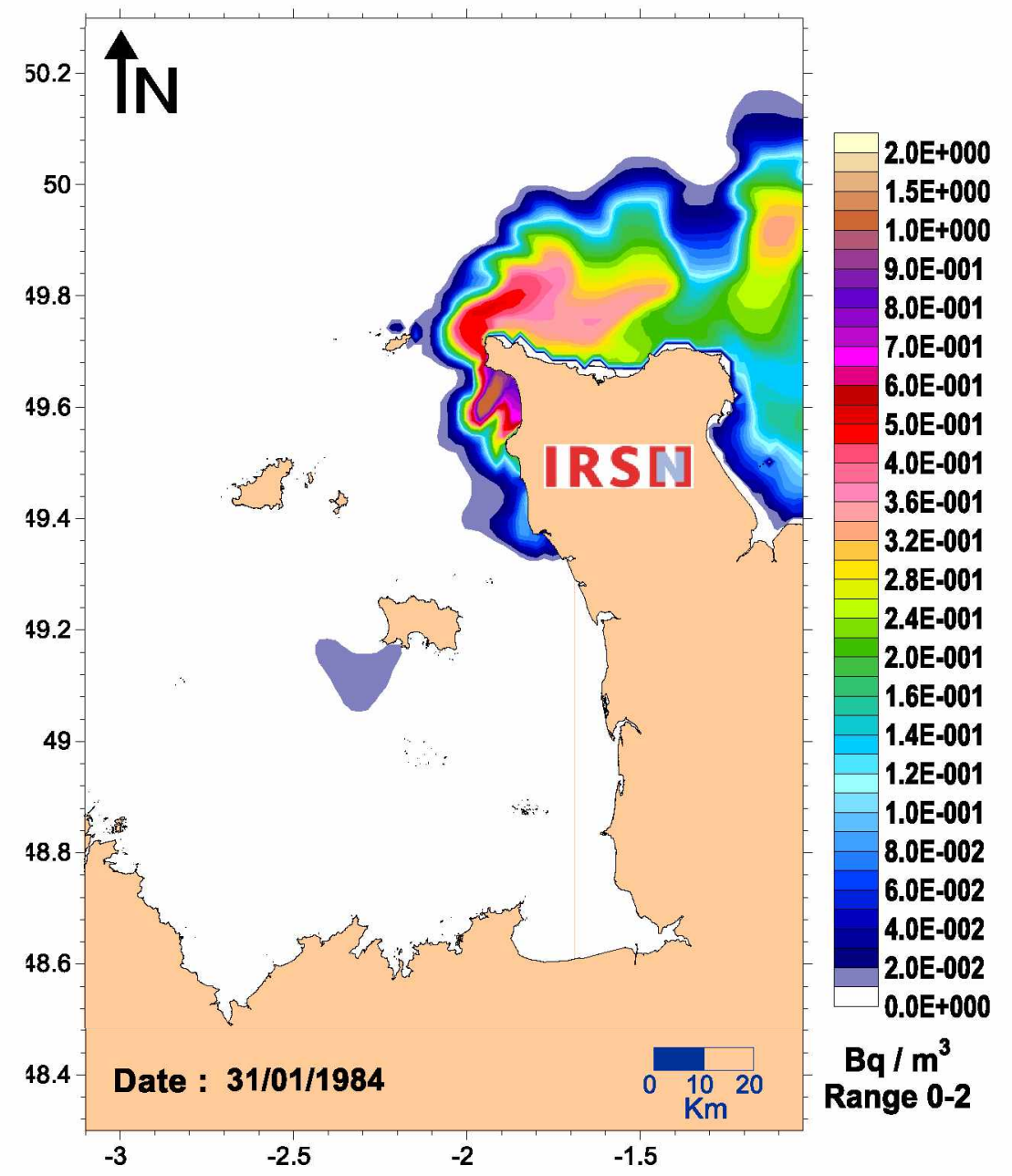

Hydrodynamic modelling (MARS 2D)
Concentrations resulting from constant discharge of 1 TBq. $\mathrm{y}^{-1}$ (31 709 Bq. $\left.\mathrm{s}^{-1}\right)$

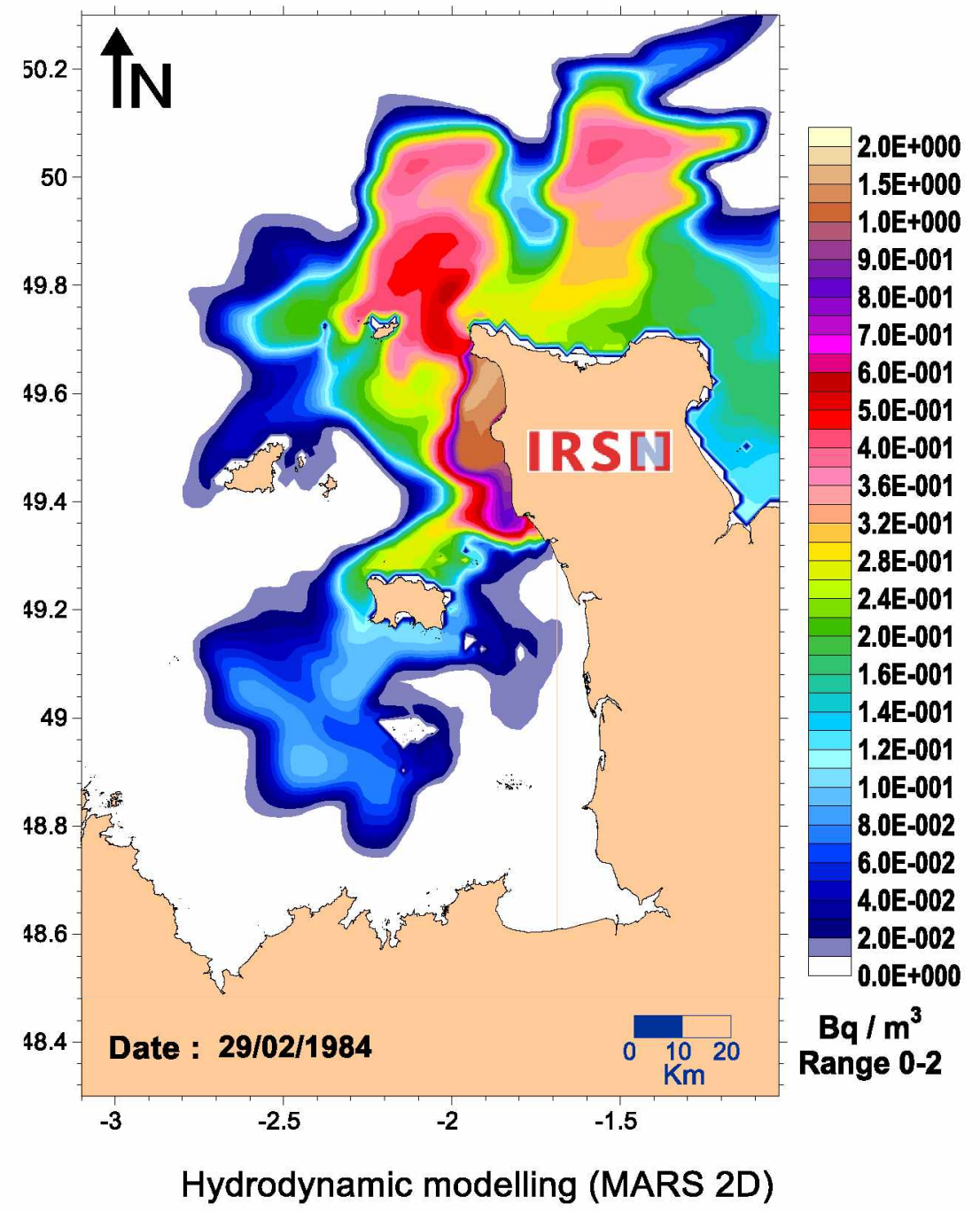


Concentrations resulting from constant discharge of 1 TBq. $\mathrm{y}^{-1}$ (31 709 Bq. $\left.\mathrm{s}^{-1}\right)$

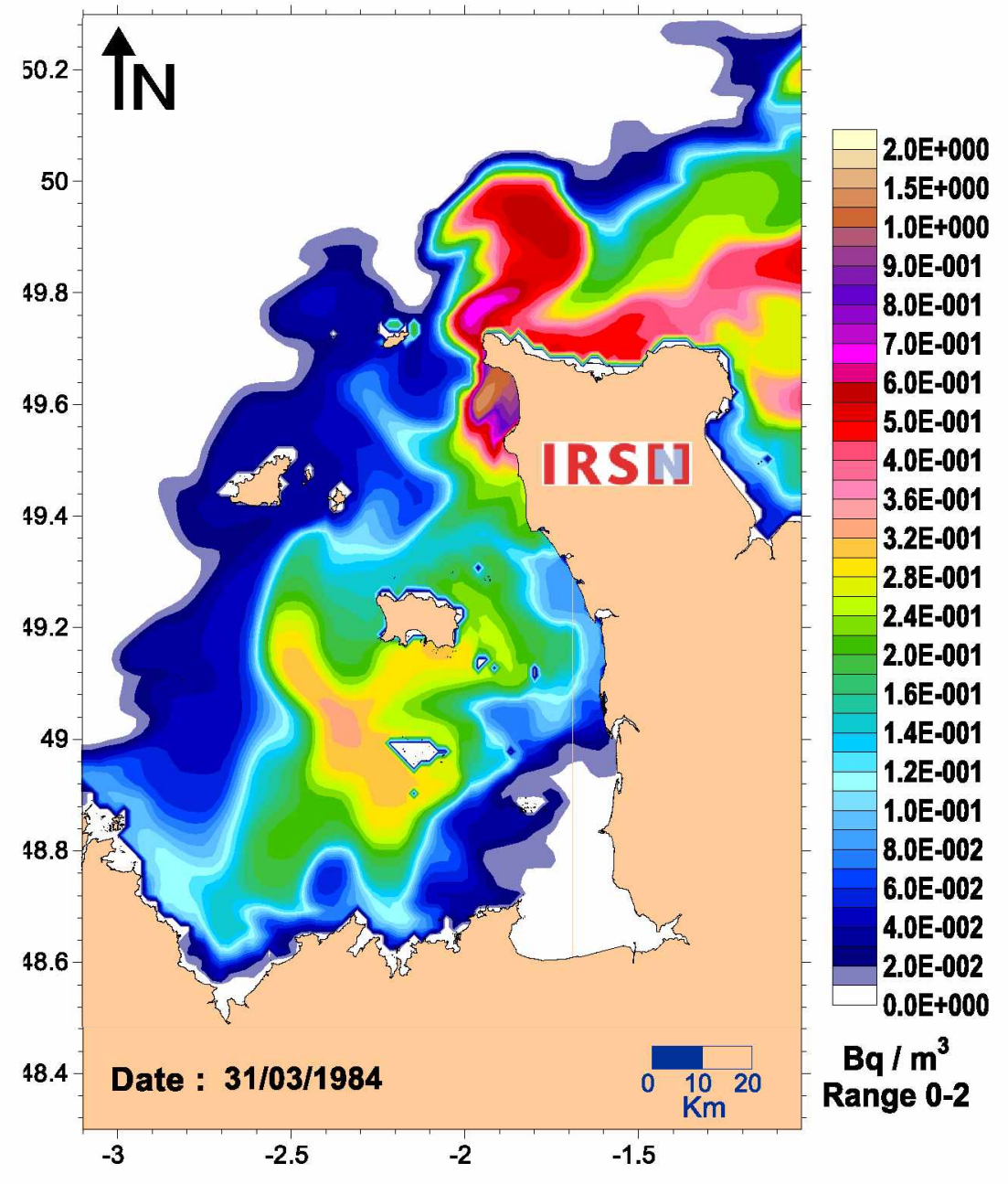

Hydrodynamic modelling (MARS 2D)
Concentrations resulting from constant discharge of 1 TBq. $\mathrm{y}^{-1}$ (31 709 Bq. $\left.\mathrm{s}^{-1}\right)$

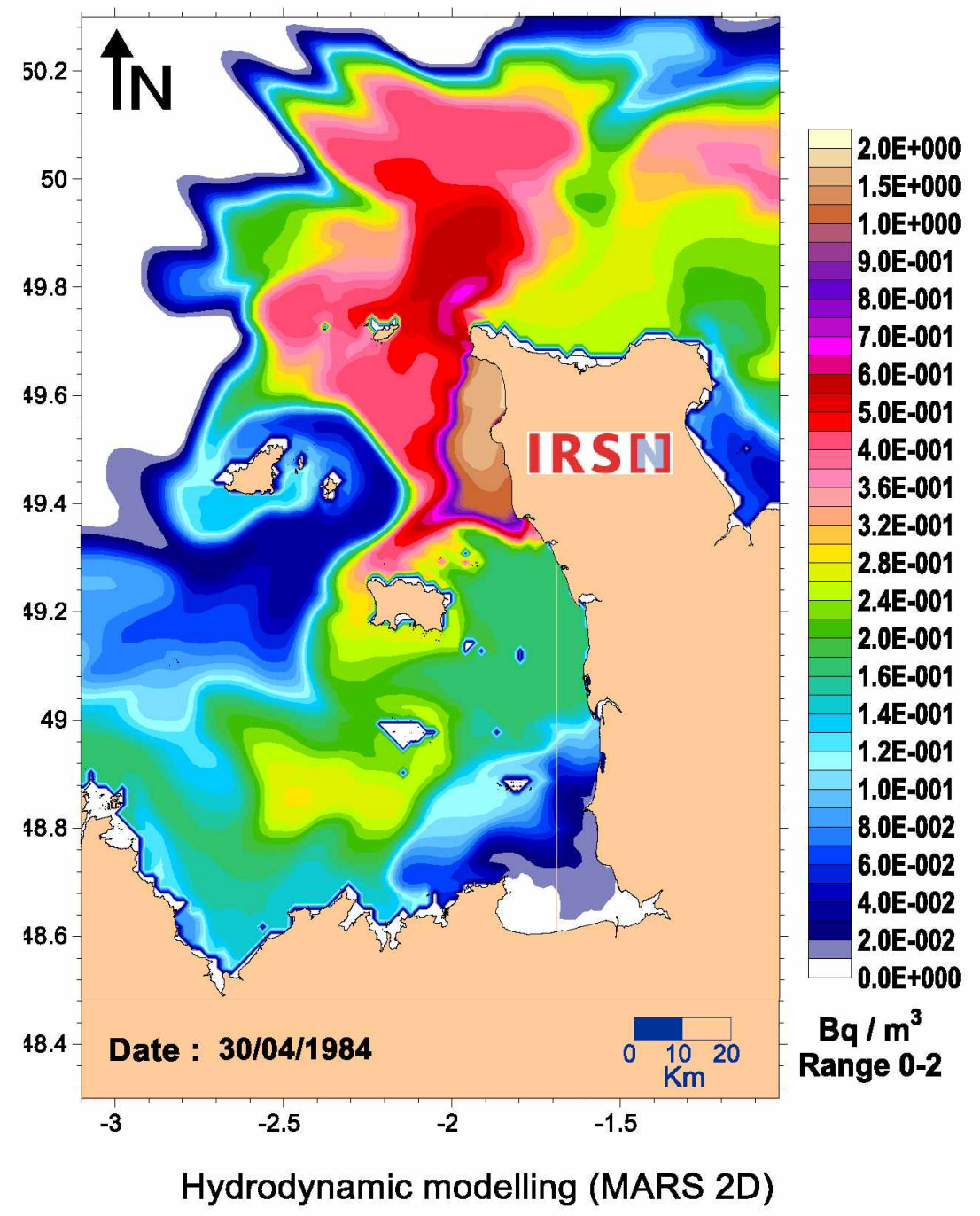


Concentrations resulting from constant discharge of 1 TBq. $\mathrm{y}^{-1}$ (31 709 Bq. $\left.\mathrm{s}^{-1}\right)$

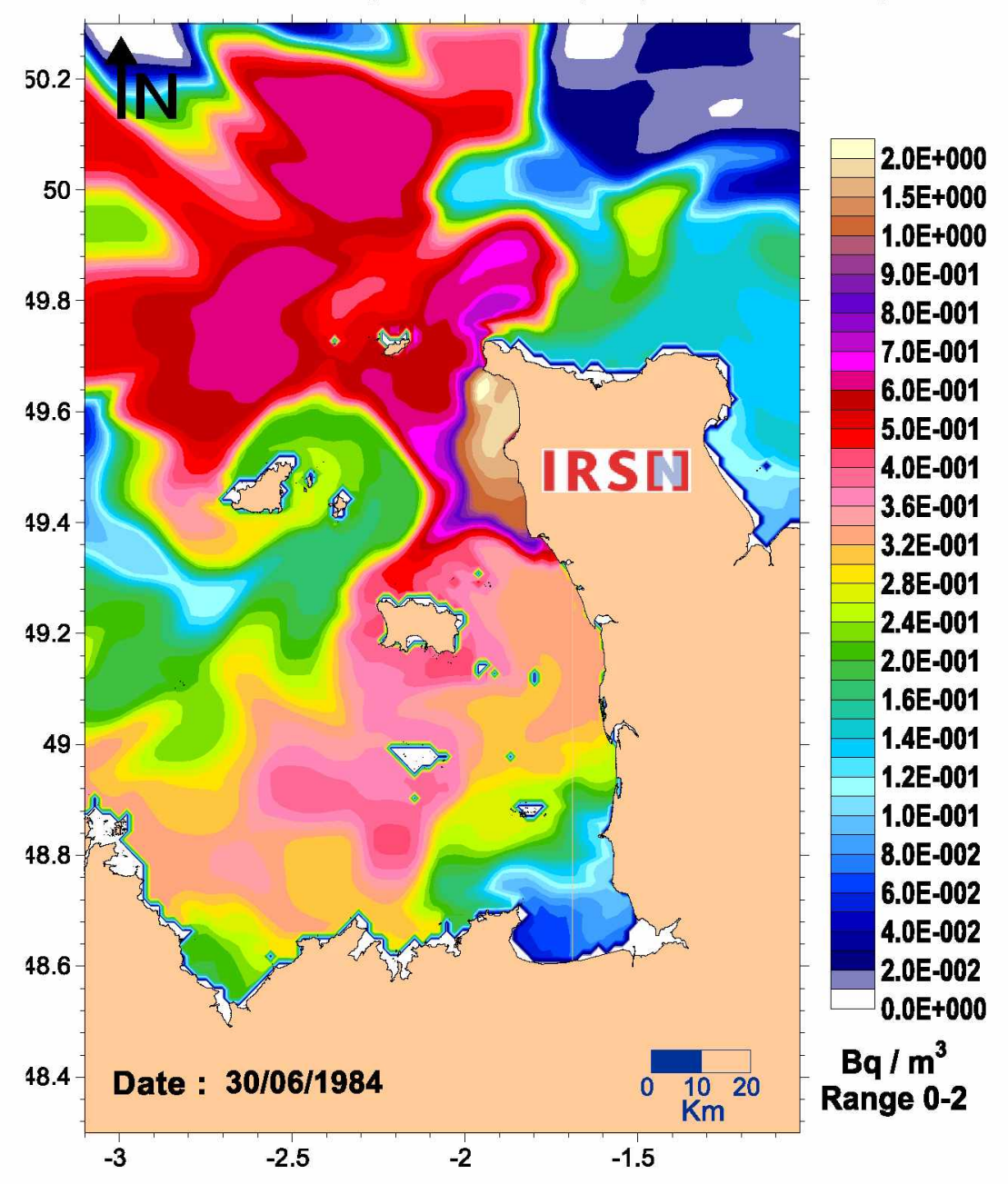

Hydrodynamic modelling (MARS 2D)
Concentrations resulting from constant discharge of 1 TBq. $y^{-1}$ (31 709 Bq. $\left.\mathrm{s}^{-1}\right)$

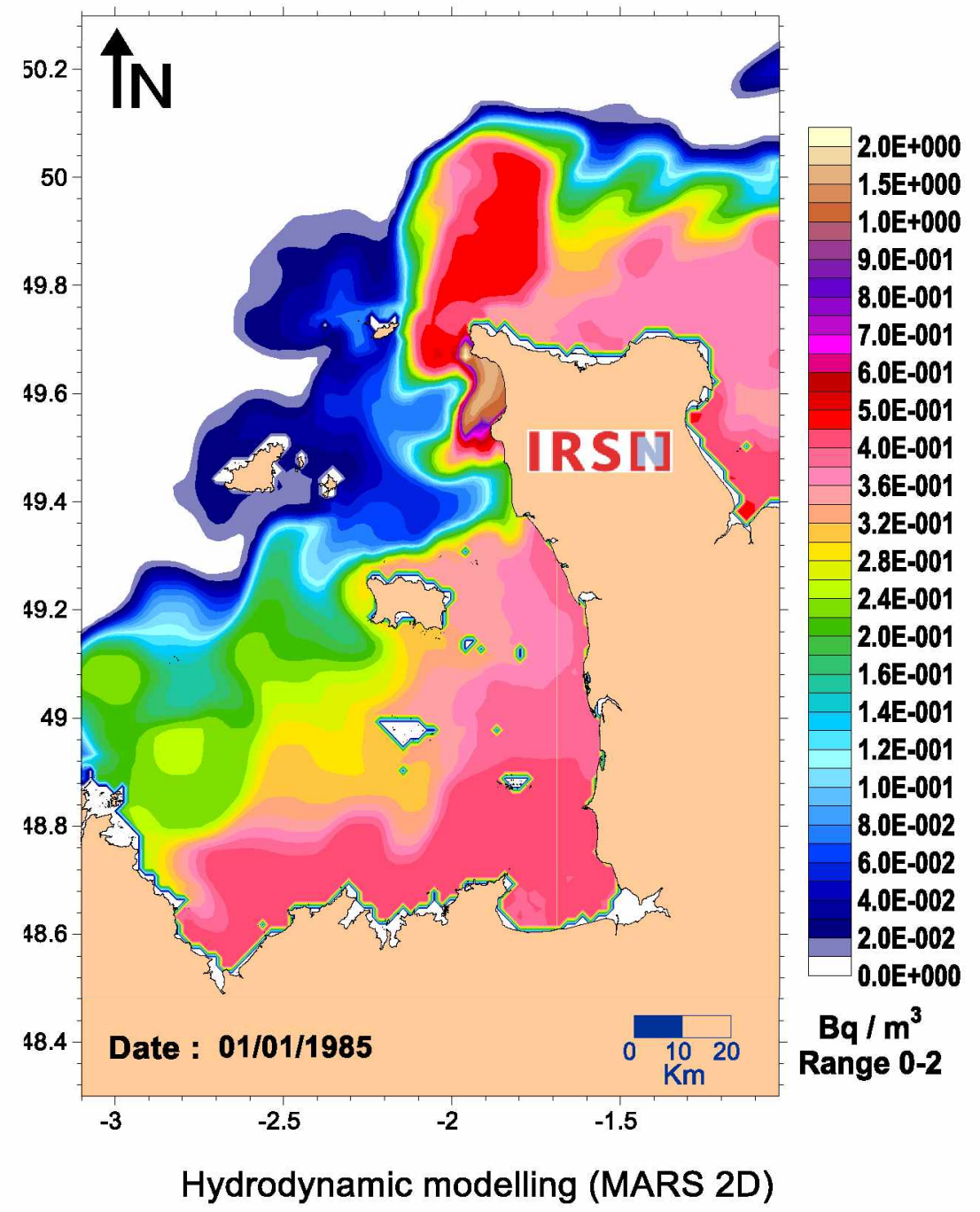


Annual mean concentrations resulting from constant discharge of 1 TBq. $\mathrm{y}^{-1}$ (31 $\left.709 \mathrm{~Bq} . \mathrm{s}^{-1}\right)$

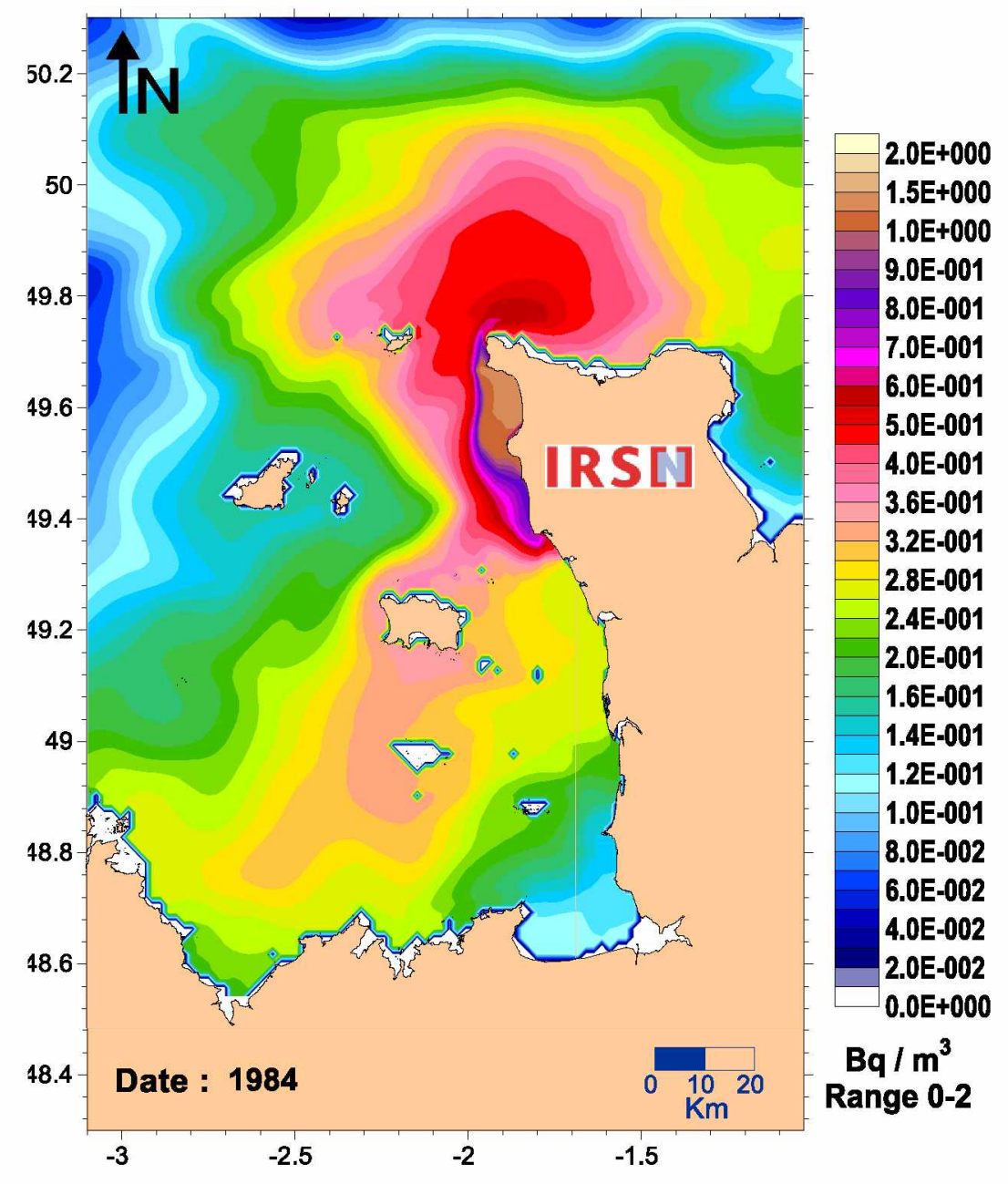

Hydrodynamic modelling (MARS 2D)
Annual mean concentrations resulting from constant discharge of 1 TBq. $\mathrm{y}^{-1}$ (31 709 Bq. $\left.\mathrm{s}^{-1}\right)$

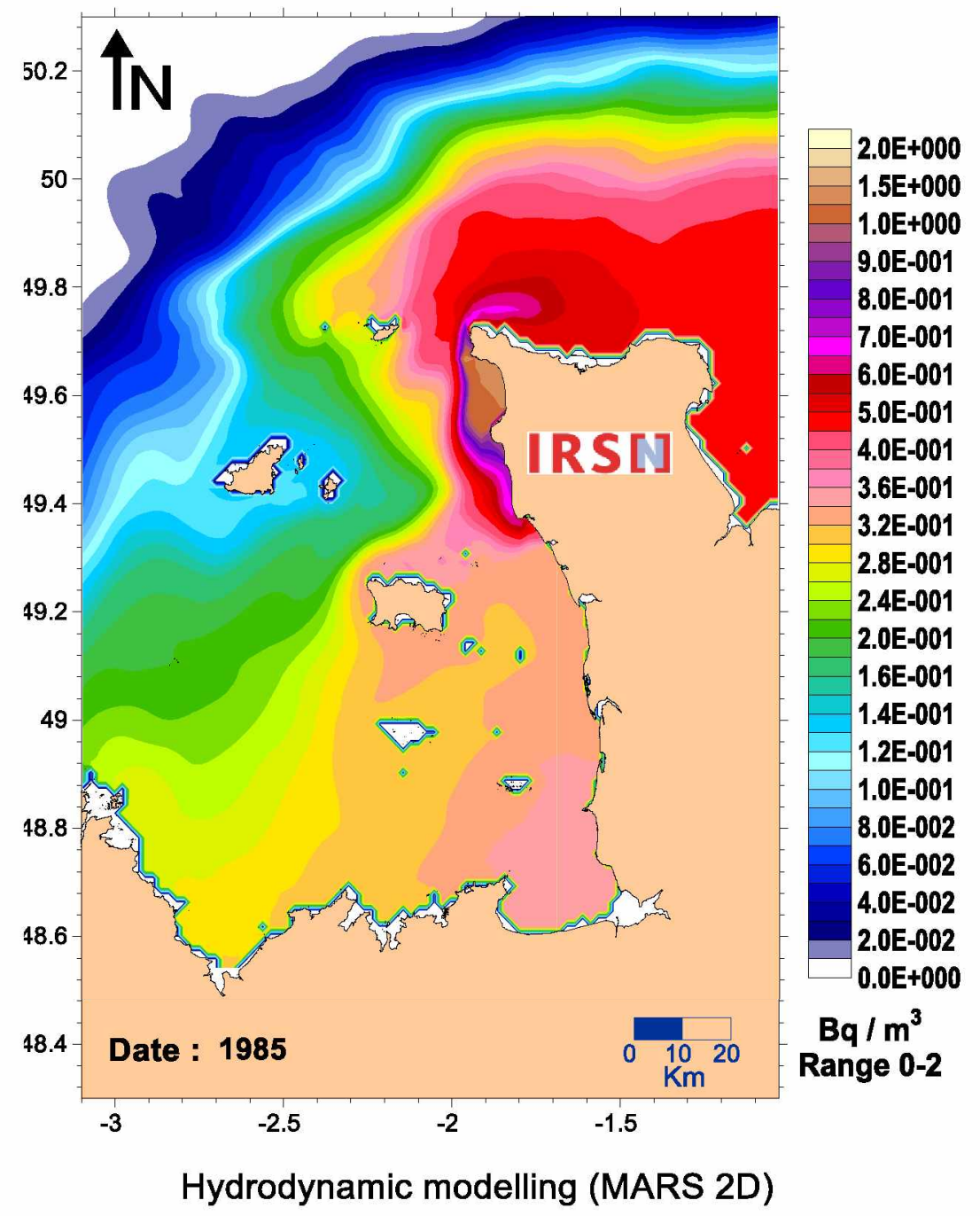




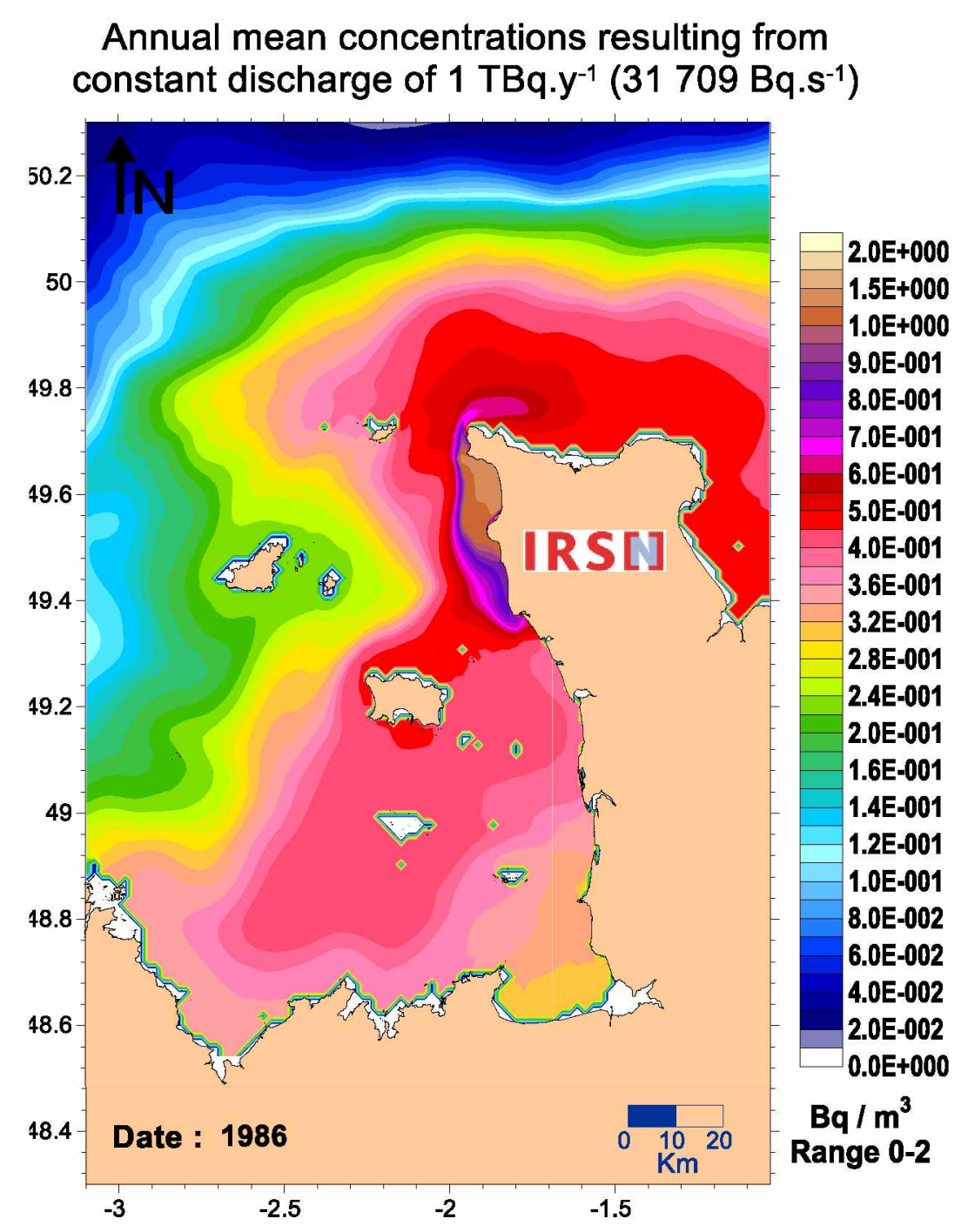

Hydrodynamic modelling (MARS 2D)
Annual mean concentrations resulting from constant discharge of 1 TBq. $\mathrm{y}^{-1}$ (31 709 Bq. $\left.\mathrm{s}^{-1}\right)$

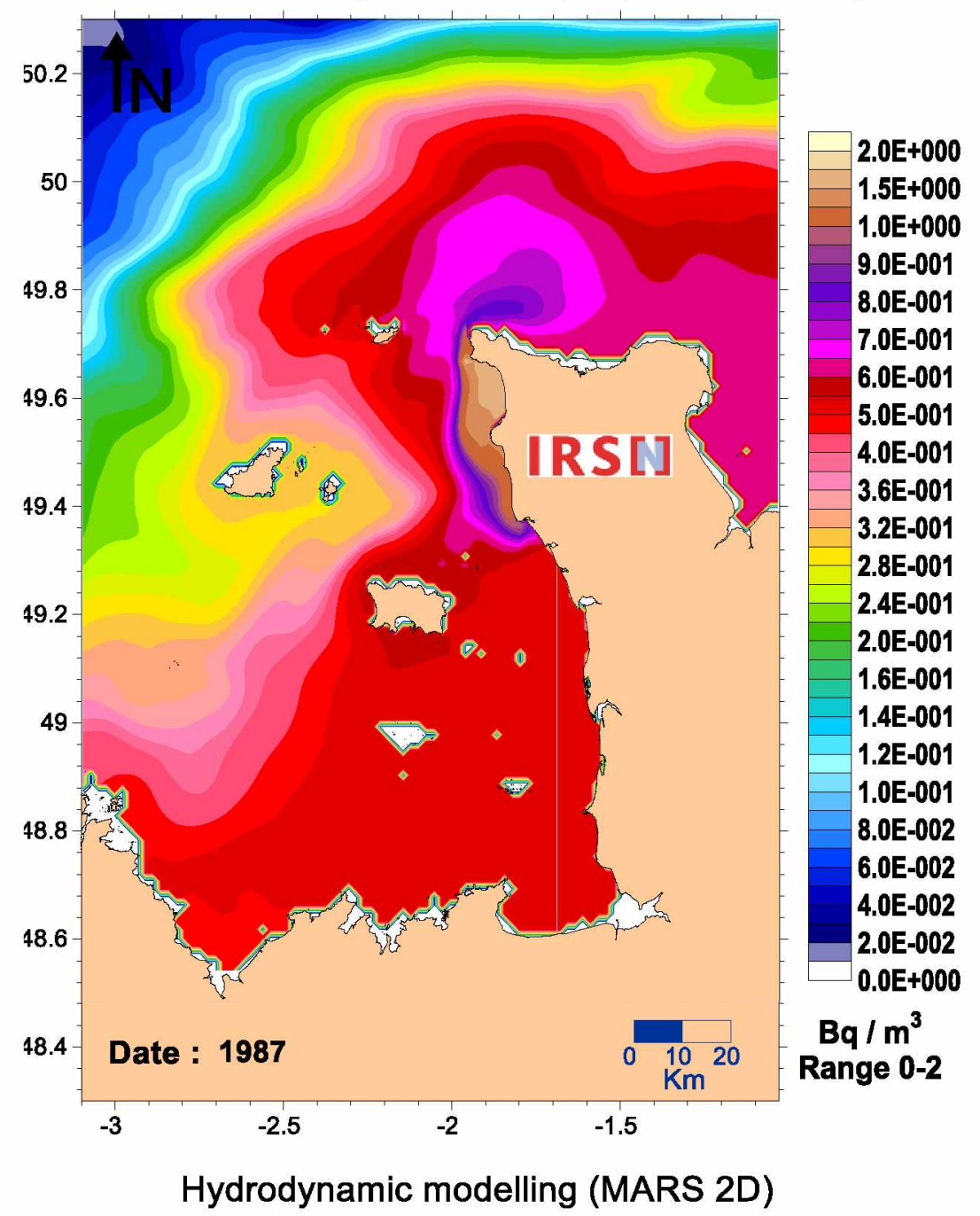


Annual mean concentrations resulting from constant discharge of 1 TBq. $\mathrm{y}^{-1}$ (31 $\left.709 \mathrm{~Bq} . \mathrm{s}^{-1}\right)$

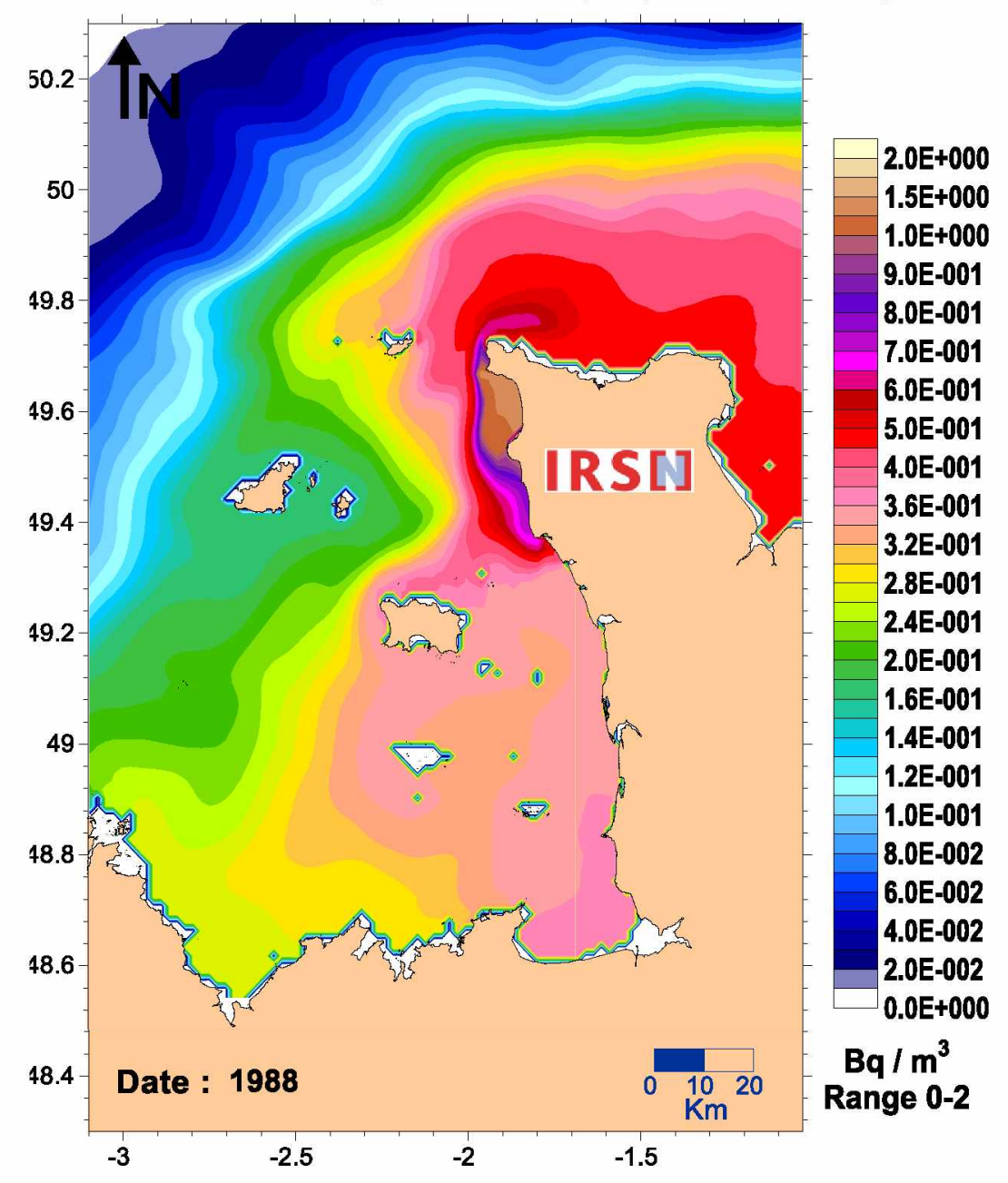

Hydrodynamic modelling (MARS 2D)
Annual mean concentrations resulting from constant discharge of 1 TBq. $\mathrm{y}^{-1}$ (31 $709 \mathrm{~Bq} . \mathrm{s}^{-1}$ )

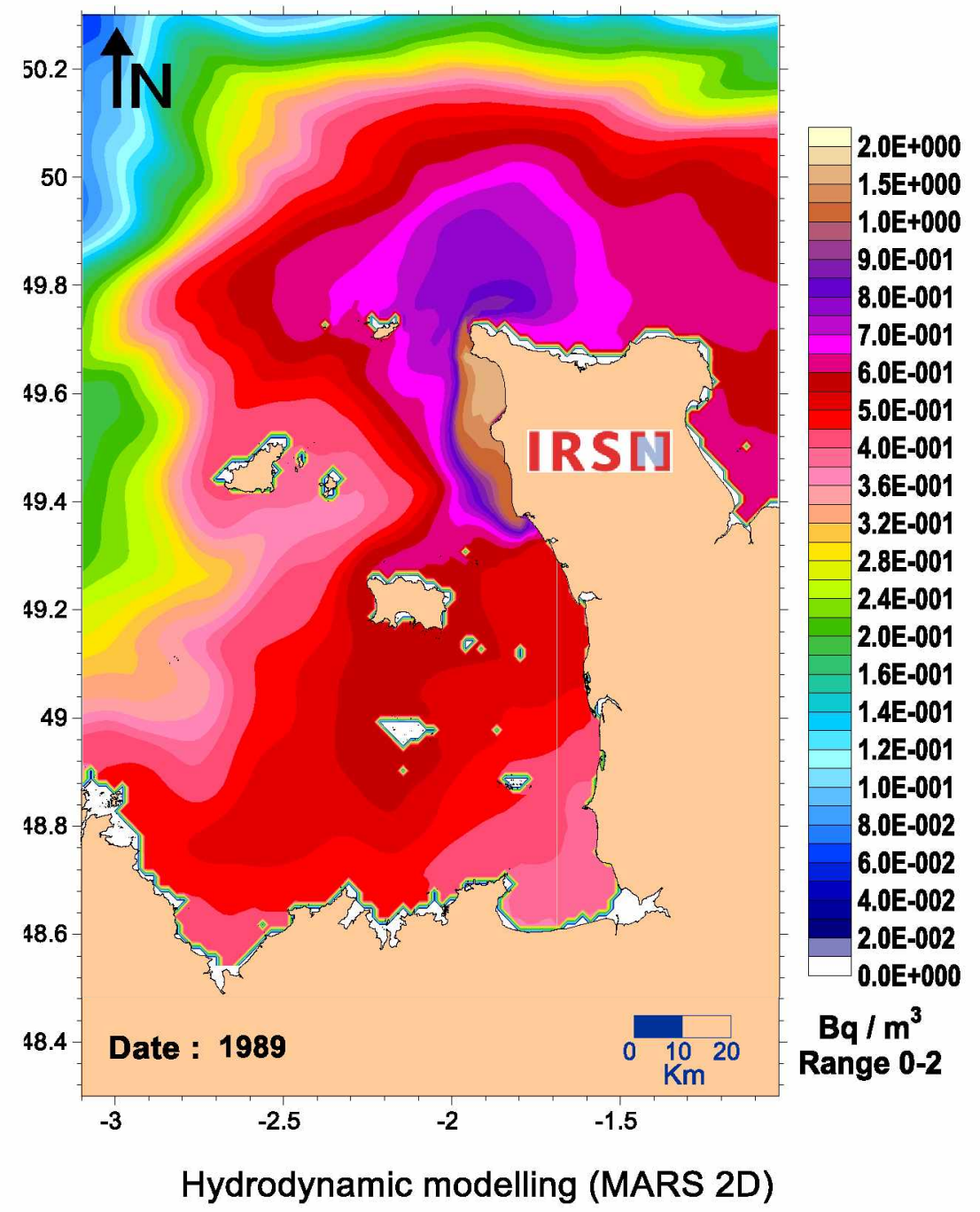


Annual mean concentrations resulting from constant discharge of 1 TBq. $\mathrm{y}^{-1}$ (31 $\left.709 \mathrm{~Bq} \cdot \mathrm{s}^{-1}\right)$

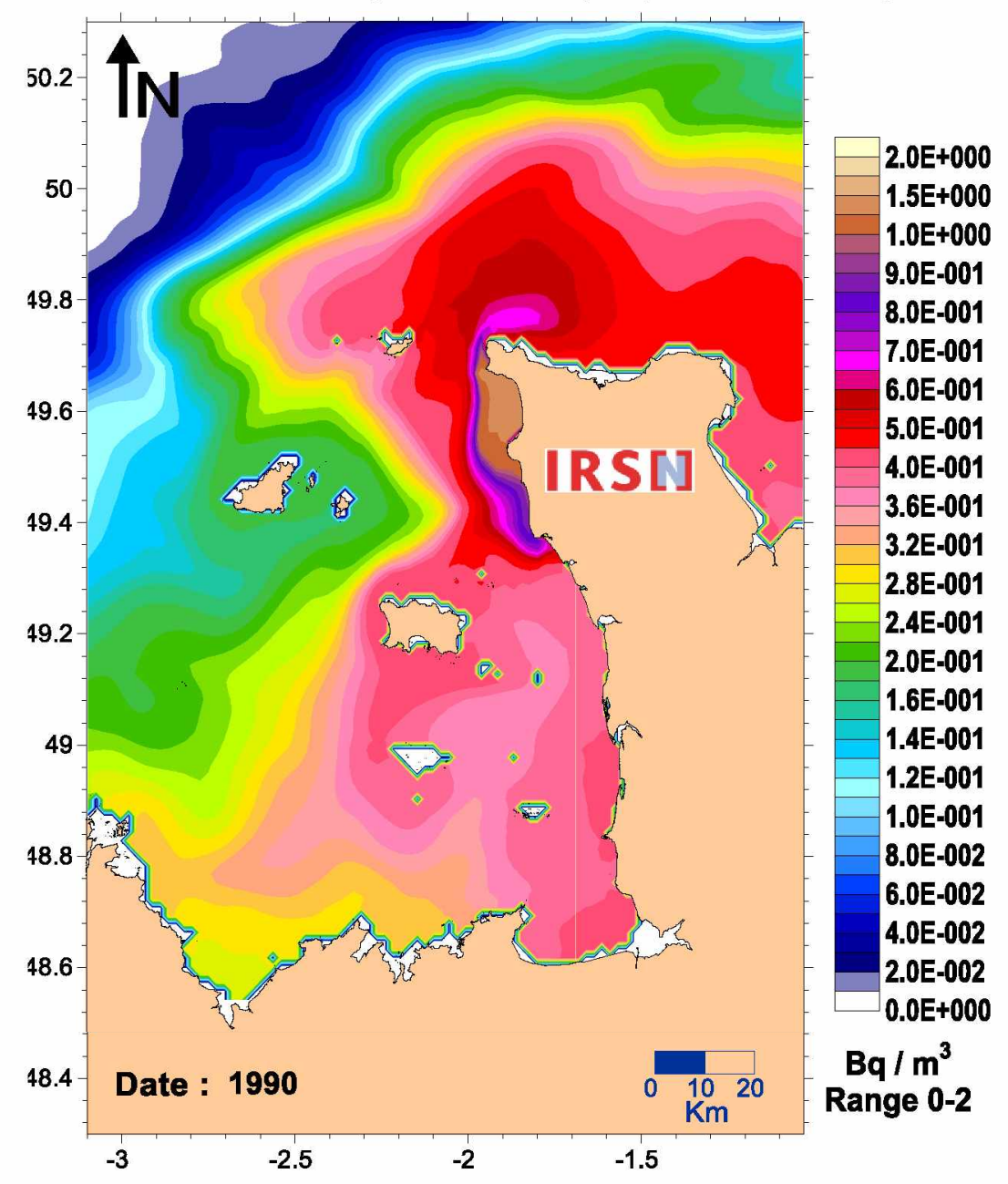

Hydrodynamic modelling (MARS 2D)
Annual mean concentrations resulting from constant discharge of $1 \mathrm{TBq} . \mathrm{y}^{-1}$ (31 $\left.709 \mathrm{~Bq} \cdot \mathrm{s}^{-1}\right)$

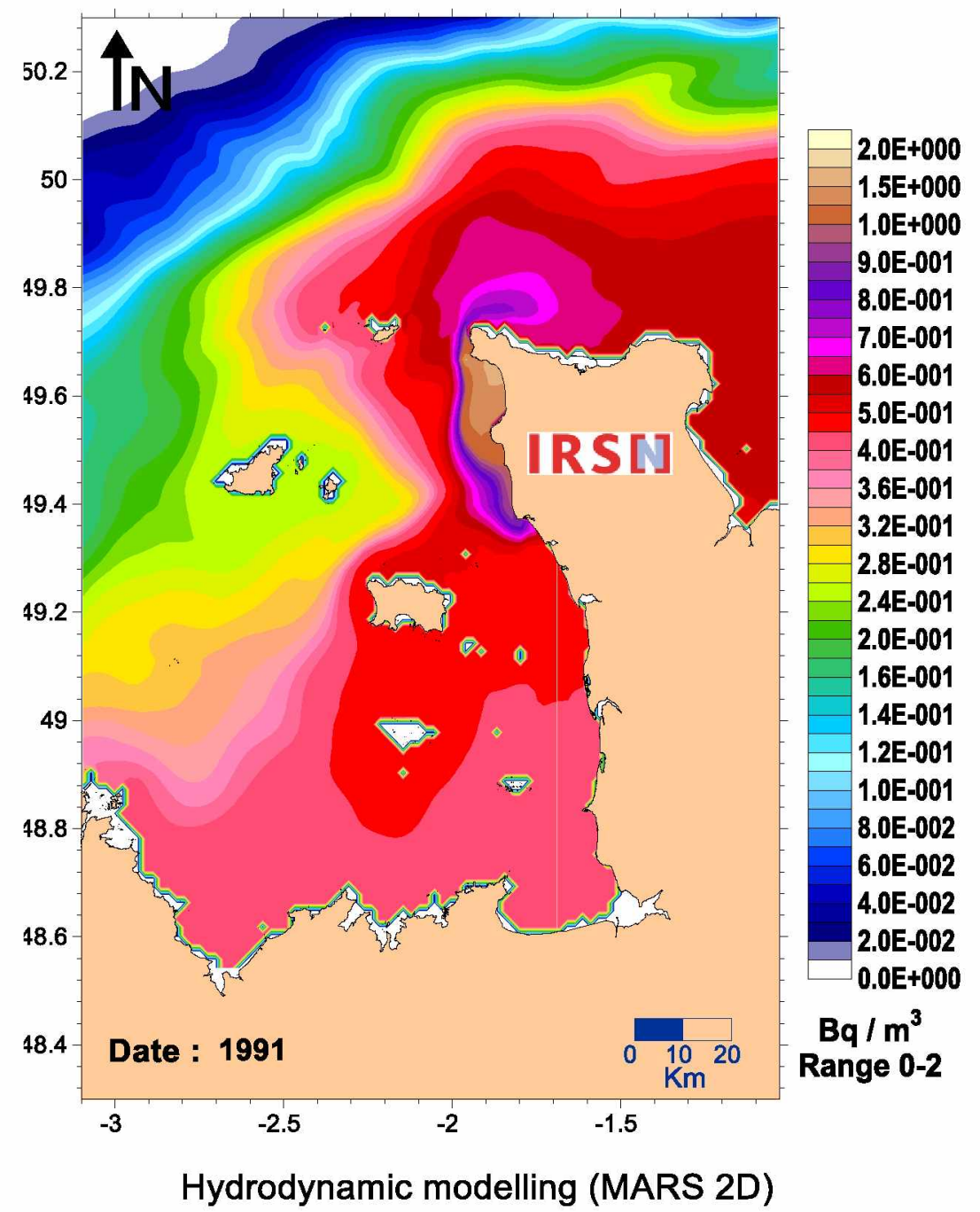


Annual mean concentrations resulting from constant discharge of 1 TBq. $\mathrm{y}^{-1}$ (31 $\left.709 \mathrm{~Bq} \cdot \mathrm{s}^{-1}\right)$

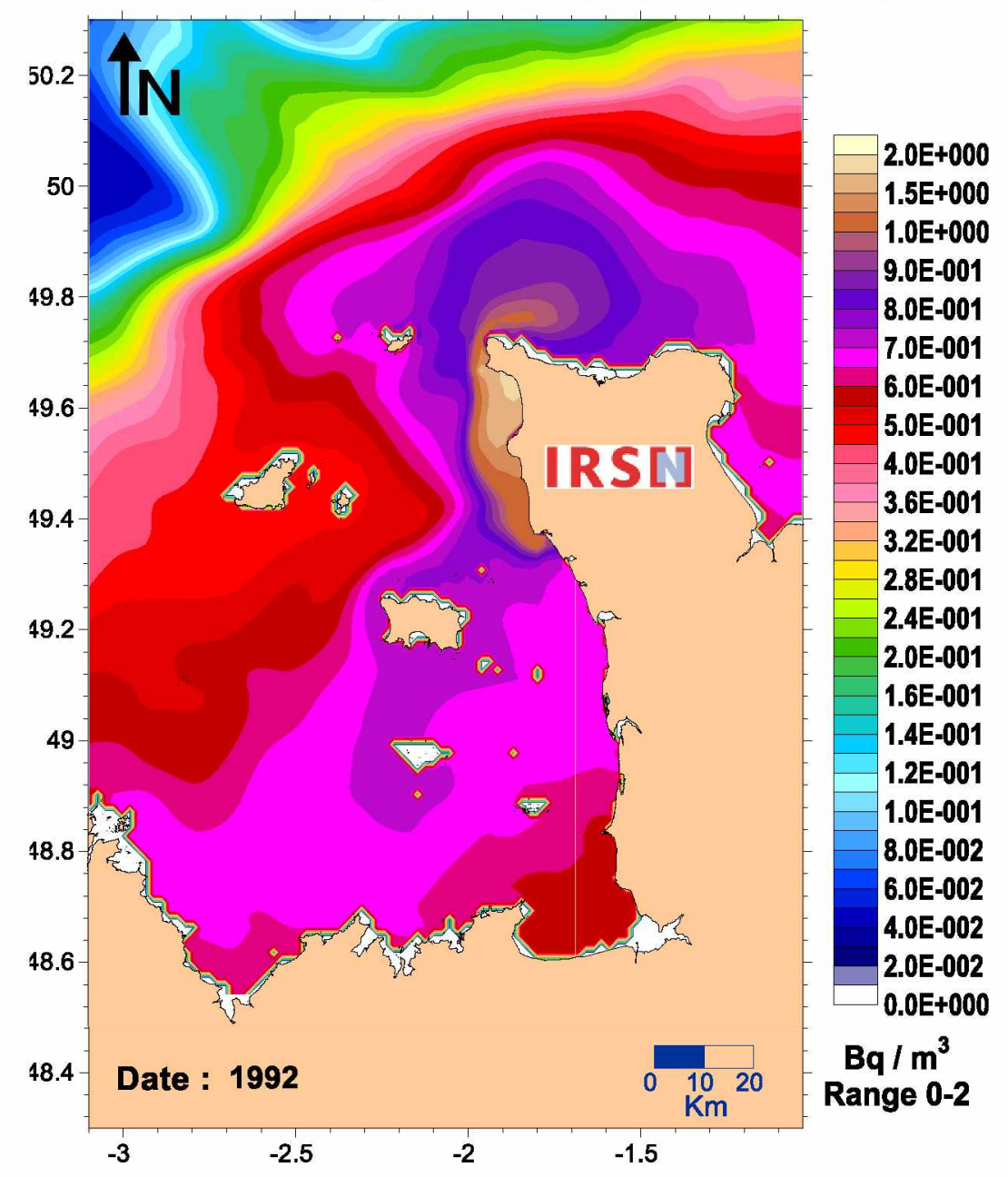

Hydrodynamic modelling (MARS 2D)
Annual mean concentrations resulting from constant discharge of 1 TBq.y $\mathrm{y}^{-1}$ (31 709 Bq. $\mathrm{s}^{-1}$ )

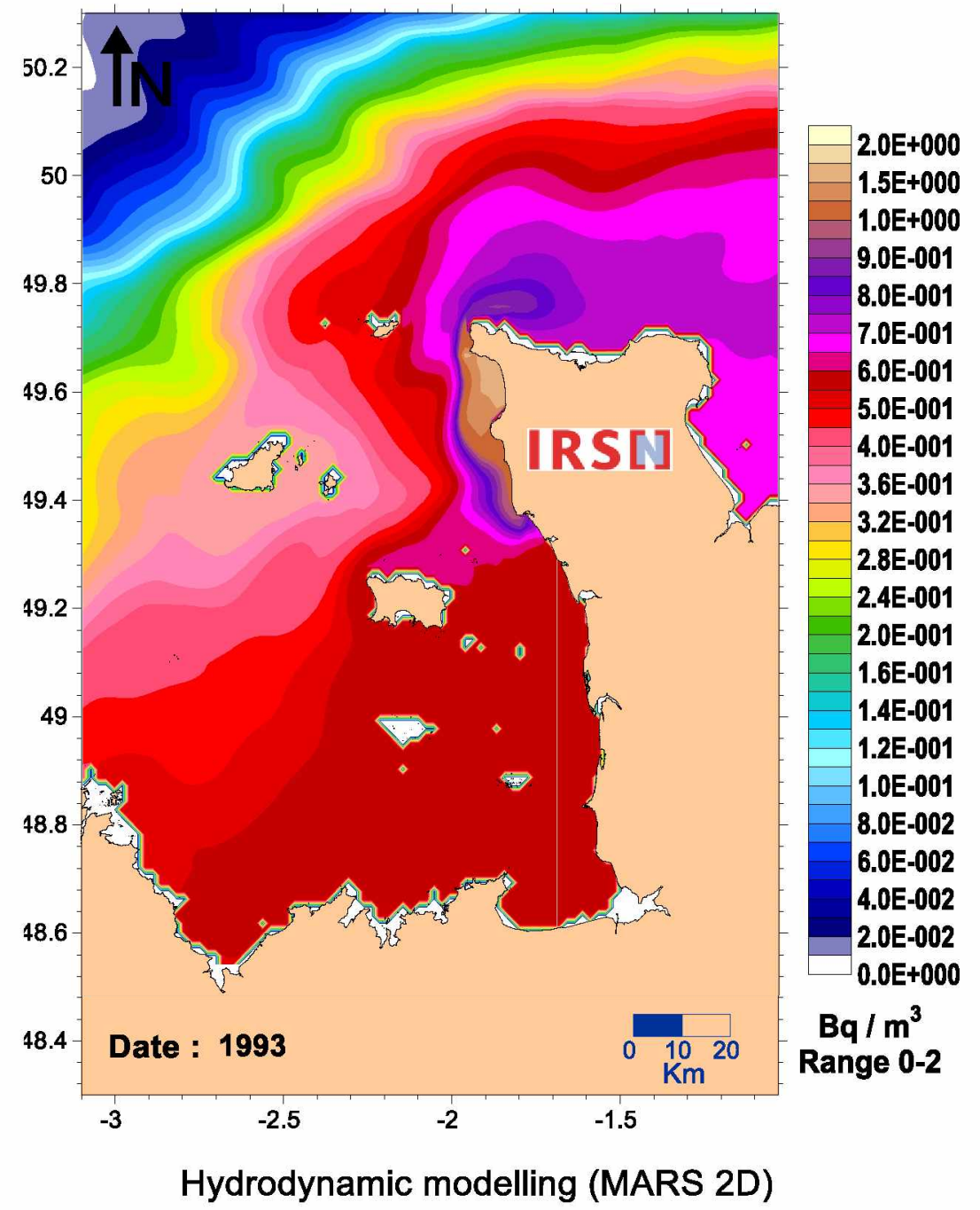


Annual mean concentrations resulting from constant discharge of 1 TBq. $\mathrm{y}^{-1}$ (31 709 Bq. $\mathrm{s}^{-1}$ )

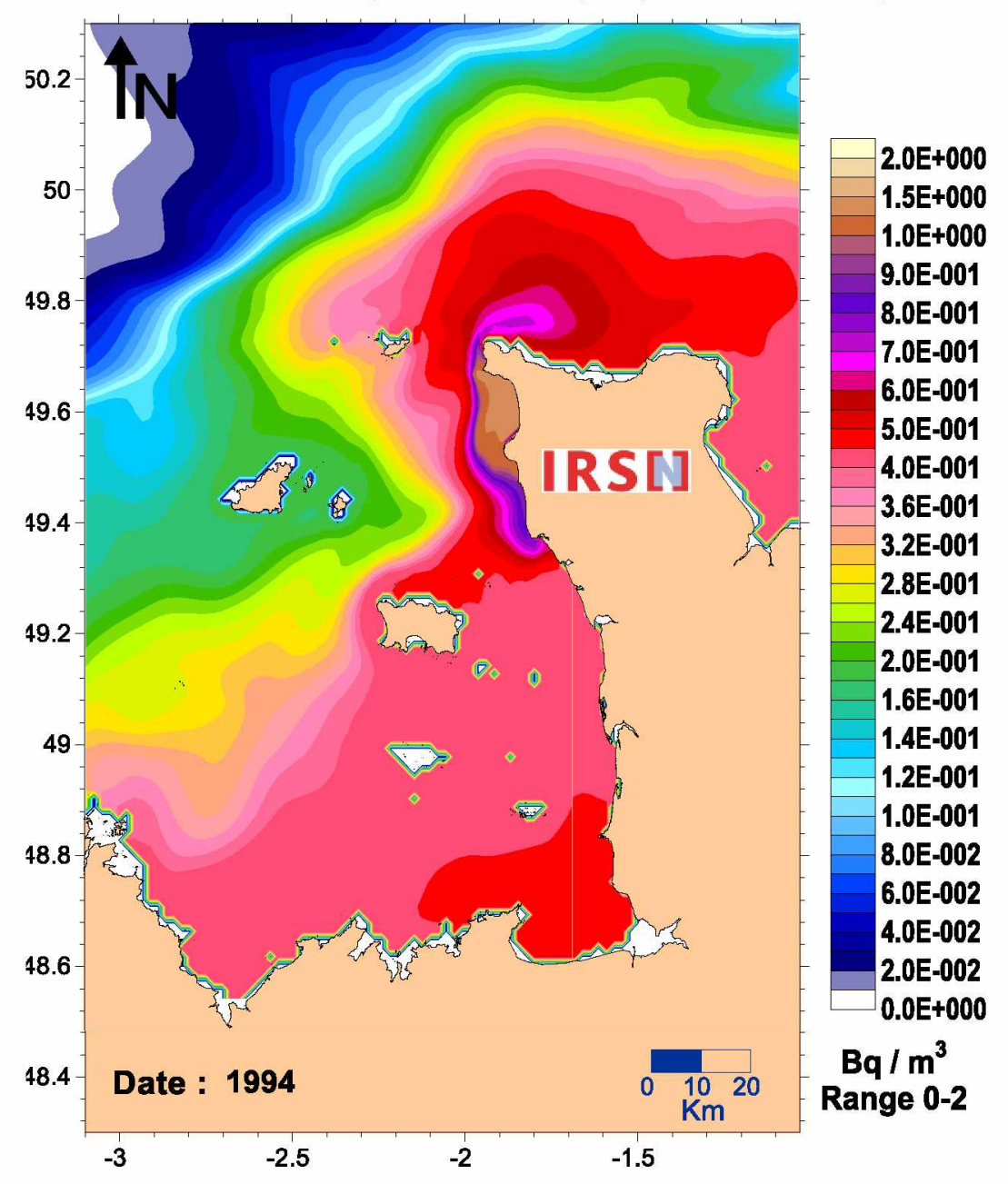

Hydrodynamic modelling (MARS 2D)
Annual mean concentrations resulting from constant discharge of 1 TBq. $\mathrm{y}^{-1}$ (31 $\left.709 \mathrm{~Bq} \cdot \mathrm{s}^{-1}\right)$

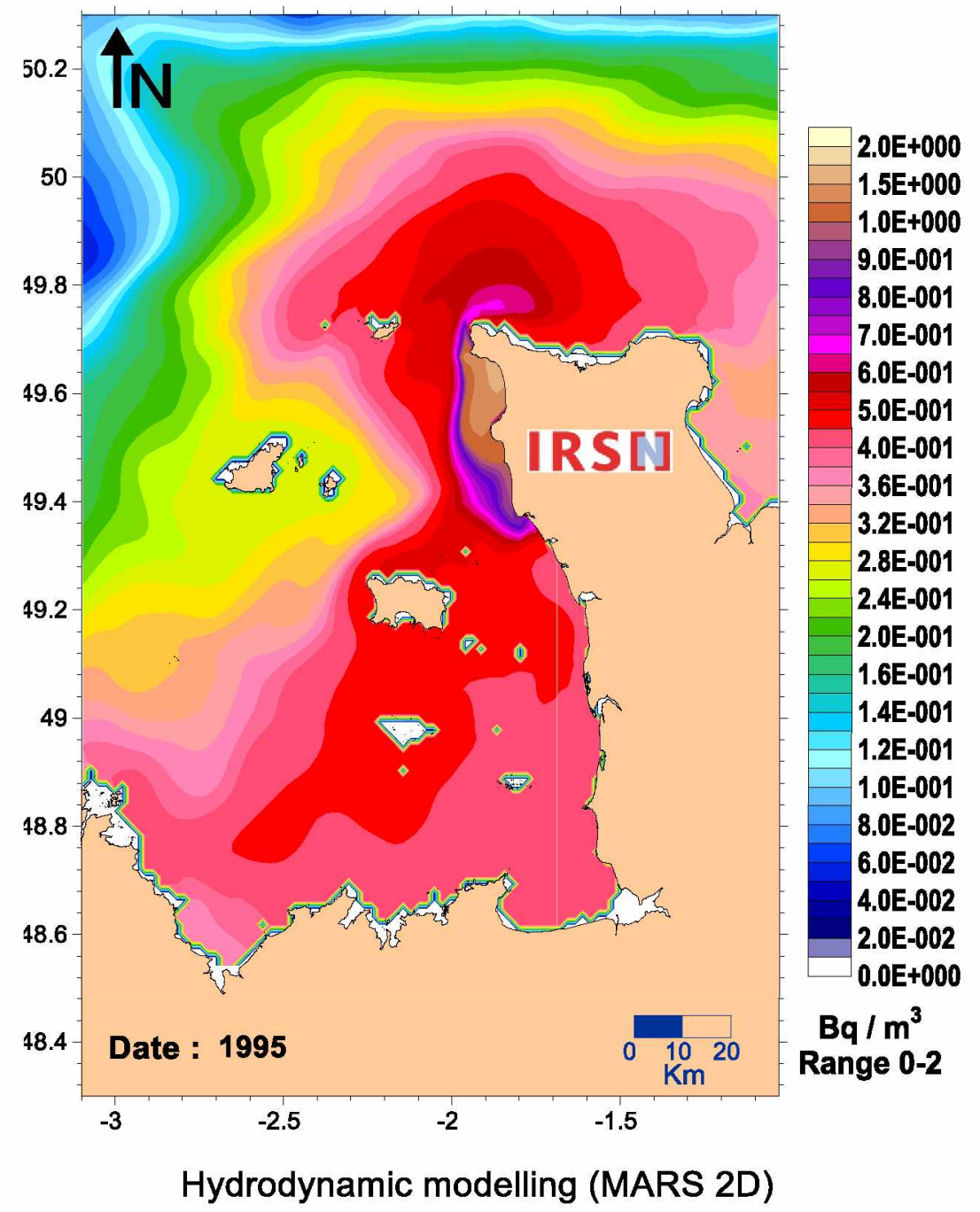


Annual mean concentrations resulting from constant discharge of 1 TBq. $\mathrm{y}^{-1}$ (31 $\left.709 \mathrm{~Bq} \cdot \mathrm{s}^{-1}\right)$

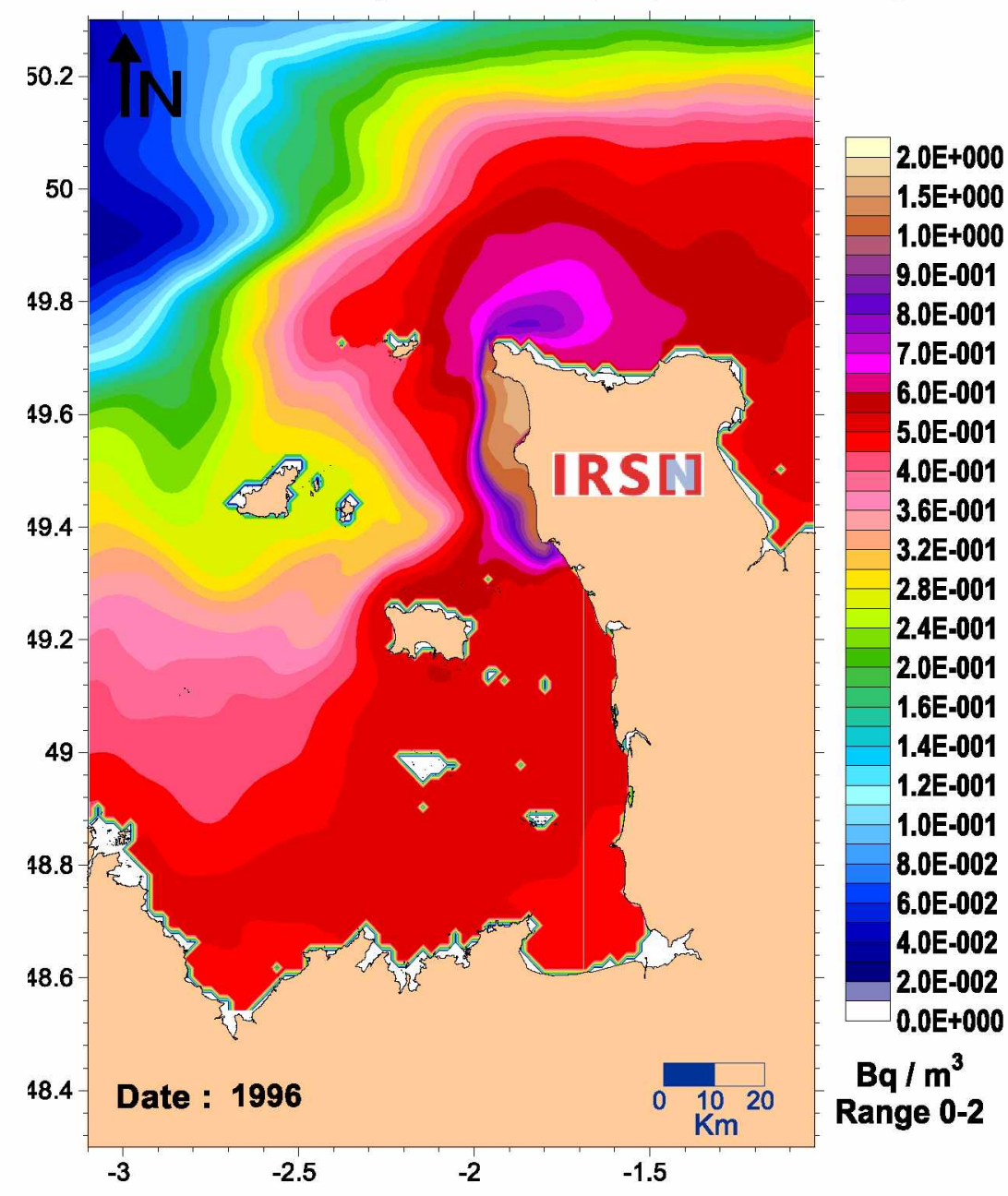

Hydrodynamic modelling (MARS 2D)
Annual mean concentrations resulting from constant discharge of 1 TBq.y $\mathrm{y}^{-1}$ (31 709 Bq. $\mathrm{s}^{-1}$ )

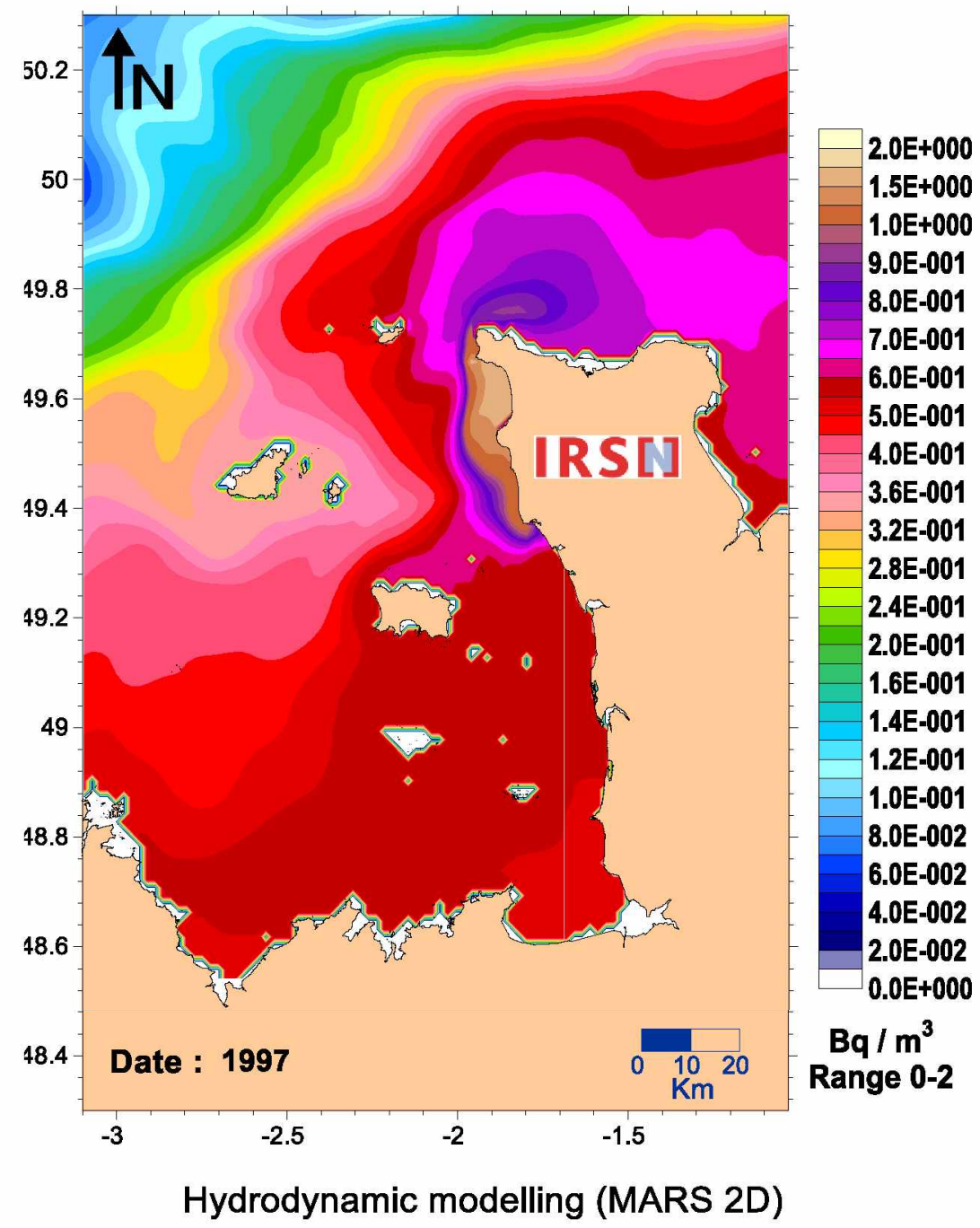


Annual mean concentrations resulting from constant discharge of 1 TBq. $\mathrm{y}^{-1}$ (31 $\left.709 \mathrm{~Bq} \cdot \mathrm{s}^{-1}\right)$

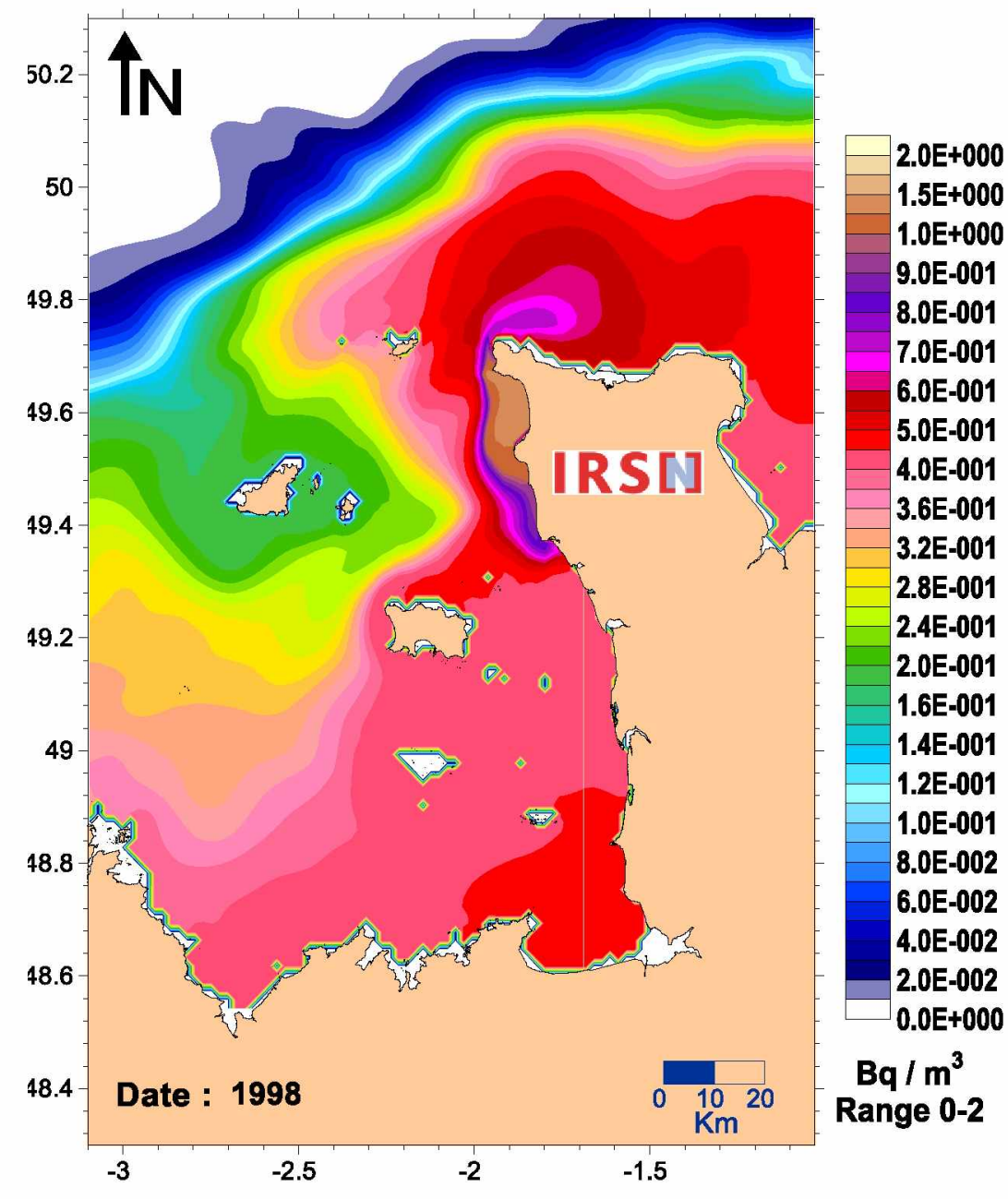

Hydrodynamic modelling (MARS 2D)
Annual mean concentrations resulting from constant discharge of 1 TBq. $\mathrm{y}^{-1}\left(31709\right.$ Bq. $\left.^{-1}\right)$

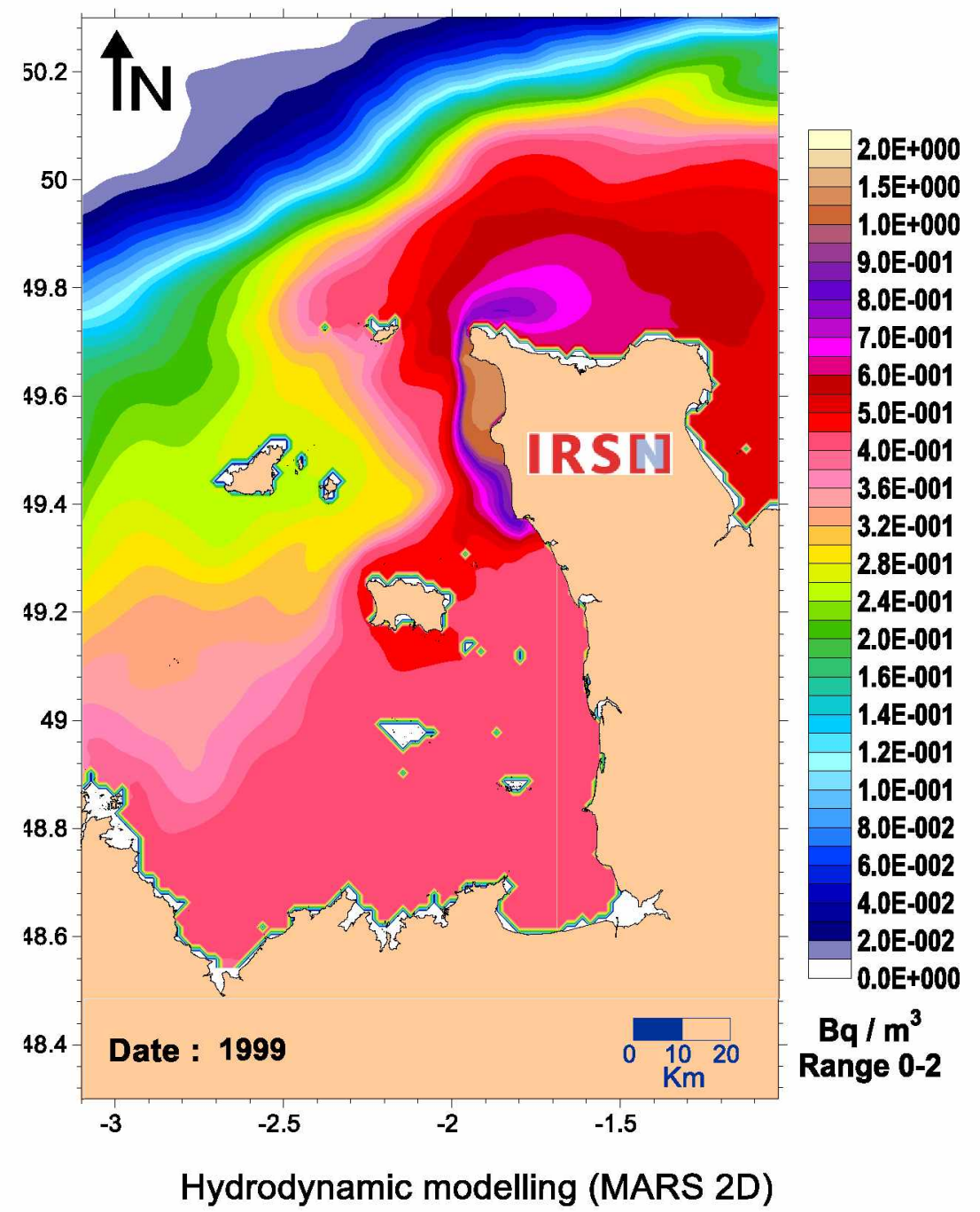


Annual mean concentrations resulting from constant discharge of 1 TBq. $\mathrm{y}^{-1}$ (31 $\left.709 \mathrm{~Bq} . \mathrm{s}^{-1}\right)$

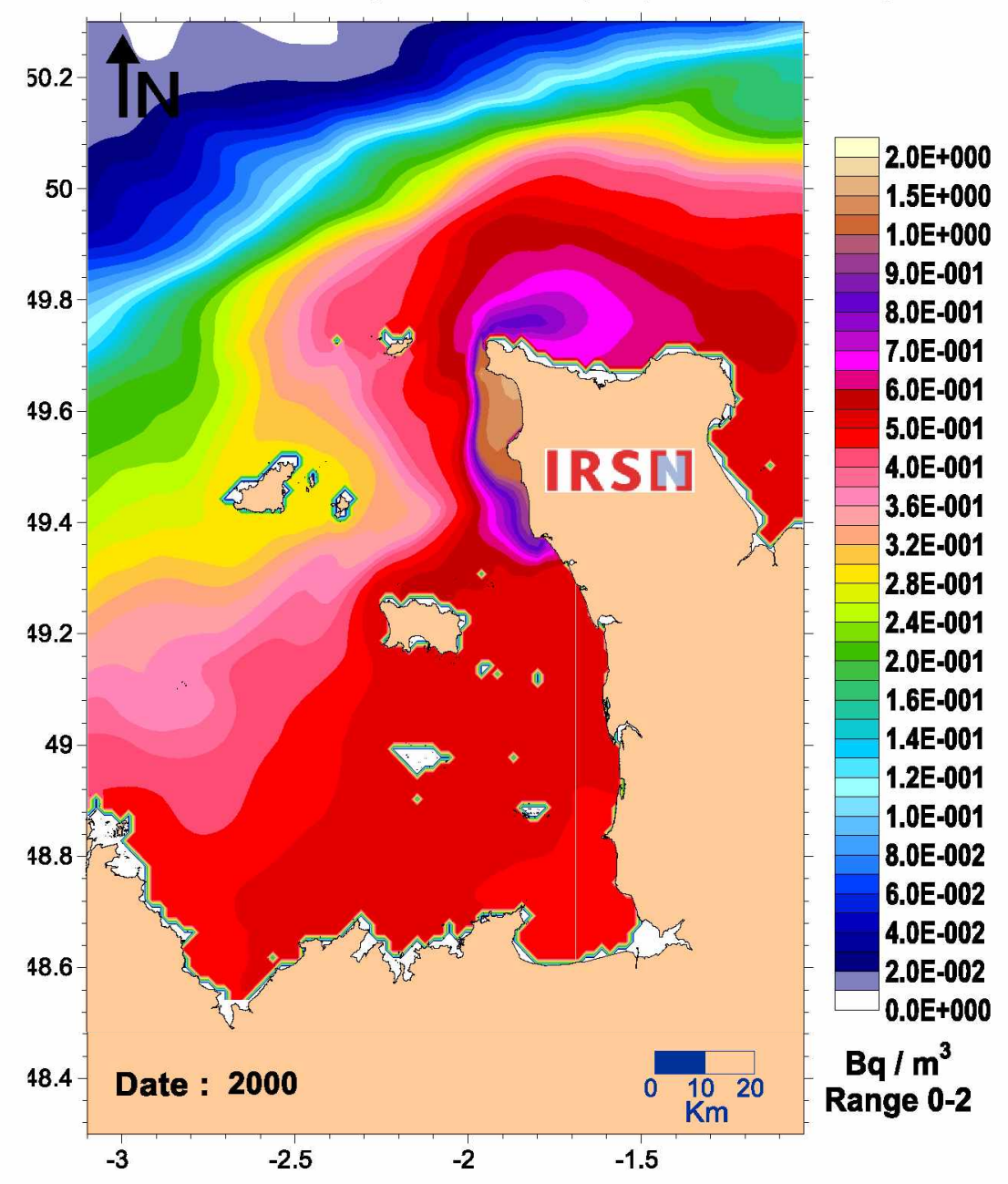

Hydrodynamic modelling (MARS 2D)
Annual mean concentrations resulting from constant discharge of $1 \mathrm{TBq}^{-\mathrm{y}^{-1}}$ (31 $\left.709 \mathrm{~Bq} . \mathrm{s}^{-1}\right)$

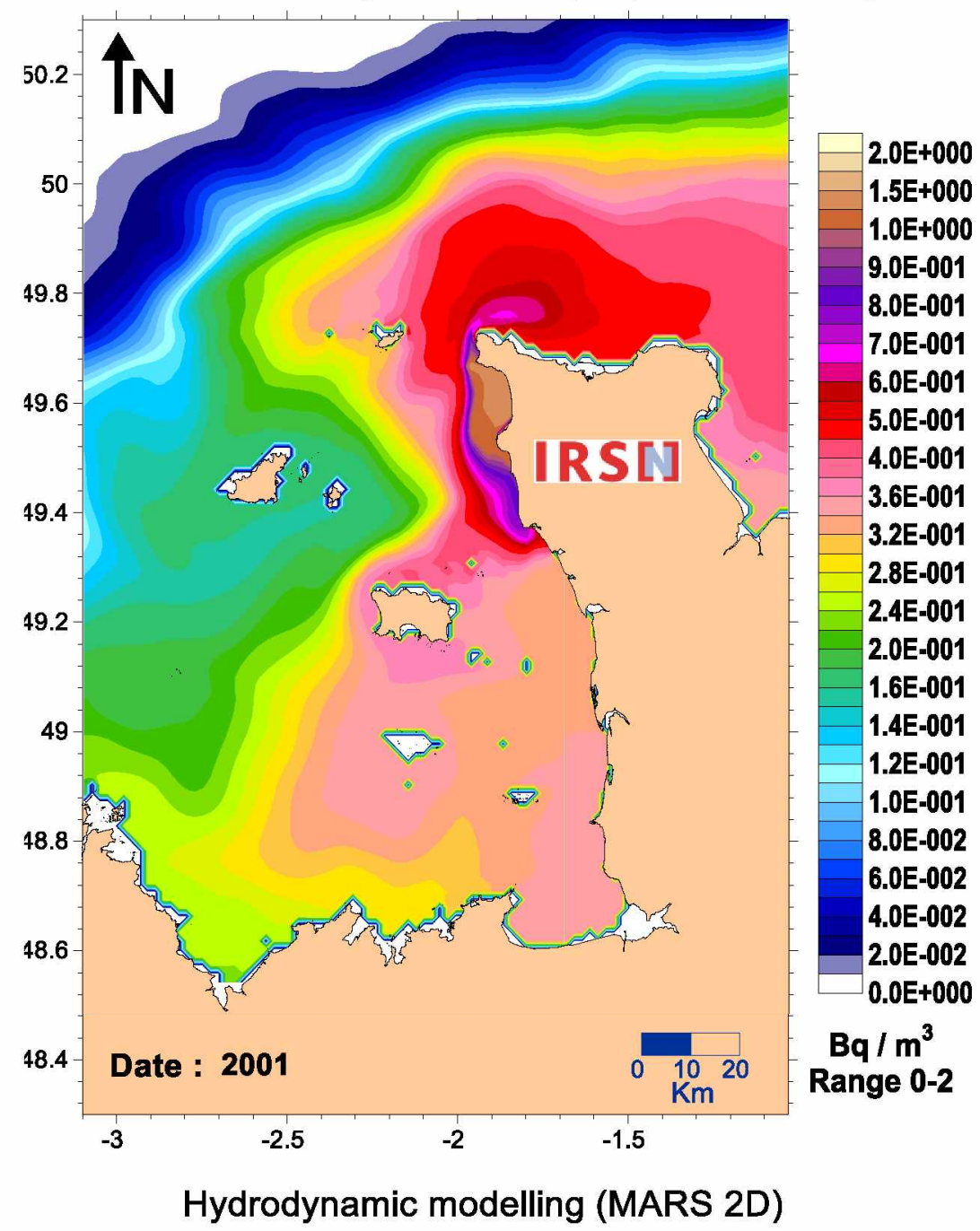


Annual mean concentrations resulting from constant discharge of 1 TBq. $\mathrm{y}^{-1}$ (31 709 Bq. $\left.\mathrm{s}^{-1}\right)$

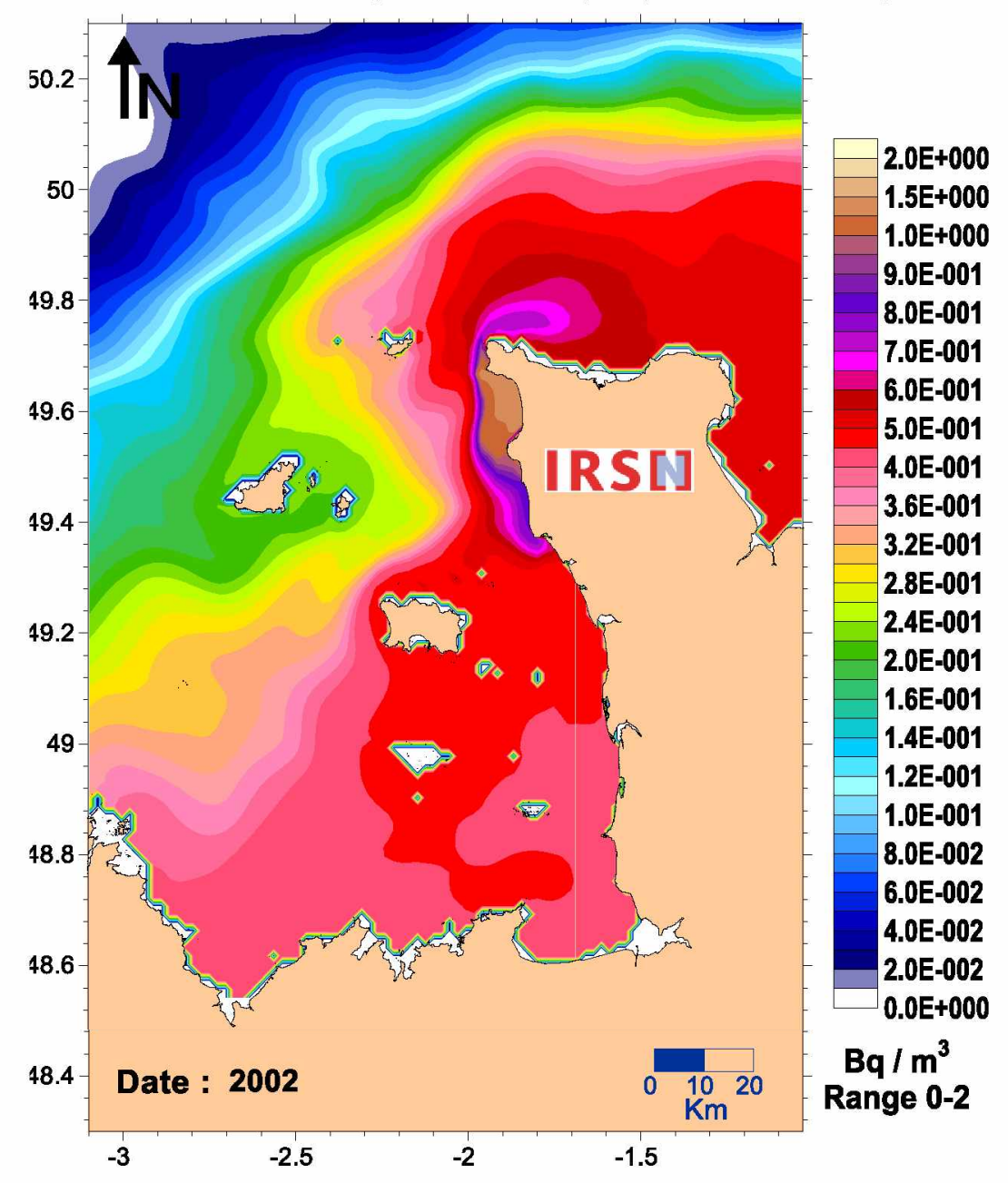

Hydrodynamic modelling (MARS 2D)
Annual mean concentrations resulting from constant discharge of 1 TBq. $\mathrm{y}^{-1}$ (31 709 Bq. $\left.\mathrm{s}^{-1}\right)$

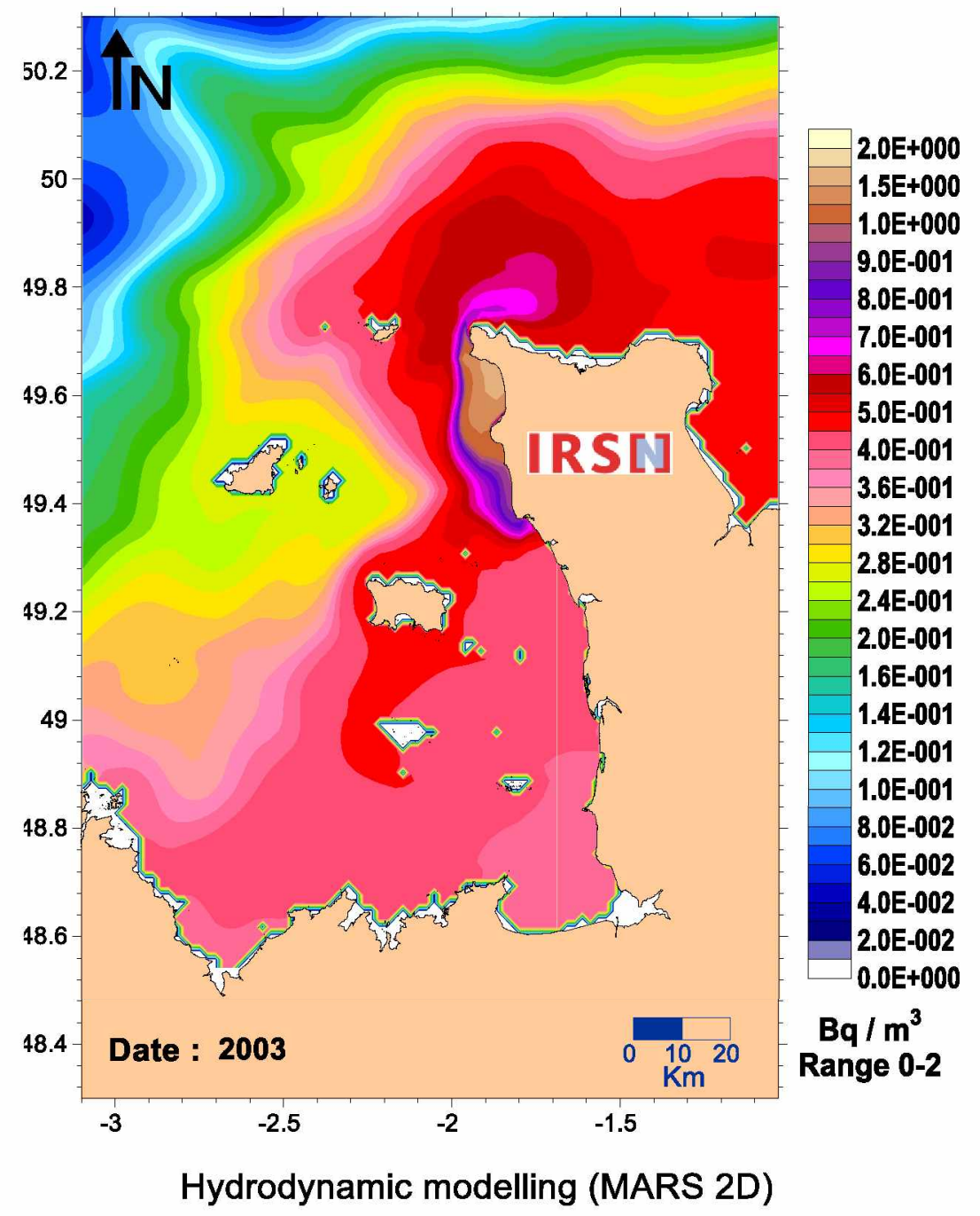


Annual mean concentrations resulting from constant discharge of 1 TBq. $^{-1}$ (31 709 Bq. $\left.\mathrm{s}^{-1}\right)$

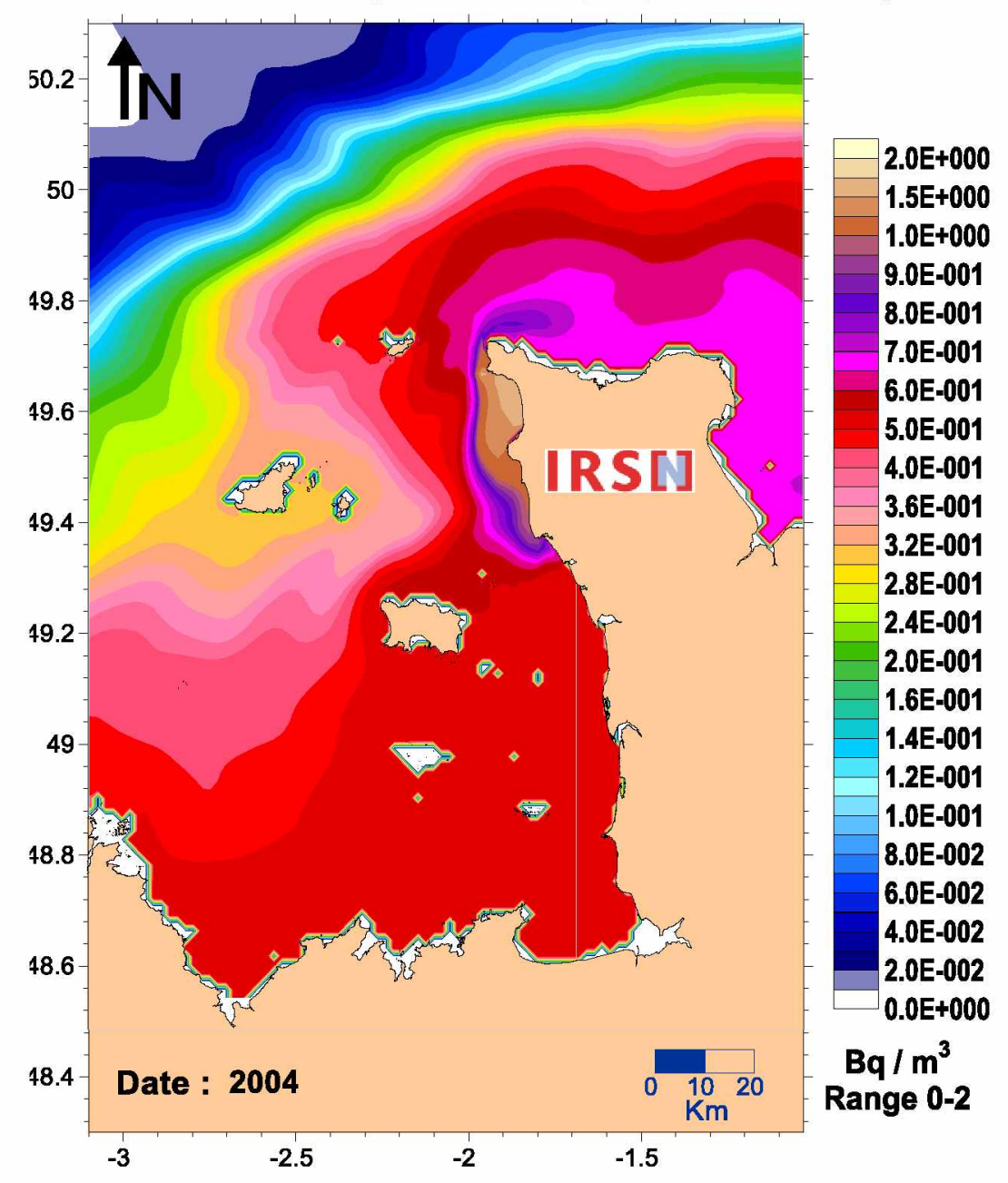

Hydrodynamic modelling (MARS 2D)
Annual mean concentrations resulting from constant discharge of 1 TBq. $\mathrm{y}^{-1}$ (31 709 Bq. $\left.\mathrm{s}^{-1}\right)$

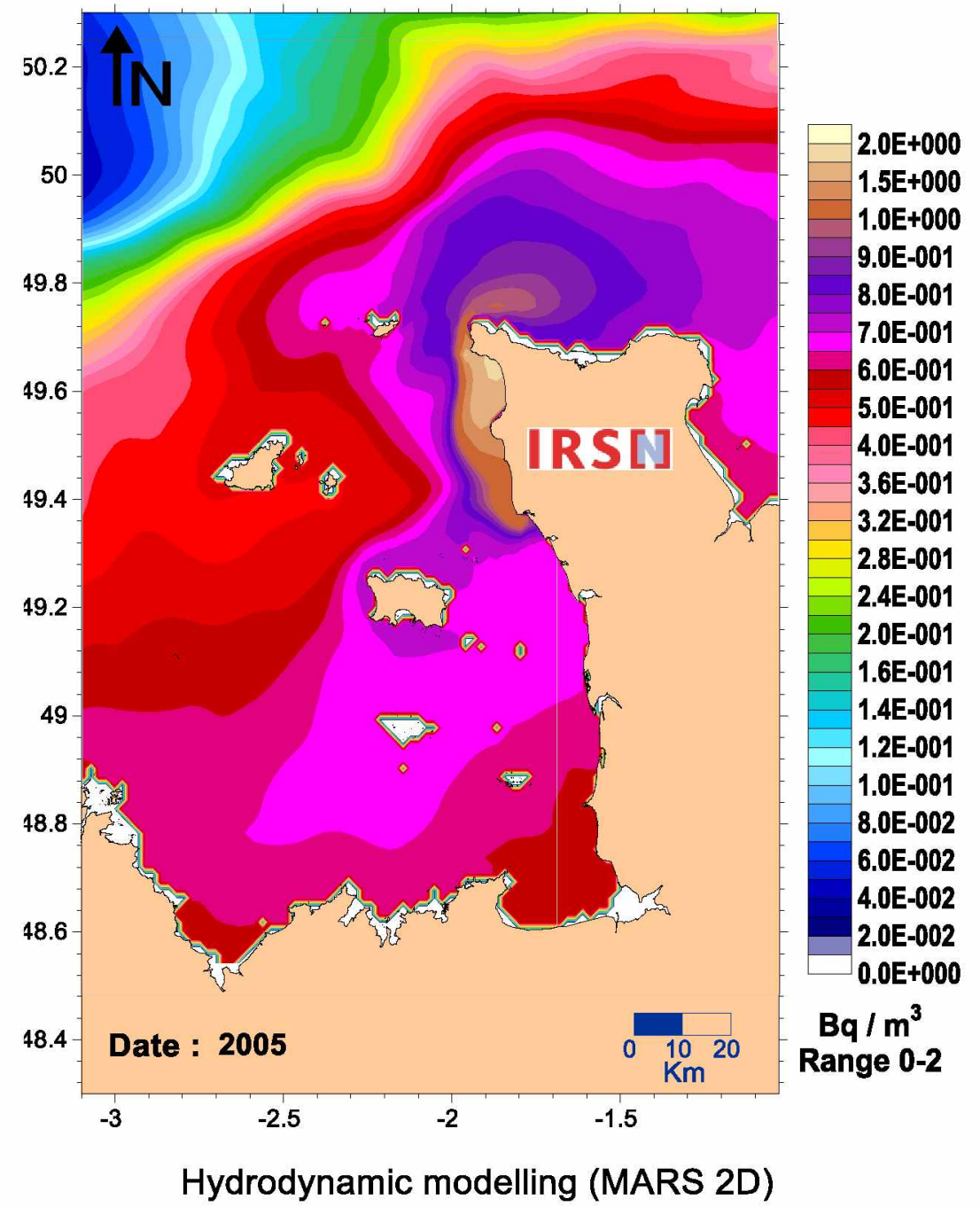


Annual mean concentrations resulting from constant discharge of 1 TBq. $\mathrm{y}^{-1}$ (31 $\left.709 \mathrm{~Bq} \cdot \mathrm{s}^{-1}\right)$

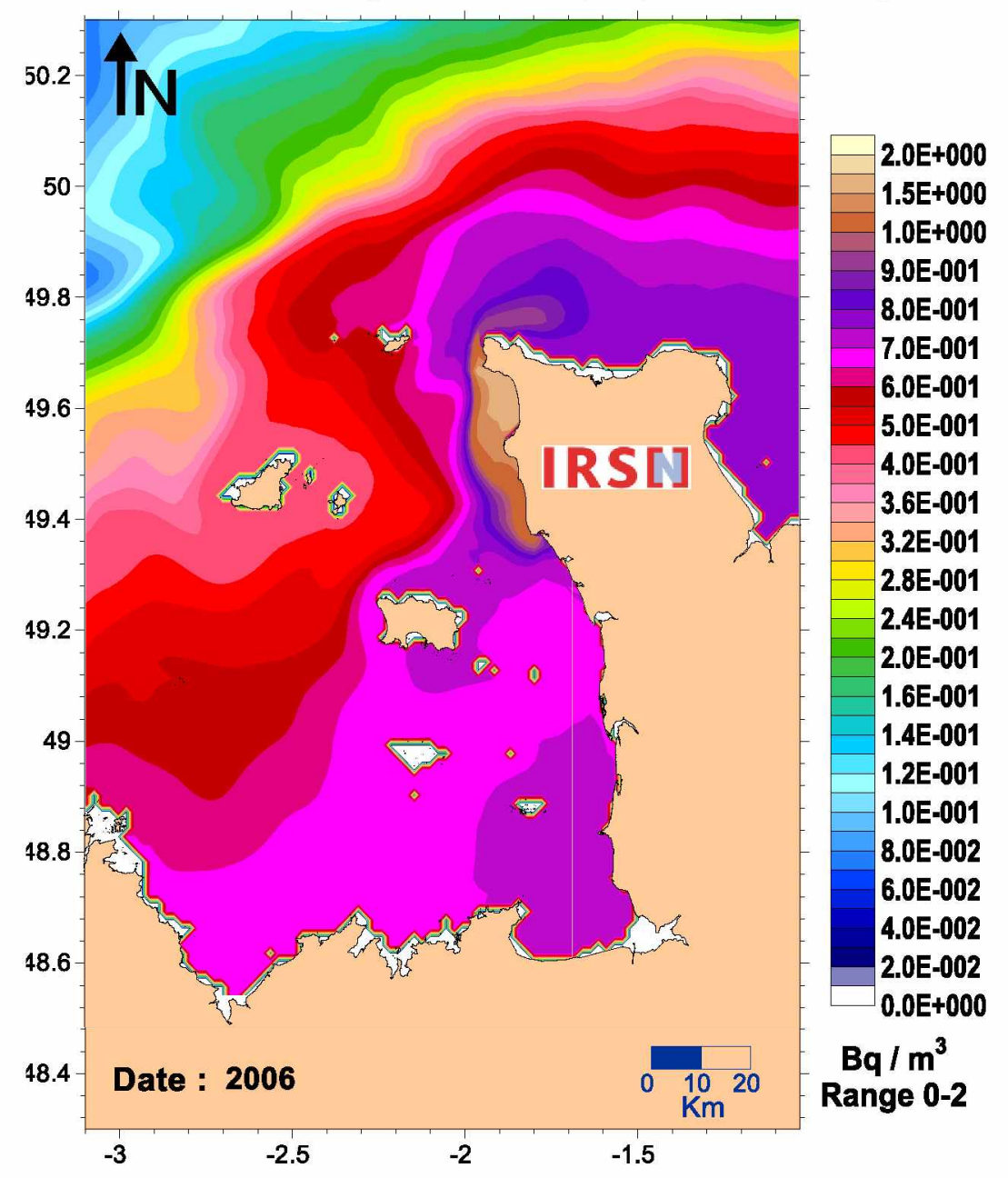

Hydrodynamic modelling (MARS 2D)
Annual mean concentrations resulting from constant discharge of 1 TBq. $\mathrm{y}^{-1}$ (31 709 Bq. $\left.\mathrm{s}^{-1}\right)$

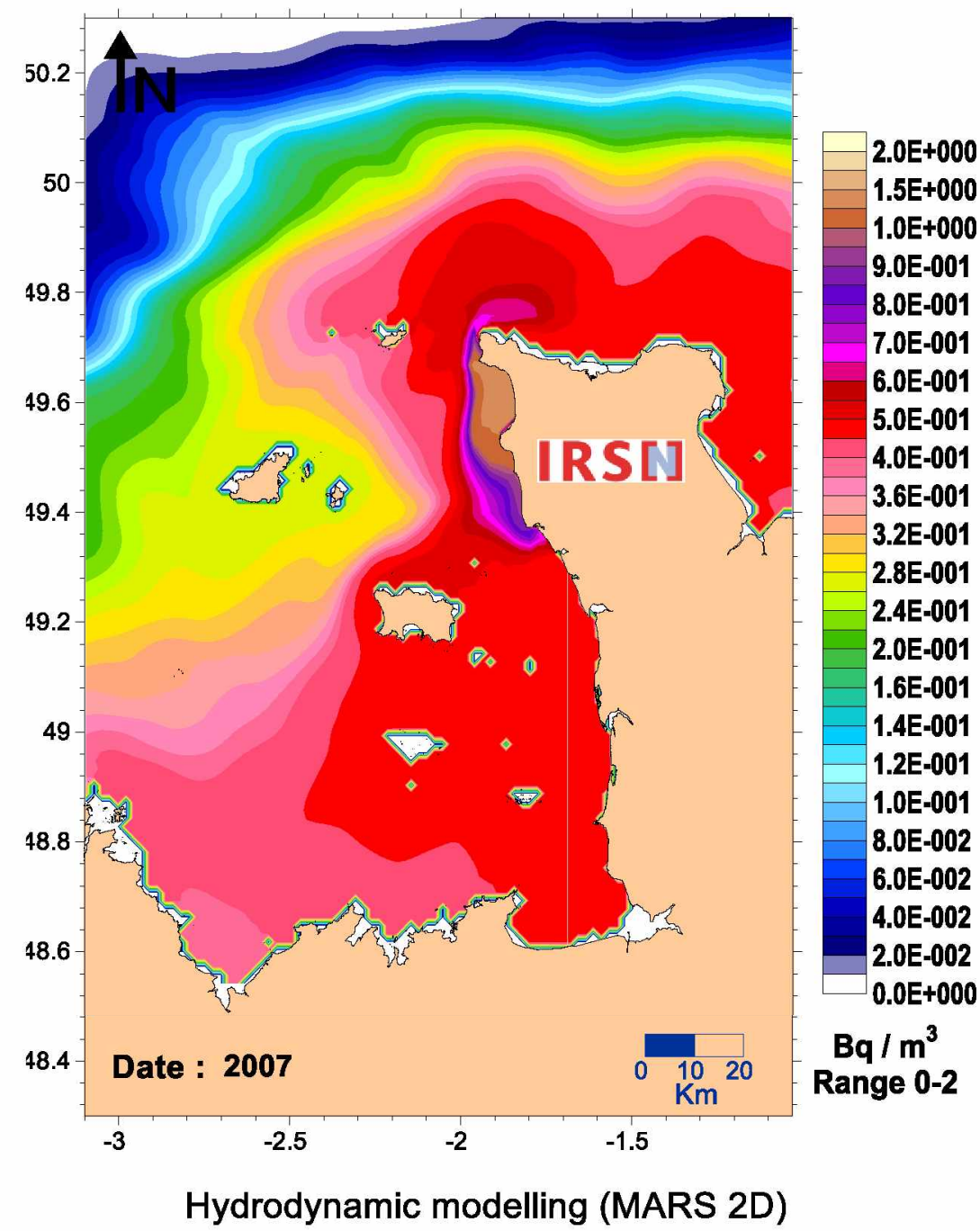


Annual mean concentrations resulting from constant discharge of 1 TBq. $\mathrm{y}^{-1}$ (31 $\left.709 \mathrm{~Bq} \cdot \mathrm{s}^{-1}\right)$

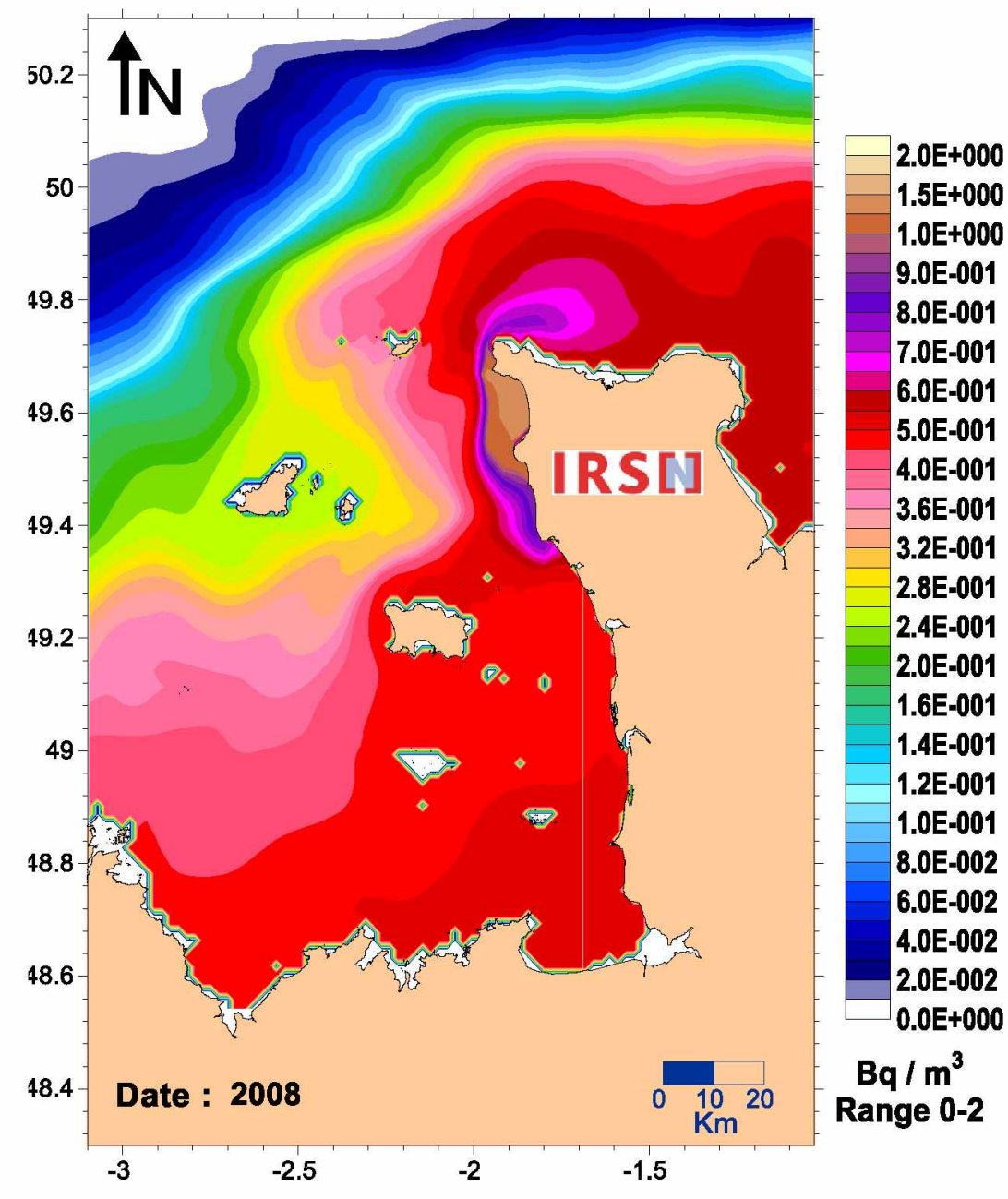

Hydrodynamic modelling (MARS 2D)
Annual mean concentrations resulting from constant discharge of 1 TBq. $\mathrm{y}^{-1}\left(31709\right.$ Bq. $\left.^{-1}\right)$

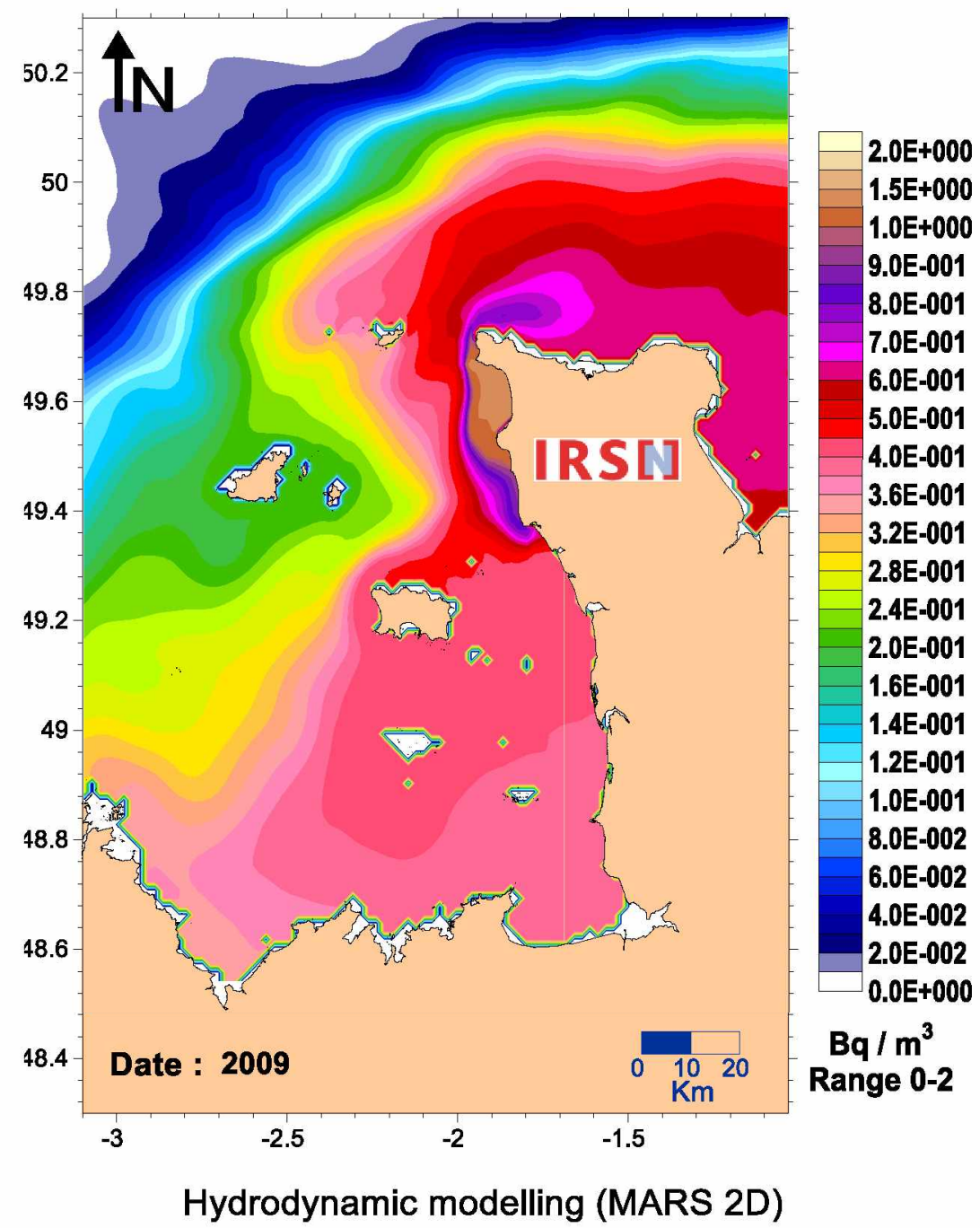


Annual mean concentrations resulting from constant discharge of 1 TBq. $\mathrm{y}^{-1}$ (31 $\left.709 \mathrm{~Bq} . \mathrm{s}^{-1}\right)$

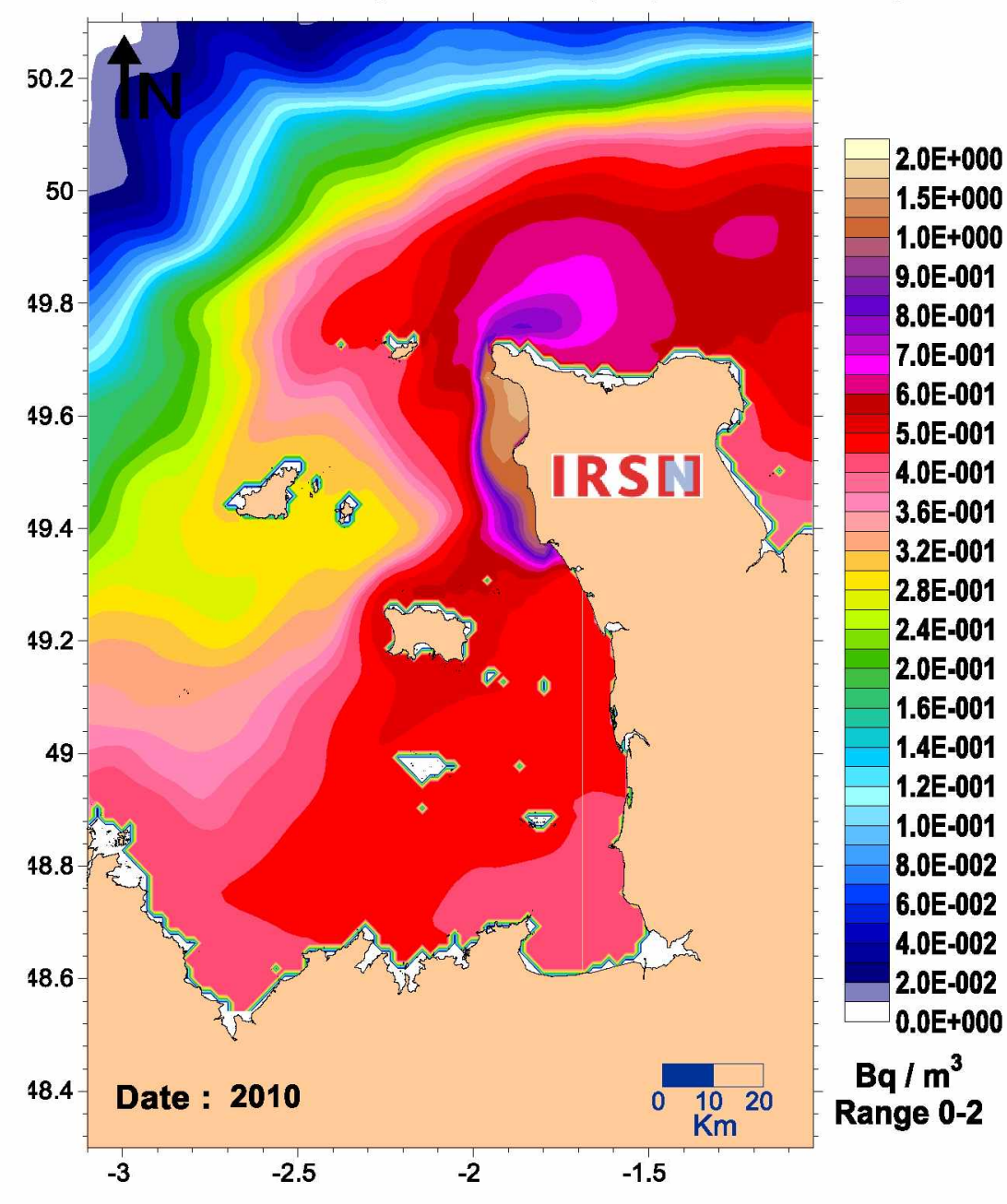

Hydrodynamic modelling (MARS 2D)
Annual mean concentrations resulting from constant discharge of 1 TBq. $\mathrm{y}^{-1}$ (31 709 Bq. $\left.\mathrm{s}^{-1}\right)$

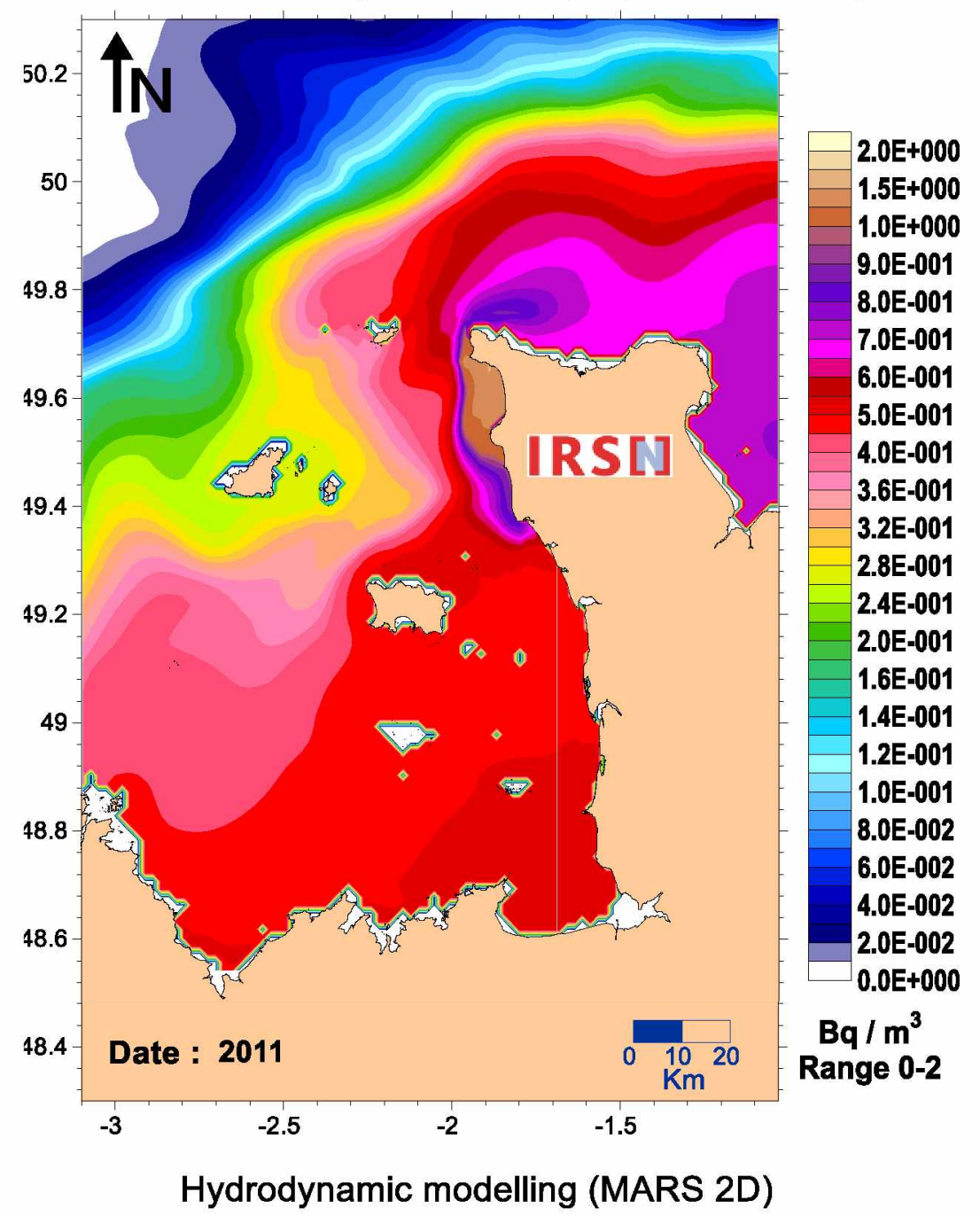


Annual mean concentrations resulting from constant discharge of 1 TBq. $\mathrm{y}^{-1}$ (31 $\left.709 \mathrm{~Bq} \cdot \mathrm{s}^{-1}\right)$

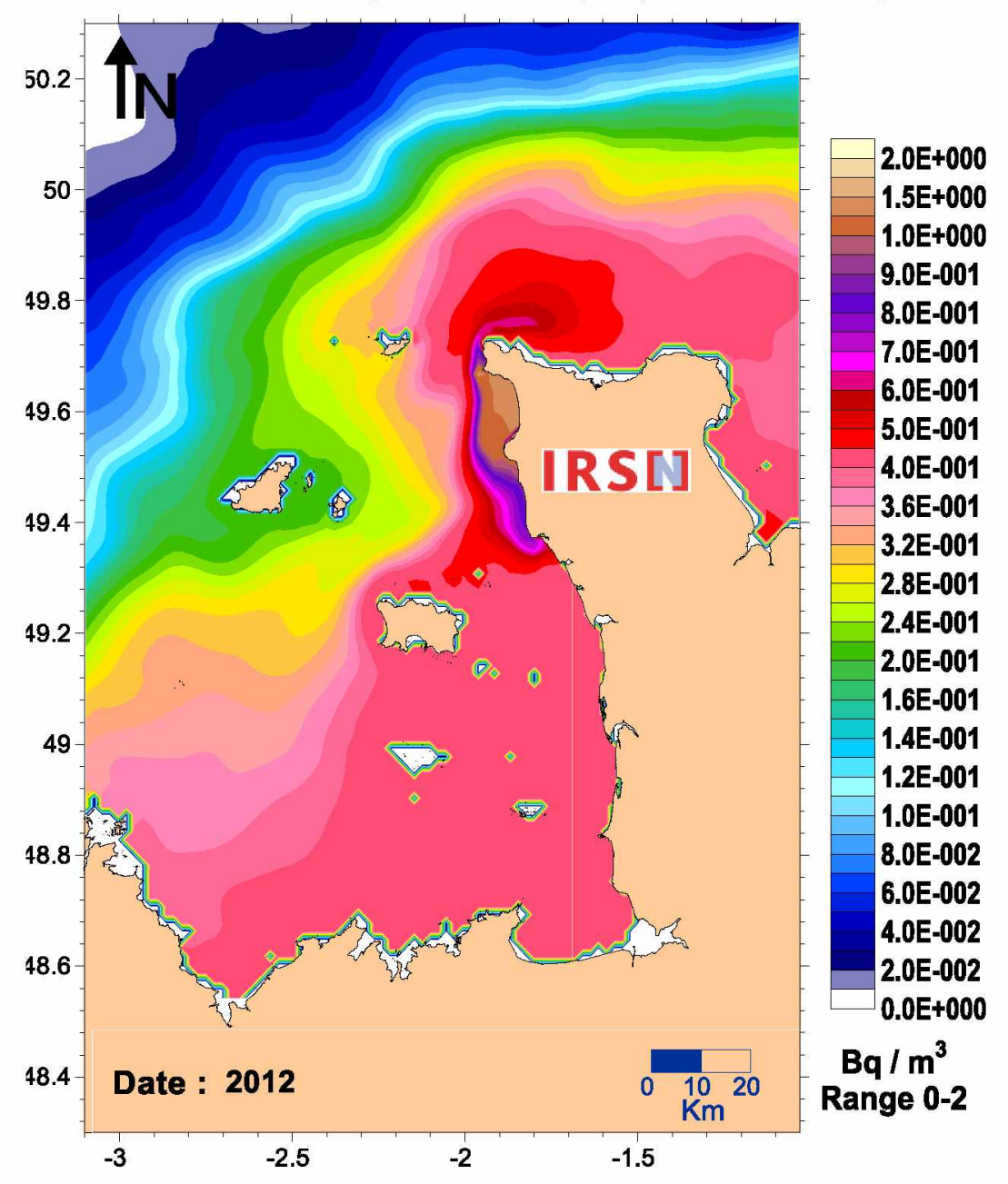

Hydrodynamic modelling (MARS 2D)
Annual mean concentrations resulting from constant discharge of 1 TBq. $\mathrm{y}^{-1}$ (31 709 Bq. $\mathrm{s}^{-1}$ )

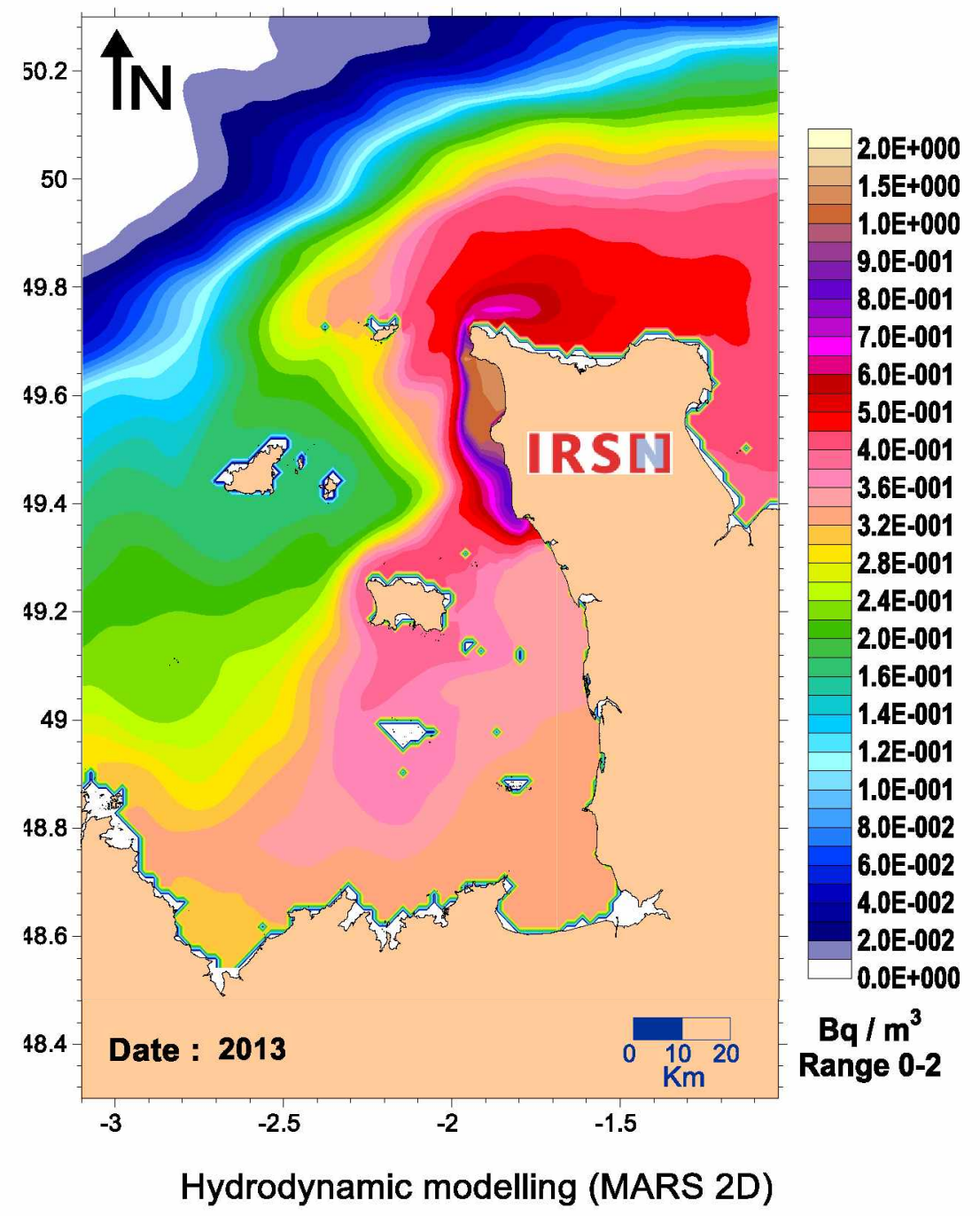


Annual mean concentrations resulting from constant discharge of 1 TBq. $y^{-1}$ (31 709 Bq. s $\left.^{-1}\right)$

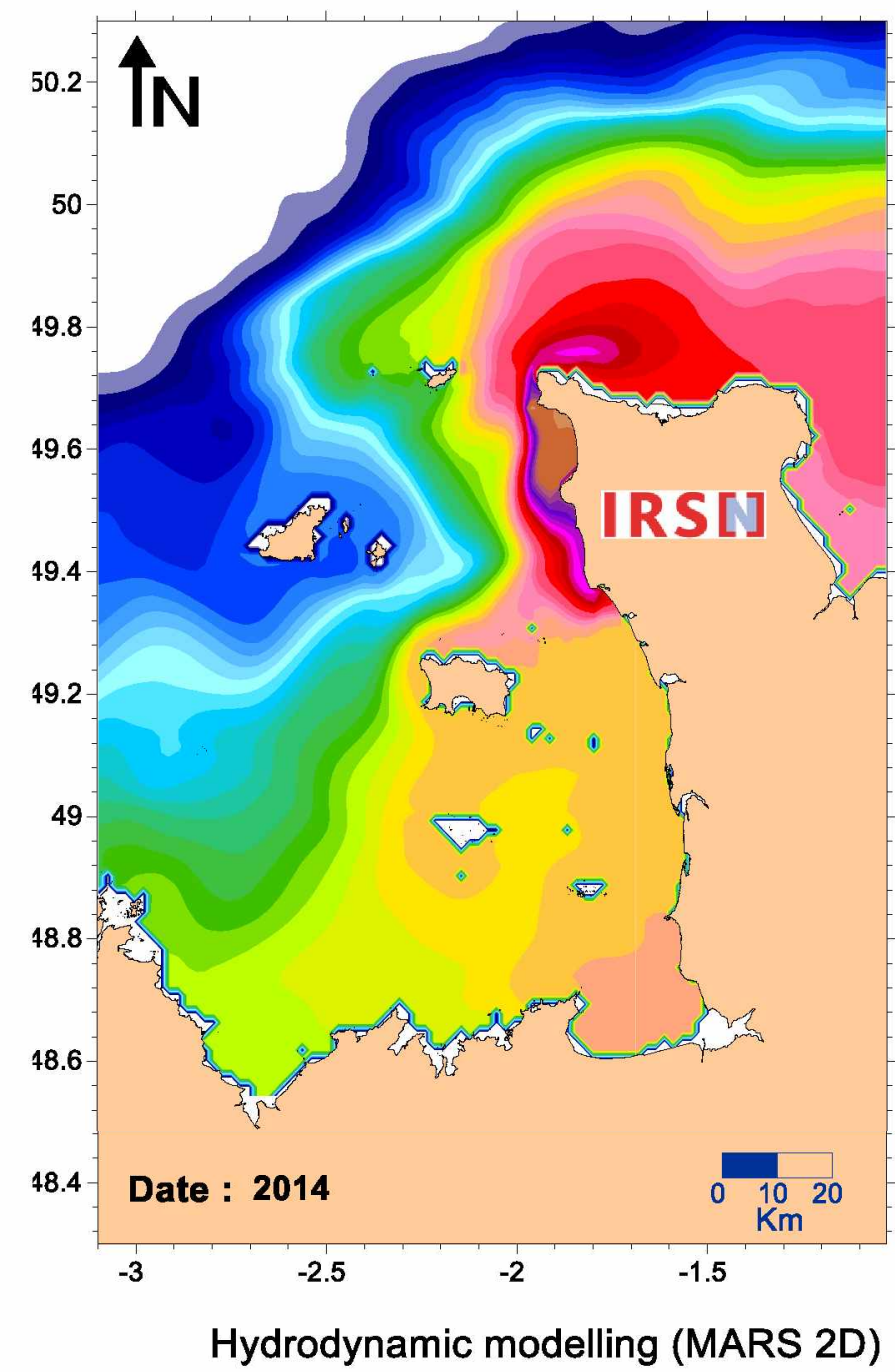

Annual mean concentrations resulting from constant discharge of $1 \mathrm{TBq} . \mathrm{y}^{-1}\left(31709 \mathrm{~Bq} . \mathrm{s}^{-1}\right)$

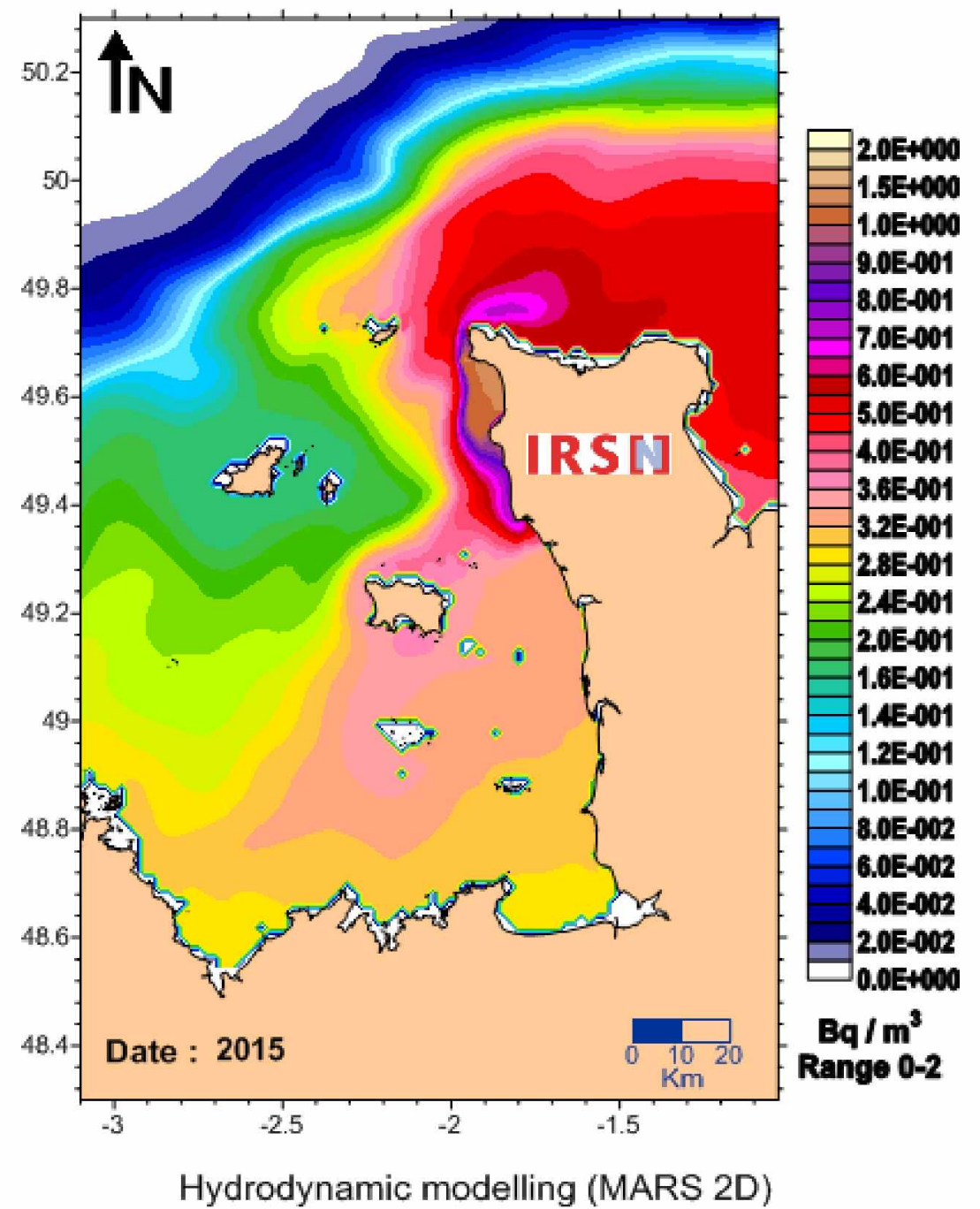



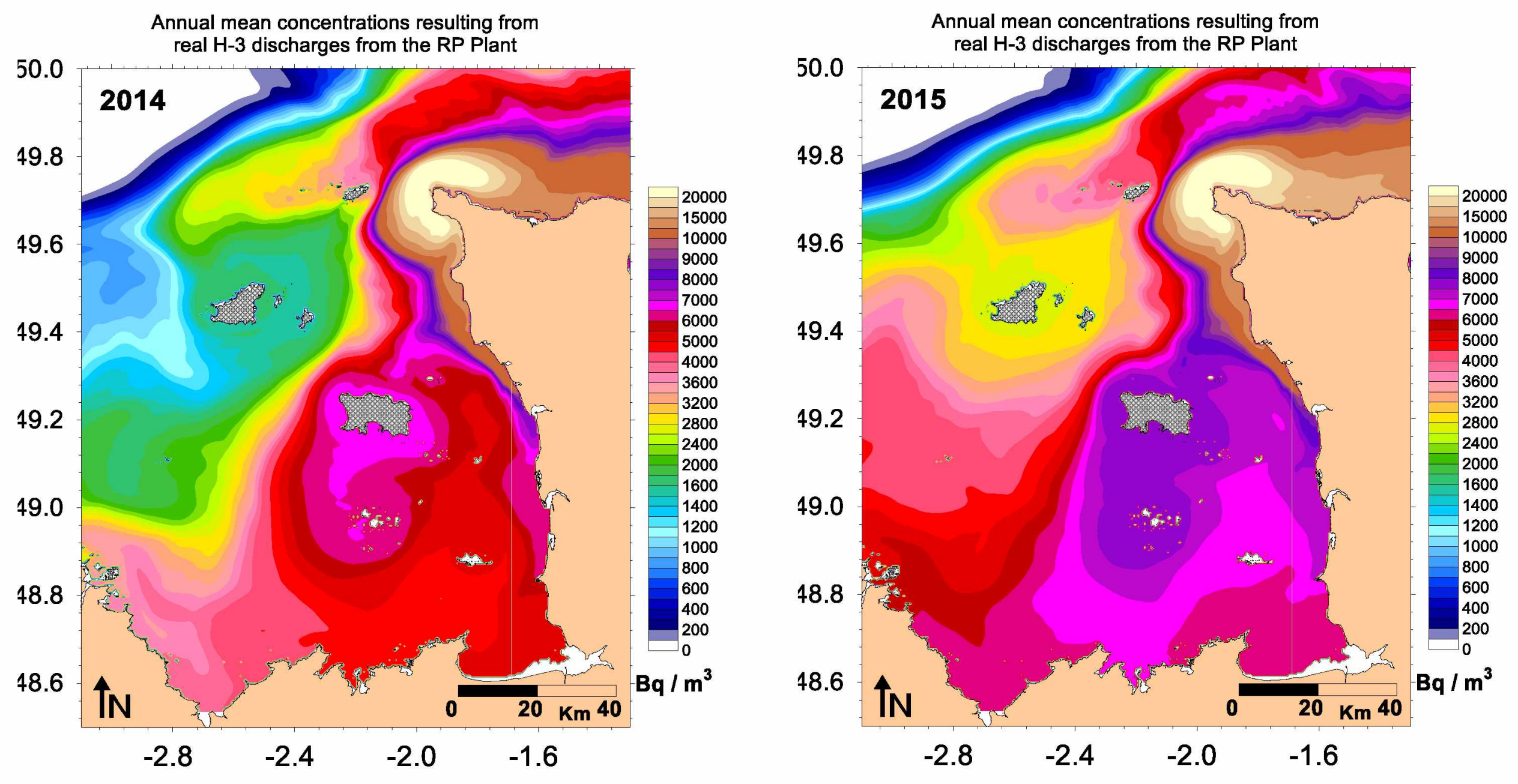


\section{Figure Caption}

Figure 1: Annual controlled amounts of liquid radioactive discharges from the reprocessing plant of ORANO La Hague (line gaps: missing data. The dashed vertical line splits the graph into pre- and postGRNC, 1999 publication data).

Figure 2: Normand-Breton Gulf (NBG) map showing the locations of sampling (cross), the ORANO La Hague reprocessing plant (RP) and the Flamanville EDF nuclear power plant (NPP). The names of the Channel Islands are written in bold, underlined. Inset: Western English Channel and Brittany showing the Concarneau and Roscoff reference locations, remote from French nuclear industry radioactive discharges.

Figure 3: Change in radionuclide activity with time in Fucus serratus collected in Corblet Bay (Alderney) and Portelet Harbour (Guernsey) over two decades since 1998. The black diamonds correspond to radionuclide activity in $\mathrm{Bq} . \mathrm{Kg}^{-1} \mathrm{dry}$ with error bars of $2 \times$ Sigma uncertainty. For activities below the limits of detection (LoD), a dashed vertical line spans from zero to the values of the LoD. §: The LoD was occasionally higher due to a reduction in counting time, depending on measurement laboratory availability constraints.

Figure 4: Change with respect to distance from the RP outfall in gamma emitter radionuclide concentrations measured in Fucus serratus collected in the NBG area and in reference locations (see map in Figure 2) in spring 2014 (thin hatching) and spring 2015 (thick hatching). The vertical bars correspond to radionuclide activity in Bq. $\mathrm{Kg}^{-1} \mathrm{dry}$ and the error bars to $2 \mathrm{x}$ Sigma uncertainty. For activities below the limits of detection (LoD), the error bars span from zero to the values of the LoD.

The vertical dashed line splits the graphs between data from the NBG and from the reference locations in Brittany. The horizontal thick bars underline the British Channel Islands.

Figure 5: Changes over time in gamma emitter radionuclide concentrations measured monthly in Fucus serratus and Patella sp (soft parts) collected at Goury (6 Km from the RP outfall) from September 2013 to June 2016. The same symbols are used as in Figure 3.

Figure 6: Changes with respect to the distance from the RP outfall in alpha and beta emitter radionuclide concentrations measured in Fucus serratus collected in the NBG area and in reference locations (see map in Figure 2) in spring 2014 and spring 2015. The same symbols are used as in

Figure 4.

Figure 7: General water mass circulation in the NBG resulting from Lagrangian residual currents for a constant wind direction $\left(\mathrm{SW}=231^{\circ}\right)$ and speed $(8 \mathrm{~m} / \mathrm{s})$ and a constant medium tide coefficient (70). The shades of grey show the current speeds $\left(\mathrm{m}^{-1} \mathrm{~s}^{-1}\right)$ and the black arrows show the current directions and speeds. The star symbol shows the outfall of the radioactive releases from the RP. 
Figure 8: 1985 and 2015 mean annual seawater concentrations resulting from a theoretical constant discharge of $1 \mathrm{TBq} . \mathrm{Y}^{-1}$ (31 $709 \mathrm{~Bq} \cdot \mathrm{s}^{-1}$ ) calculated by MARS2D with real wind and tide conditions. The numbers on the 1985 map (left) are the estimated average turnover values (d) of soluble radionuclides released from the RP outfall.

Figure 9: 2014 and 2015 mean annual H-3 concentration in seawater (Bq. $\mathrm{m}^{-3}$ ) calculated by the MARS2D model with real discharges from the ORANO La Hague RP, and real wind and tide conditions.

Figure 10: Comparison of the dispersion patterns of radionuclides in the NBG. A: Dilution factors based on 2014 and 2015 annual mean H-3 levels in seawater calculated by the MARS2D model and normalized to $\mathrm{H}-3$ discharges from the RP. B, C, D: Concentrations of radionuclides in seaweed measured in the NBG in 2014 and 2015 divided by the Concentration Factors (Table 1), normalized to the 12-month discharges preceding sampling. Average concentrations from Concarneau were substracted as background values from NBG data for C-14.

Figure 11: Concentrations of radionuclides in seaweed measured in the NBG in 2014 and 2015 divided by the Concentration Factors (Table 1), normalized to the 12-month discharges preceding sampling. Average concentrations from Concarneau were substracted as background values from all data for Cs-137 (A), Pu-239,240 (C) and Am-241 (D).

Figure 12: Monthly time-series measurement data for Fucus serratus from Goury divided by the Concentration Factors (Table 1) and normalized to the 12-month discharges preceding the sampling date. 


\section{Table Caption}

Table 1: parameters used to normalize the biota data.

The CF values were taken from IAEA TRS 422 (2004), except for C-14 (Fiévet et al., 2006).

Table 2. Alpha and beta emitter radionuclide concentrations in Fucus serratus collected on shore in the Channel Islands between 1999 and 2017. Activities are expressed as \pm uncertainty ( $2 \times$ sigma), and in Bq. $\mathrm{Kg}^{-1} \mathrm{C}$ for $\mathrm{C}-14$, in Bq. $\mathrm{L}^{-1}$ for $\mathrm{H}-3$ and in Bq. $\mathrm{Kg}^{-1}$ dry for alpha emitters. In the 2017 samples, OBT was measured in parallel with $\mathrm{HTO}$ and the OBT values in Bq. $\mathrm{L}^{-1}$ of combustion water are given in brackets next to the HTO values. 